\title{
Bending Response of Timber Mortise and Tenon Joints Reinforced with Filler-Modules and FRP Gussets
}

\author{
Andrew Robert Pacifico \\ arpacifico@mix.wvu.edu
}

Follow this and additional works at: https://researchrepository.wvu.edu/etd

Part of the Civil Engineering Commons, Other Materials Science and Engineering Commons, Structural Engineering Commons, and the Structural Materials Commons

\section{Recommended Citation}

Pacifico, Andrew Robert, "Bending Response of Timber Mortise and Tenon Joints Reinforced with FillerModules and FRP Gussets" (2019). Graduate Theses, Dissertations, and Problem Reports. 4125.

https://researchrepository.wvu.edu/etd/4125

This Problem/Project Report is protected by copyright and/or related rights. It has been brought to you by the The Research Repository @WVU with permission from the rights-holder(s). You are free to use this Problem/Project Report in any way that is permitted by the copyright and related rights legislation that applies to your use. For other uses you must obtain permission from the rights-holder(s) directly, unless additional rights are indicated by a Creative Commons license in the record and/ or on the work itself. This Problem/Project Report has been accepted for inclusion in WVU Graduate Theses, Dissertations, and Problem Reports collection by an authorized administrator of The Research Repository @ WVU. For more information, please contact researchrepository@mail.wvu.edu. 


\title{
Bending Response of Timber Mortise and Tenon Joints Reinforced with Filler-Modules and FRP Gussets
}

\author{
Andrew Robert Pacifico \\ Problem Report submitted to the \\ College of Engineering and Mineral Resources at \\ West Virginia University in \\ partial fulfillment of the requirements \\ for the degree of
}

\section{Master of Science \\ in \\ Civil Engineering}
Hota V.S. GangaRao, PhD, PE, Chair Roger H.L. Chen, $\mathrm{PhD}$
Gregory Dahle, $\mathrm{PhD}$

\section{Department of Civil and Environmental Engineering}

\author{
Morgantown, West Virginia \\ 2019
}

Keywords: Fiber Reinforced Polymers, composites, gussets, filler-modules, timber framing, mortise and tenon joints, retrofit technique

Copyright 2019 Andrew Robert Pacifico 


\title{
ABSTRACT \\ Bending Response of Timber Mortise and Tenon Joints Reinforced with Filler-Modules and FRP Gussets
}

\author{
Andrew Robert Pacifico
}

In 2013, the California Bay Area (CBA) passed a set of ordinances to ensure that their 10,000 plus timber soft-story buildings were prepared for seismic events, through nondestructive evaluation methods. Many property owners are searching for an affordable retrofitting system that will also meet CBA's new laws focusing on installations by the mandated deadlines in 2020 . Over the past three to four decades, Fiber Reinforced Polymer (FRP) composites have found their way into the civil infrastructure sector for rehabilitation. The objective of this study is to evaluate the bending behavior retrofitted mortise and tenon timber joints reinforced with engineered wood filler-modules and FRP composite gussets. In addition failure modes with filler-modules and/or gussets are evaluated for future studies to develop design methodologies. The above efforts are focused on a West Virginia University (WVU) patented joint performance enhancement system.

A total of ten specimens with varying retrofitting schemes were studied by using a static bending test. A 6" by 6" timber post joining system with a mortise and tenon connection style were used throughout this study. These bending tests are conducted and reported herein to determine the predominate failure modes based off of the inclusion of filler-modules and gussets. The increase in load capacity and energy absorption after retrofitting the joints subjected to bending and shear, and also the limit states on deflections and deformations of timber joints after incorporating the proposed retrofit schemes, are evaluated from the test data and reported herein.

The results from the tests indicate that a joint with filler-modules and a FRP gusset with an enhanced stiffness will perform better than a conventional joint system. The control specimens, i.e. without retrofit schemes, averaged a maximum load of $\sim 2,900 \mathrm{lbs}$. A retrofitted specimen was able to reach a maximum load of $\sim 16,000 \mathrm{lbs}$. Conventional beam-column mortise and tenon joints made of 6" x 6" size could only deflect 0.29 " at the peak load with a 18 " bending span, while a retrofitted joint with filler-modules and gussets was able to reach 0.96 " at peak load. Joints retrofit with the proposed scheme also show up to $500 \%$ increase in energy absorption.

Mortise and tenon joints have a shear failure on tenon when the dowel is made of a harder wood than the beam and column but will have a dowel bending/shear failure if it is softer than the bearing material. Joints retrofitted with filler-modules were able to prevent the tenon failure but failed once the filler-module on the tension side would debond. To delay the debond, FRP gussets were installed which resulted in FRP rupture failure at the tip of the joint area or beam-column interface.

The retrofit system proposed in this paper displayed an increase in strength, ductility, and energy absorption by factors of about 3 to 5 . The data herein proves that the filler-module and gusset combination is an effective retrofitting scheme. The system is an easy to learn installation process which can be implemented cost-effectively in a short amount of time and would save millions, in both the rehabilitation and retrofit costs. 


\section{ACKNOWLEDGEMENTS}

First and foremost, I would like to thank my family. It is the constant support and encouragement from my parents that have instilled the confidence in me to which I knew I could accomplish anything. They continuously put my sister and myself first and I am forever grateful for their sacrifices so that I could achieve my dream of receiving my Master's Degree. To my sister, Danielle, who is always there for me. She was an inspiration upon entering West Virginia University. She showed me the ropes and helped bring out my adventurous, social side. She is always there for me to provide an opinion or just listen when I am in need. To my grandparents, aunts, uncles, and cousins who have always checked in on me while in school and always put a smile on my face with the simplest card, phone call or quick message. Thanks to my entire family and taking this journey with me.

I would also like to thank many professors and educators that provided the knowledge, encouragement and mentorship throughout my years at WVU. To Dr. Hota GangaRao for offering me a research assistantship, for agreeing to chair my committee, for sharing his wisdom, offering guidance, and giving me a chance to continue my education. To Mark Skidmore and Jerry Nestor: thank you Mark for all your help; from testing the timber joints to the simple task of plugging cables into the correct slot: thanks to Jerry who was another helping hand as well as providing an outside prospective which opened my eyes to being objective about possible outcomes. To Dr. Roger Chen and Dr. Greg Dahle for their participation as members of my committee. To the many Professors and assistants, I am grateful and thank each of you profusely.

Thank you Praveen Majjigapu, my peer and a wonderful friend. Praveen has been my rock since day one as an undergraduate research assistant. He provided guidance and encouragement and is the main reason why I continued my education. He was the one who planted the seed of attending graduate school and insisted it was something I should do. Thank you Praveen for believing in me. To Shane Moore, all the hours we put in together covering the timber and getting our hand sticky was a memory that I will never forget. I would like to also thank all the other graduate students I had the pleasure to meet and spend time with these past two years. To the wonderful people I met through ASCE and Steel Bridge, thank you. Looking back on the time we spent staying up late in the machine shop doing last-minute welding or up in the computer lab trying to finish up a project for class are memories I will cherish. The memories from all these friends will last a lifetime.

For the man who introduced me to engineering as a freshman in high school, David Rader. It all started with his balsa wood bridge project and now it ends as a Structural Engineer. Mr. Rader provided a deep love for critical thinking, innovation, and hands on experience.

Lastly, I would like to thank Dr. Ordel Brown and Dr. Melissa Morris. Without the aid of these two professors and the Academy of Engineering Success I am not sure I would have pursued my education this far. They saw potential in an average incoming college freshman and laid the foundation for my engineering knowledge, as constant mentors throughout my entire college career, thank you! 


\section{TABLE OF CONTENTS}

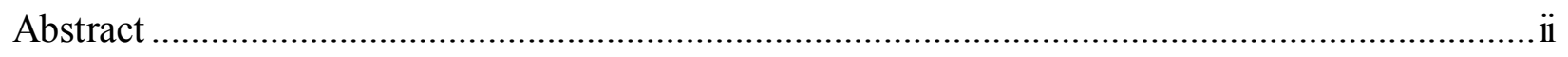

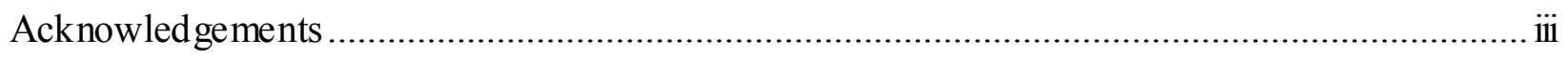

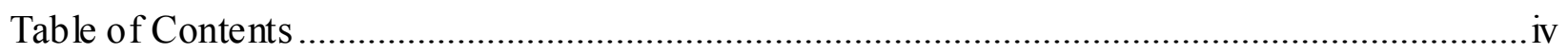

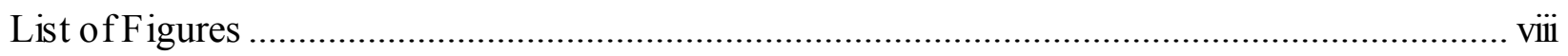

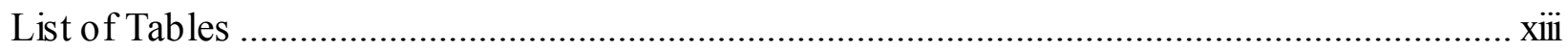

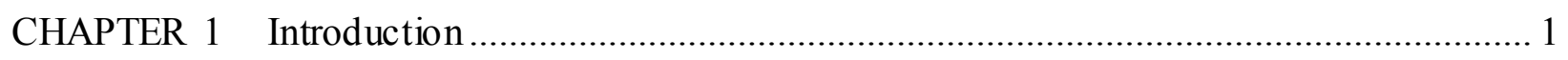

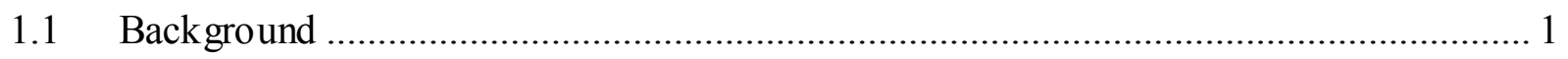

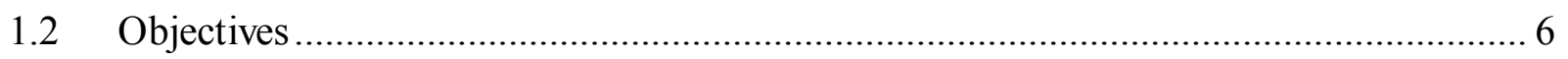

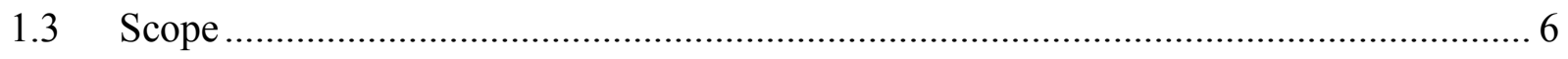

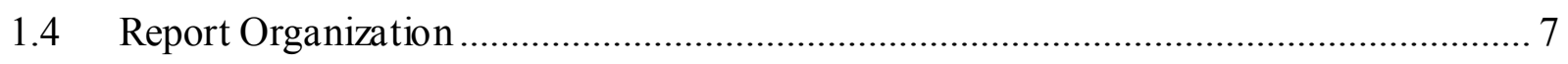

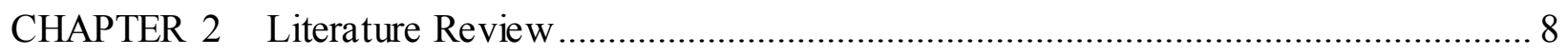

2.1 Timber Construction Introduction.................................................................. 8

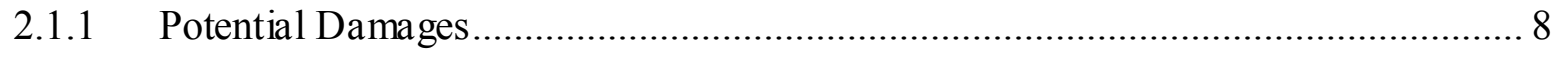

2.2 Timber Moment Connections........................................................................ 11

2.2.1 Dowel- Type Fasteners .......................................................................... 13

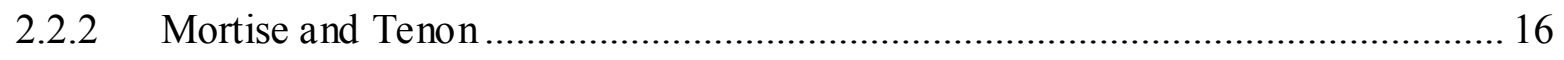

2.2.3 Available Retrofit Methods........................................................................ 18

CHAPTER 3 Experimental Materials and Methodology ................................................. 20

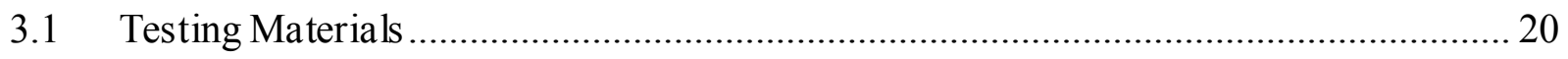




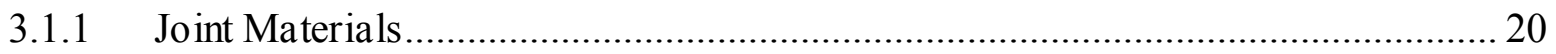

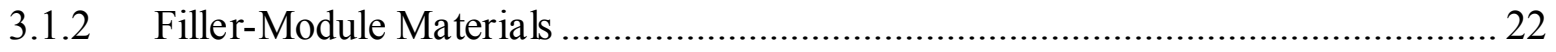

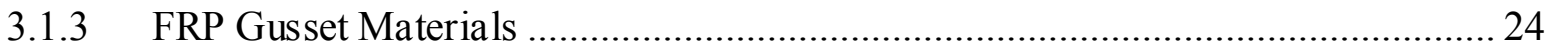

3.2 Filler-Module/Gusset Retrofit Schemes............................................................ 25

3.2.1 Filler-Module Schemes ............................................................................... 25

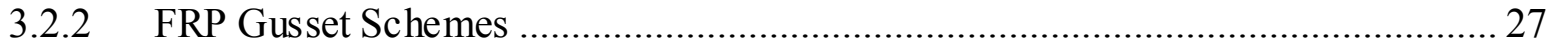

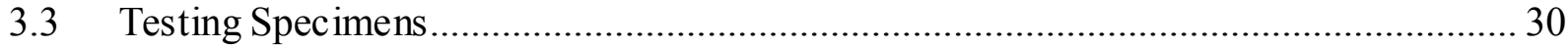

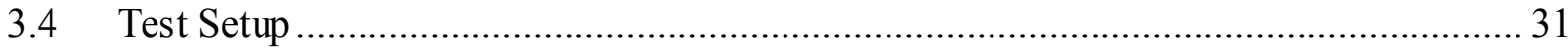

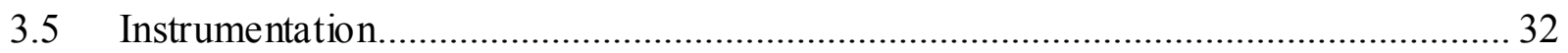

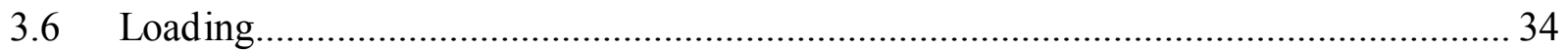

CHAPTER 4 Test Results and Evaluation ................................................................... 35

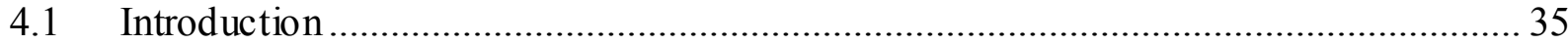

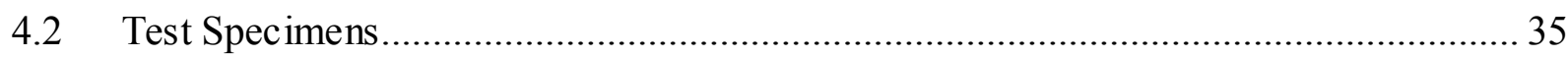

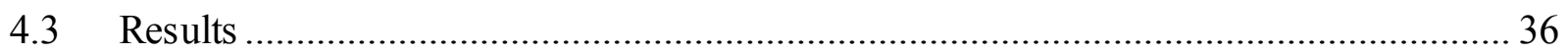

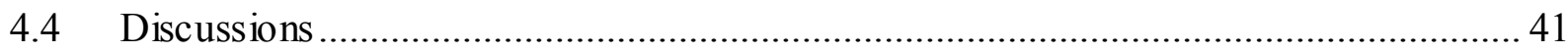

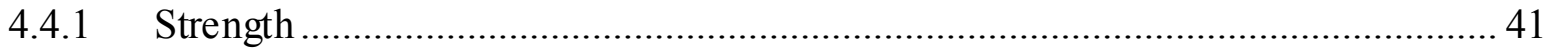

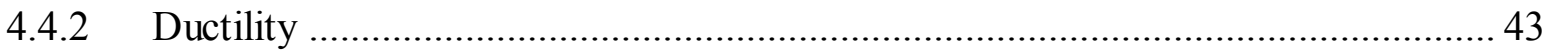

4.4.3 Energy Absorption .................................................................................. 44

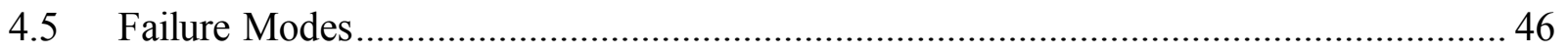

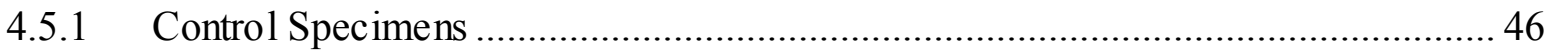




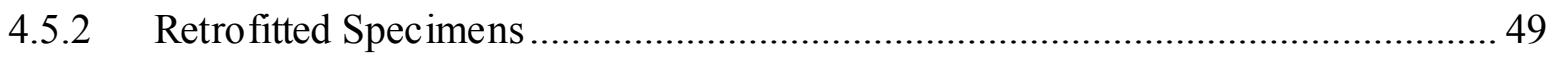

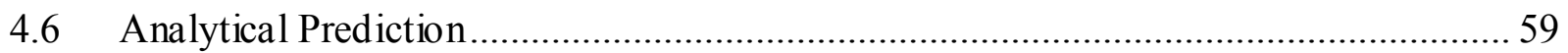

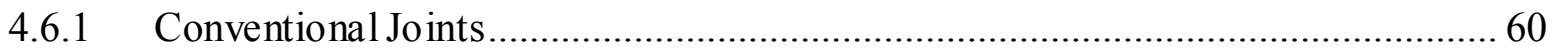

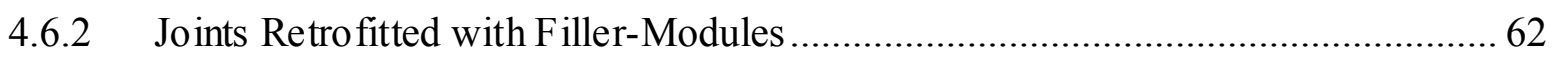

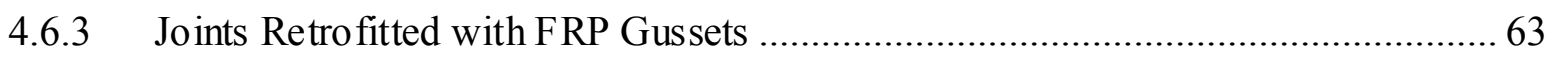

4.6.4 Joints Retrofitted with Filler-Modules and FRP Gussets ........................................ 64

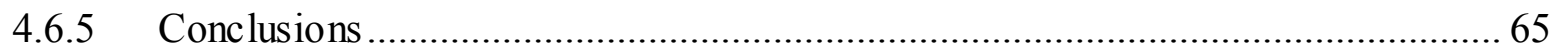

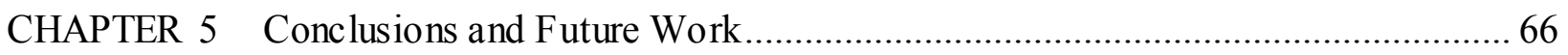

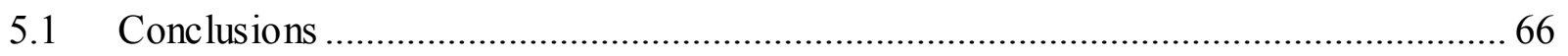

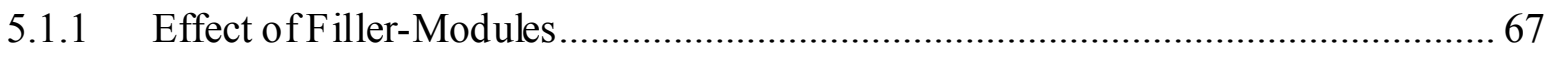

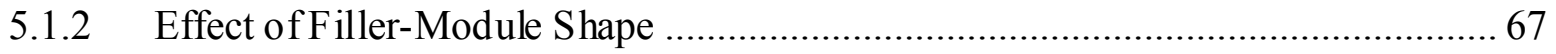

5.1.3 Effect of Filler-Module Reinforcing Dowels....................................................... 67

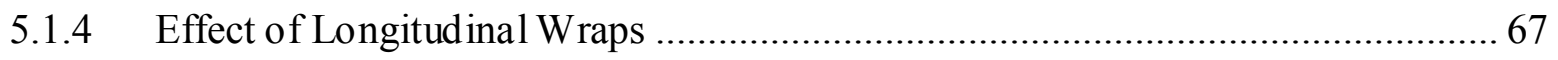

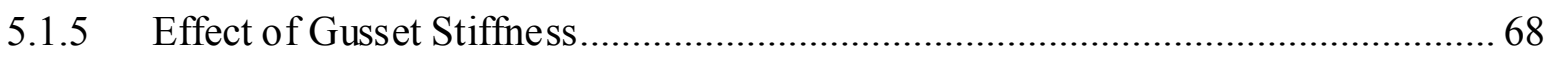

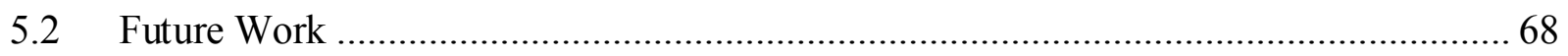

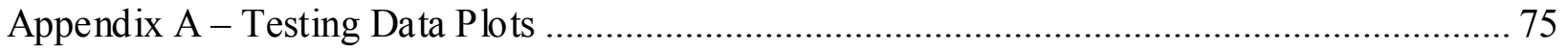

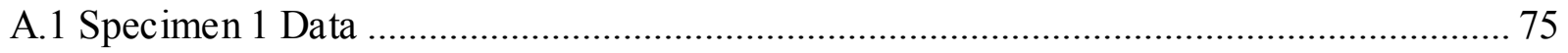

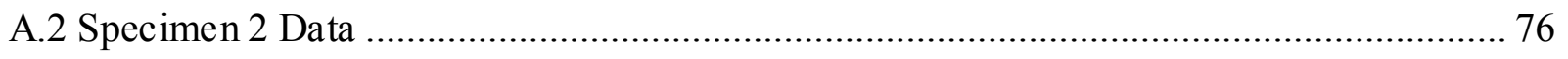

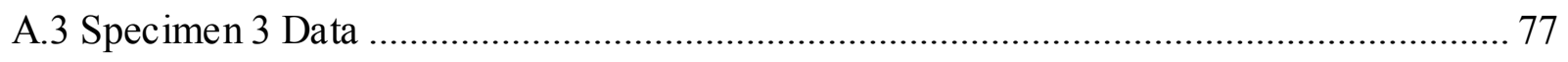

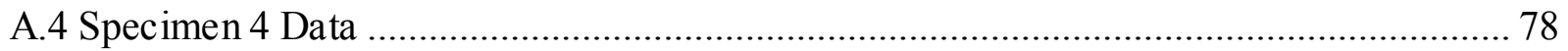




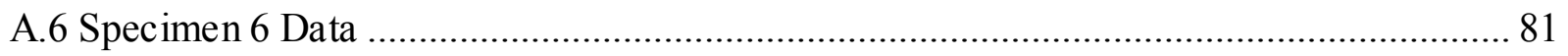

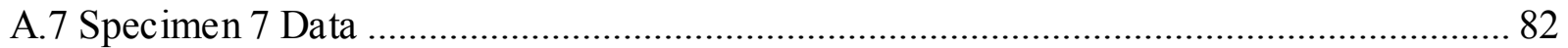

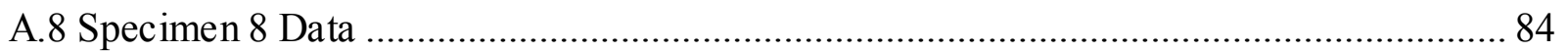

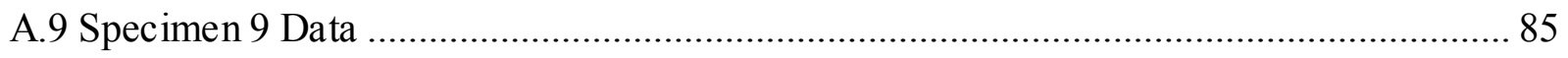

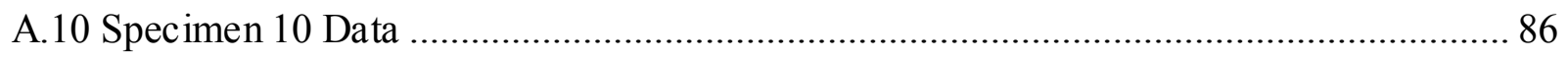




\section{LIST OF FIGURES}

Figure 1-1: Example of a Soft Story Building (Rañoa et. al 2015) .......................................... 2

Figure 1-2: Soft Story Building Damage from Hurricane Katrina (Pan 2014).......................... 2

Figure 1-3: Soft Story Build ing Failure due to a Seismic Event (Arroyo 2015) ....................... 3

Figure 1-4: Proposed Retrofit System Installed on a Building System (Majjigapu 2019) ............ 5

Figure 1-5: Finite Element Simulations Showing Principle Stress (Top Row) and Shear Stress

(Bottom Row) Concentration Effect on Varying Filler-Module Shapes Due to Transverse

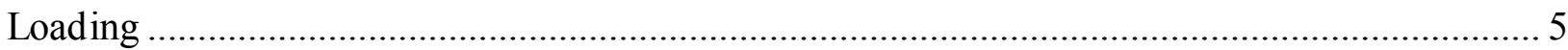

Figure 2-1: Depiction ofFire Damage on a Timber Cross Section (Ross et. al 2005)................ 9

Figure 2-2: High Winds Causing a Building to Tilt (FEMA 2006) ..................................... 10

Figure 2-3: Example of Timber Decay on Beam Members (Houspect WA 2015) .................... 11

Figure 2-4: Typical Timber Connection Methods on a Residential Building (FEMA 2006)...... 12

Figure 2-5: Typical Timber Beam/Girder Connections to Columns: (a) Girder to Steel Column;

(b) Girder to Timber Column; (c) Beam to Pipe Column; (d) Beam to Wood Column, with Steel

Trap Welded to Steel Side Plates; (e) Beam to Wood Column, with a T-Plate; (f) Beam-Column

Connection with Spiral Dowel and Shear Plates (Merritt and Ricketts 2001) ......................... 13

Figure 2-6: Examples of Dowel Type Fasteners: Nails (Top Left) (Encyclopedia Britannica n.d.),

Wooden Dowels (Top Right) (Craftsmanspace n.d.), and Screws/Bolts (Bottom) (DIY Extra n.d.)

Figure 2-7: Failure Modes for Dowel-Type Fasteners in (a) Two Member Connections and (b)

Three Member Connections (Rammer 2016) ................................................................ 16

Figure 2-8: Mortise and Tenon Connection in a Building System (Vermont Timber Works n.d.) 
Figure 2-9: Beam Column Mortise and Tenon Connection (Schmidt and Daniels 1999)........... 17

Figure 2-10: Mortise and Tenon Split (Schmidt and Daniels 1999).................................... 18

Figure 2-11: Installation of a Steel Moment Resisting Frame on a Soft Story Building (City of

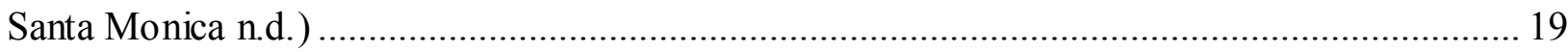

Figure 2-12: Shear Wall Layout on a Building (Civilengineer 2017) .................................... 19

Figure 3-1: Mortise and Tenon Timber Joint Dimensions..................................................... 21

Figure 3-2: Mortise and Tenon Dowel Layout ............................................................... 21

Figure 3-3: Before and After Attaching Wood Veneer to Filler-Module ................................. 23

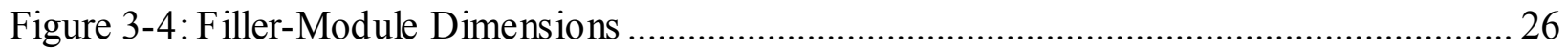

Figure 3-5: Wed ge Shaped Filler-Module $\left(45^{\circ}\right)$ - Engineered Wood ..................................... 26

Figure 3-6: FRP Dowel Layout on Filler-Module ......................................................... 27

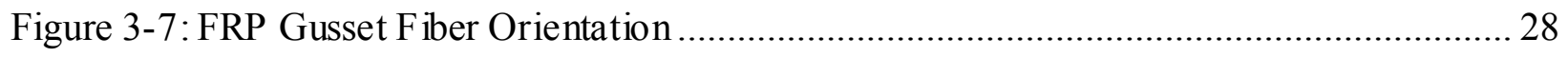

Figure 3-8: Dimensions of all Gusset Sizes ............................................................................ 28

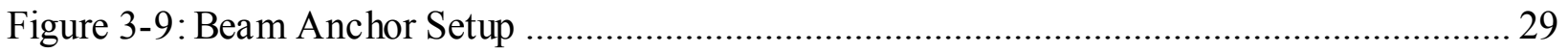

Figure 3-10: Filler-Module Wrap Setup ............................................................................ 30

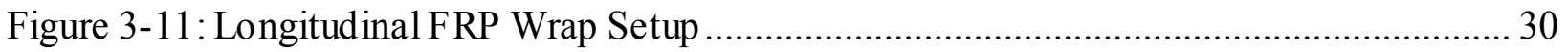

Table 3-6: Testing Specimen Breakdown....................................................................... 31

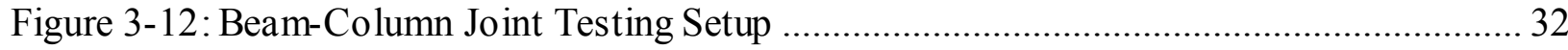

Figure 3-13: Strain Gage Location and Orientation on the FRP Gusset................................ 33

Figure 3-14: Strain Gage Location on the Filler-Modules............................................... 33

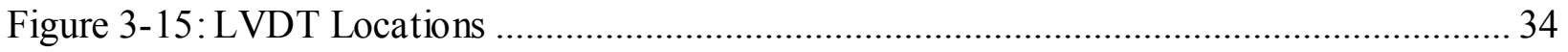

Figure 4-1: Load vs Beam Deflection under Beam Loading ................................................ 37

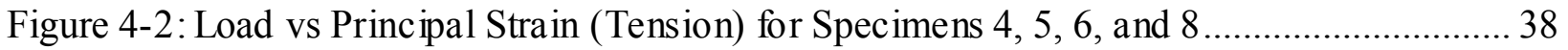


Figure 4-3: Load vs Principal Strain (Tension) for Specimens 7, 9, and 10 .......................... 38

Figure 4-4: Load vs Principal Strain (Compression) for Specimens 4, 5, 6, and 8 .................. 39

Figure 4-5: Load vs Principal Strain (Compression) for Specimens 7, 9, and 10 .................... 39

Figure 4-6: Load vs Top Filler-Module Strain ............................................................ 40

Figure 4-7: Load vs Bottom Filler-Module Strain ........................................................... 40

Figure 4-8: Load vs Tenon Pullout for Specimen 1 ........................................................... 47

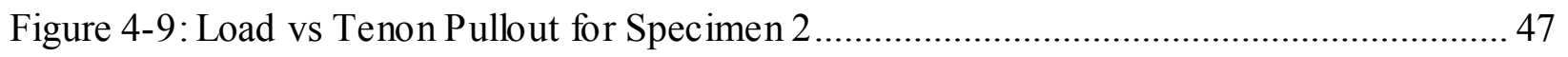

Figure 4-10: Failure Mode for the Control Specimens .................................................. 48

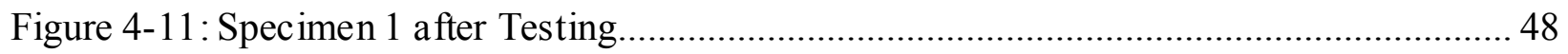

Figure 4-12: Close up of the Tenon Pull Away from Mortise on Specimen 2 ........................ 49

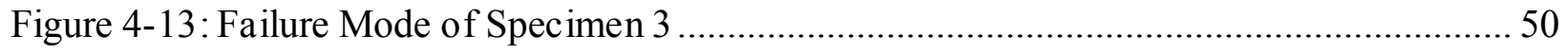

Figure 4-14: Load vs Top Module Deflection for Specimen 3 ........................................... 50

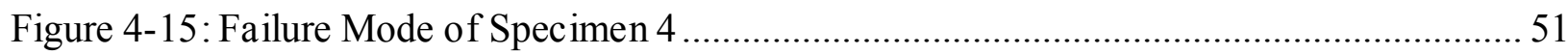

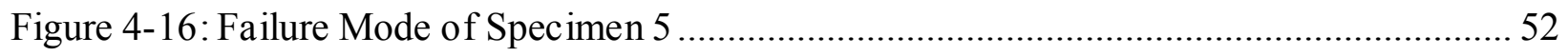

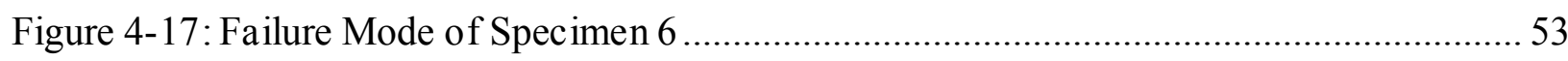

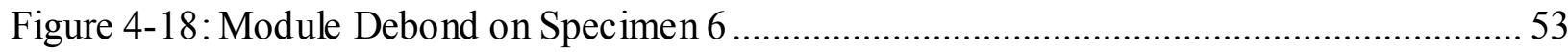

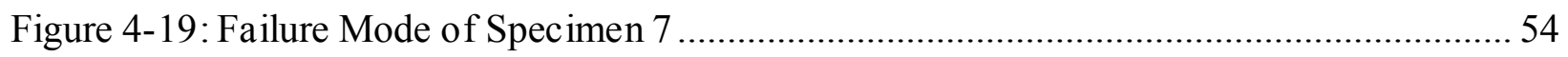

Figure 4-20: Top Filler-Module Tip Debond on Specimen 7 ............................................. 55

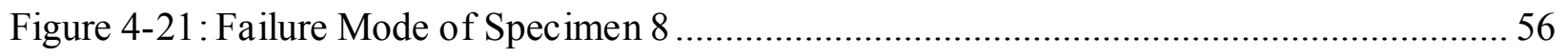

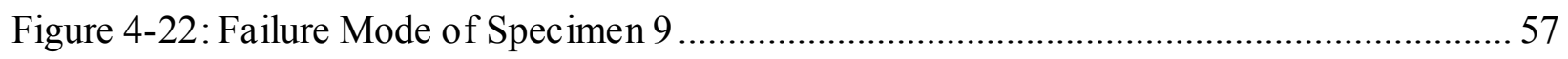

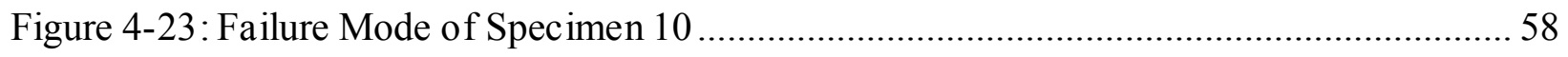

Figure 4-24: Buckling Effect on the Bottom Filler-Module of Specimen 10 ...........................59

Figure A-1: Load vs Beam Pull Out (Specimen 1) ........................................................... 75 


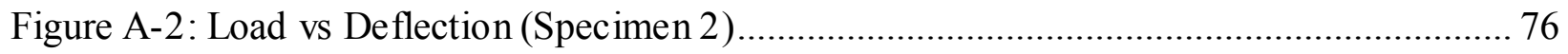

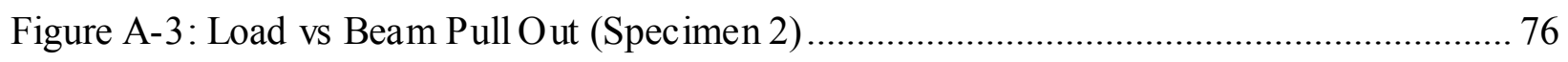

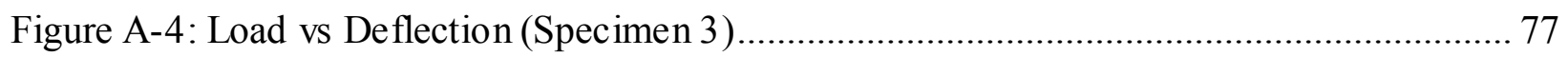

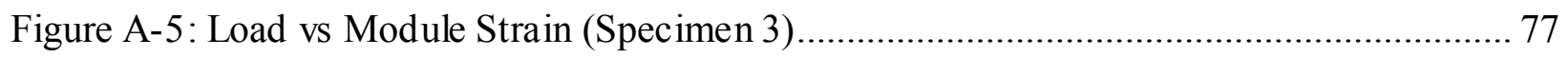

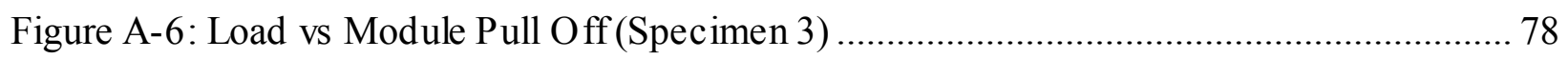

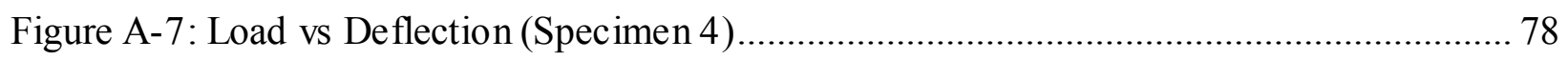

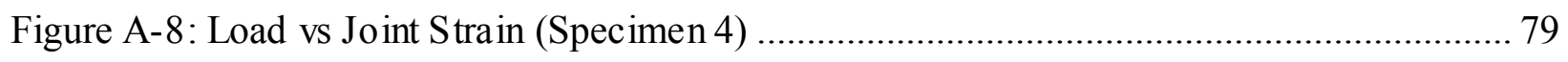

Figure A-9: Load vs Deflection (Specimen 5) ....................................................................... 79

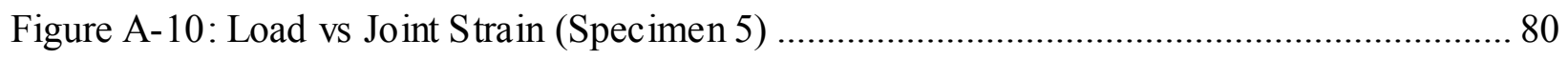

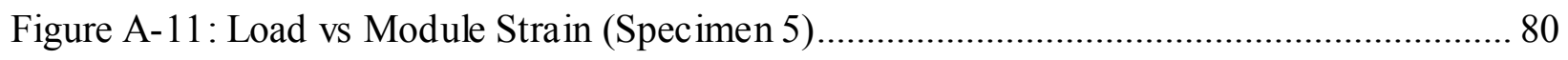

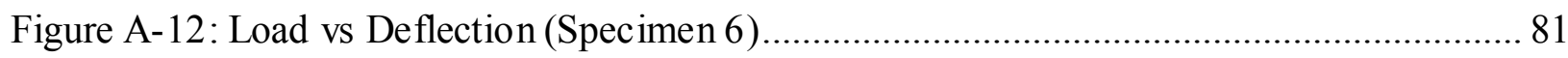

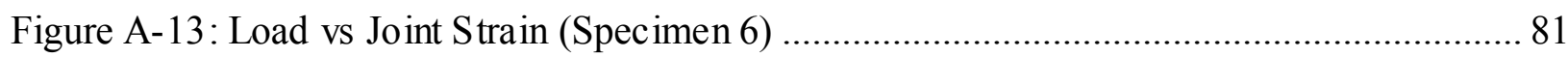

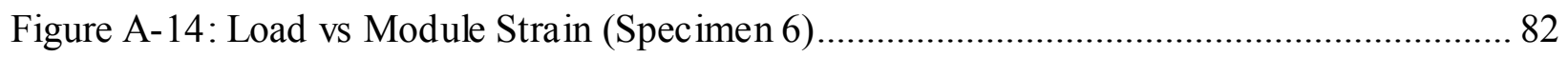

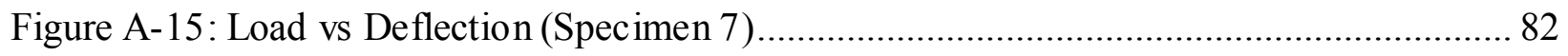

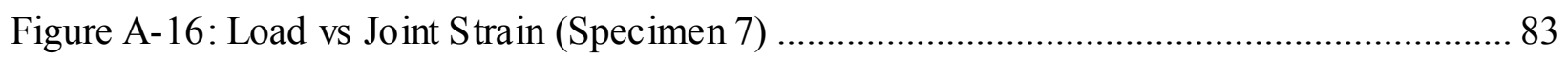

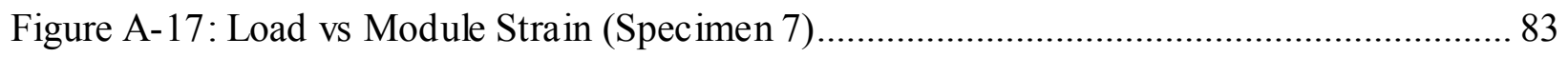

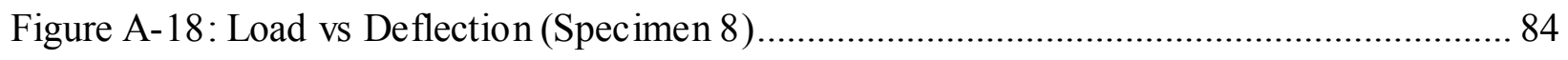

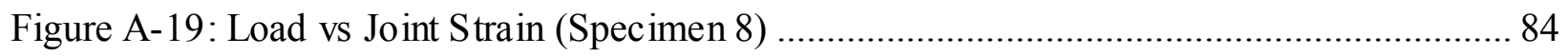

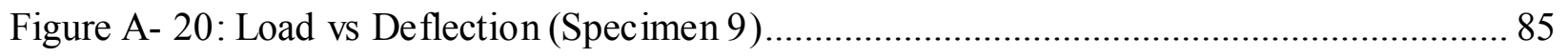

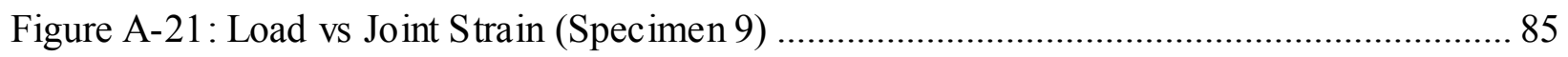

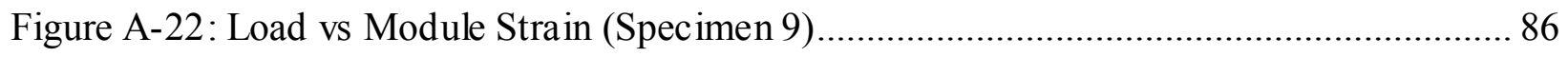

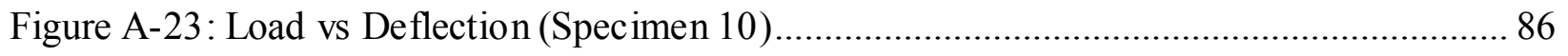

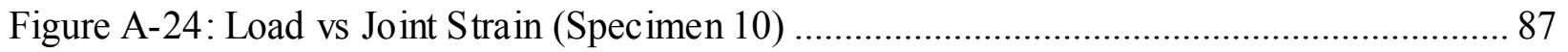


Figure A-25: Load vs Module Strain (Specimen 10) 


\section{LIST OF TABLES}

Table 3-1: Design Values for \#2 Southern Yellow Pine (Southern Forest Products Association 2013) 22

Table 3-2: Design Values for PSL (Trus Joist 2018)........................................................ 23

Table 3-3: Design Values for Sikadur ${ }^{\circledR}-31$ (Resin) (Sika 2018)............................................ 23

Table 3-4: Design Values for Glass Fabric (Sika 2018) (Sika n.d.) (Sika 2018) ...................... 24

Table 3-5: Design Values for Sikadur ${ }^{\circledR}$ Resins (Sika 2018) (Sika 2018) ............................... 24

Table 3-6: Testing Specimen Breakdown..................................................................... 31

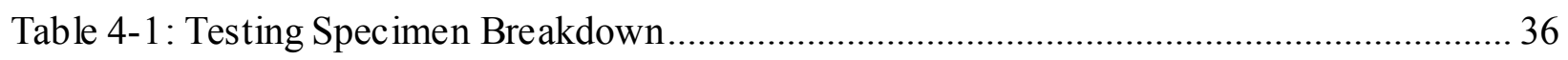

Table 4-2: Joint Test Results - Failure Load vs Deflection.................................................... 37

Table 4-3: Strength Comparison for All Specimens ........................................................... 41

Table 4-4: Ductility Comparison for All Specimens (*Did Not Reach 25\% Past Peak Load) .... 43

Table 4-5: Energy Absorption Comparison for All Specimens (*Did Not Reach 25\% Past Peak

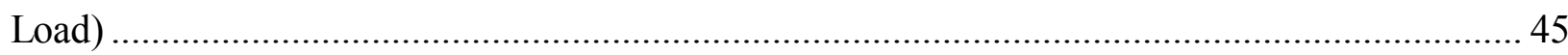

Table 4-6: Analytical Prediction of Joint Strength vs Material Property Strength..................... 60

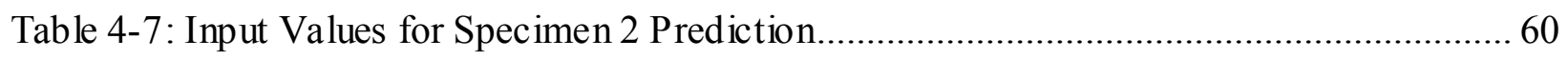

Table 4-8: Mohr's Circle Results for Sample 2 .............................................................. 61

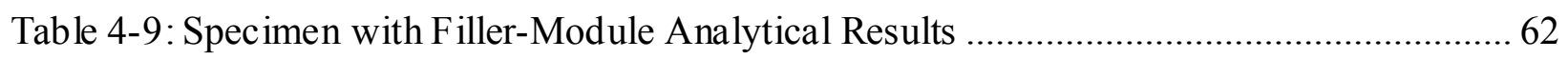

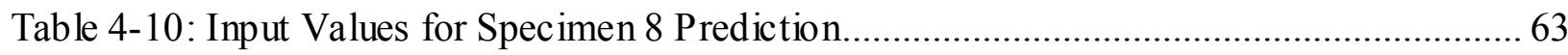

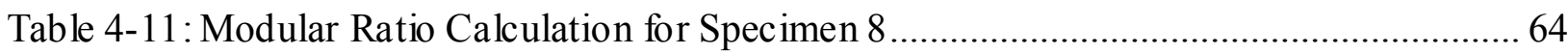

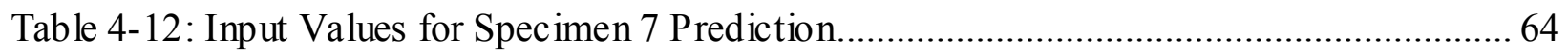

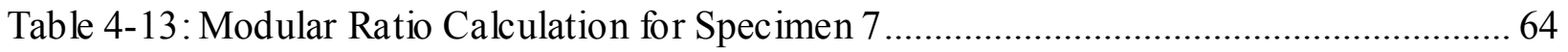




\section{CHAPTER 1 INTRODUCTION}

\subsection{Background}

Natural disasters such as earthquakes and hurricanes induce extreme lateral forces onto structures and can cause catastrophic failures in structures that are not designed to resist dynamic forces. In the San Francisco area, a highly seismic zone, there are over 10,000 timber soft story buildings (ground floor weaker than above) that are highly vulnerable to failure under seismic forces (The City and County of San Francisco n.d.). An example of a soft story structure can be seen in Figure 1-1. Absence of framing is ideal for open spaces such as apartments, parking or commercial areas; but it results in weakening the lateral resistance of a structure, commonly referred to as a 'soft story' structure. Over 115,000 San Francisco residents live in buildings that are classified as a soft story structure. On record the United States averages 1.75 hurricanes every year, and 3 hurricanes that are classified as Category 4 or 5 every five years. Major structural damage, which can be seen in Figure 1-2, renders building uninhabitable until rehabilitation or reconstruction is completed, which can take months to years. The U.S. spent a record \$306 billion in damages from natural disasters in 2017 (Ferris 2018), and \$91 billion in 2018 (Chappell 2019). The high population density of soft story buildings and the high cost of repair after disasters made retrofitting a high priority, as legislated by many comminutes and municipalities in the Bay - LA area. 


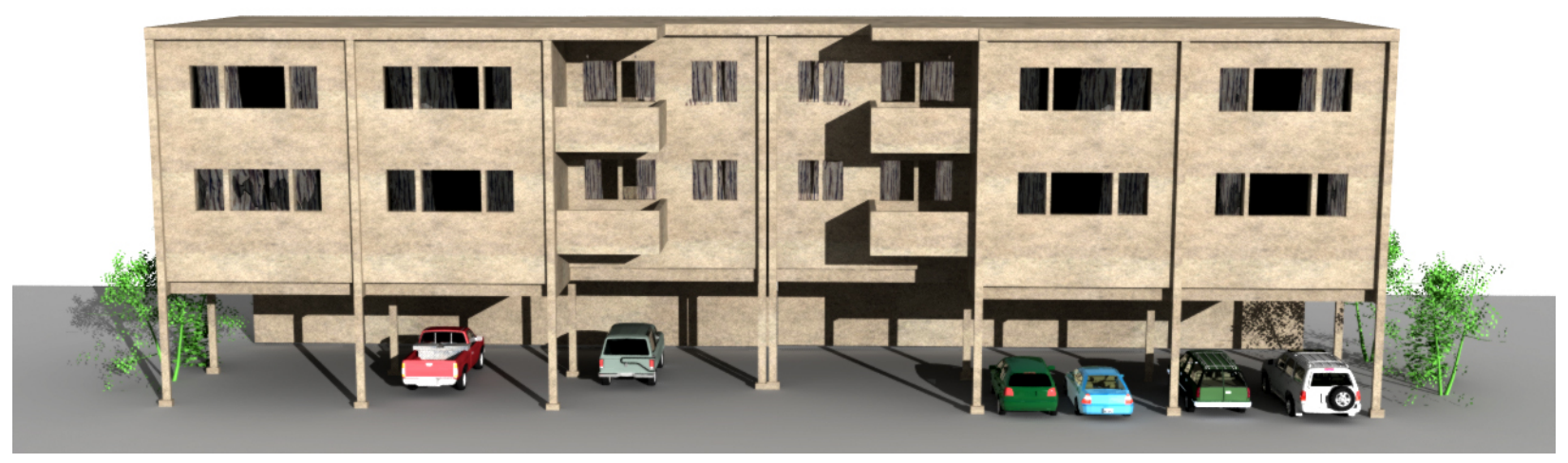

Figure 1-1: Example of a S oft S tory Building (Rañoa et. al 2015)

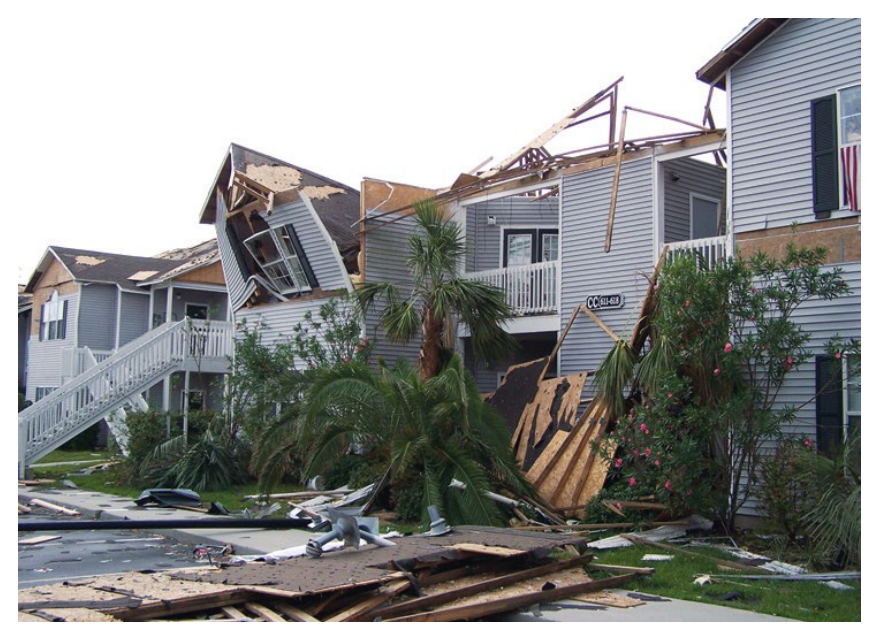

Figure 1-2: Soft Story Building Damage from Hurricane Katrina (Pan 2014)

In 2013, the City of San Francisco approved Ordinance 66-13 which mandated many wood-frame buildings to be retrofitted to resist seismic forces and minimize failures such as the ones in Figure 1-3. The ordinance covers soft story structures covering, two or more stories over a basement, carrying a minimum of residential units, such as Type V wood framed building, and any building that had the application of permit for original construction prior to January 1,1978 (The City and County of San Francisco n.d.). The city plans on complete retrofit of deficient structures by late 2020. With many cities and counties following San Francisco's footsteps, the need for a faster, safer, and more economical retrofit solution are needed than the current ones in practice. This void can be filled by using engineered composite wood as filler-modules and also 
fiber reinforced polymer (FRP) composite gussets; thus this study focuses on retrofitting joints with engineered wood filler-modules and advanced FRP composite gussets under static loading conditions which can be used as a design equivalent load for quasi-dynamic response of framed structures.

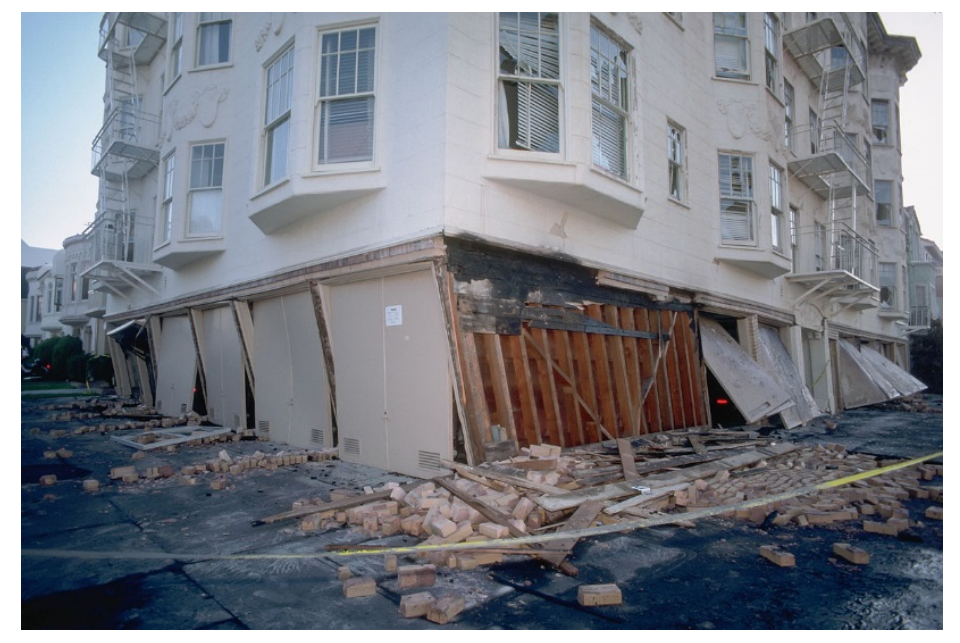

Figure 1-3: Soft S tory Building Failure due to a S eismic Event (Arroyo 2015)

The last thirty years have been a boom for FRP composites in the structural sector. FRPs are an attractive alternative to conventional retrofitting techniques due to their extraordinary properties such as lightweight, high strength-to-weight ratio, corrosion resistance, high durability, and high workability (Hollaway \& Teng 2008). Designers and contractors have been somewhat reluctant towards using FRPs since it is a relatively new material and has a learning curve to fully appreciate the correct use of FRPs in structural systems. A system is needed using FRP composites that is easy to design with, easy to install, and will improve the performance and safety of a structure.

At West Virginia University (WVU) a team of researchers developed a method of strengthening structural joints that is durable, fire resistant, energy absorbent, cost-effective, and 
safe in resisting service forces generated from seismic, hurricane, and blast actions. United States Patents 9,611,667 (GangaRao and Majjigapu 2017), 10/100,542 (GangaRao and Majjigapu 2018), and 16/133,337 (GangaRao and Majjigapu 2019) were award to the team based on a three-part invention using FRP wraps or gussets, reinforcing dowels, and filler-modules. Figure 1-4 illustrates a joint strengthening system with details for potential installation as a retrofit device in a building system requiring seismic force resistance. Filler-modules are blocks of high strength materials that are installed to help reduce the stress concentrations in a joints corner (reentrant corner) (Majjigapu 2019). Stress concentration is a location at the re-entrant corner of a joint where stress is concentrated, resulting in micro-cracking before a beam or column fails under present design guides. Figure 1-5 shows how stress is concentrated in the corner of a conventional joint, but when filler-modules are installed, the stress is distributed across the entire joint more evenly, as shown in the middle and right side of the finite element simulations of a joint under transverse loading. Also note that filler-module shape impacts the stress distribution. A wedge-shaped filler-module still has stress concentrations at the tip of the modules, but at a much lesser magnitude than a conventional joint with abrupt change in angle of $90^{\circ}$. A curveshaped filler-module can distribute the stress better than a wedge since there is a smooth transition from beam to column. Significant advances in the WVU inventions are needed before field implementing them as affordable retrofit systems in building or bridge codes across the world. 

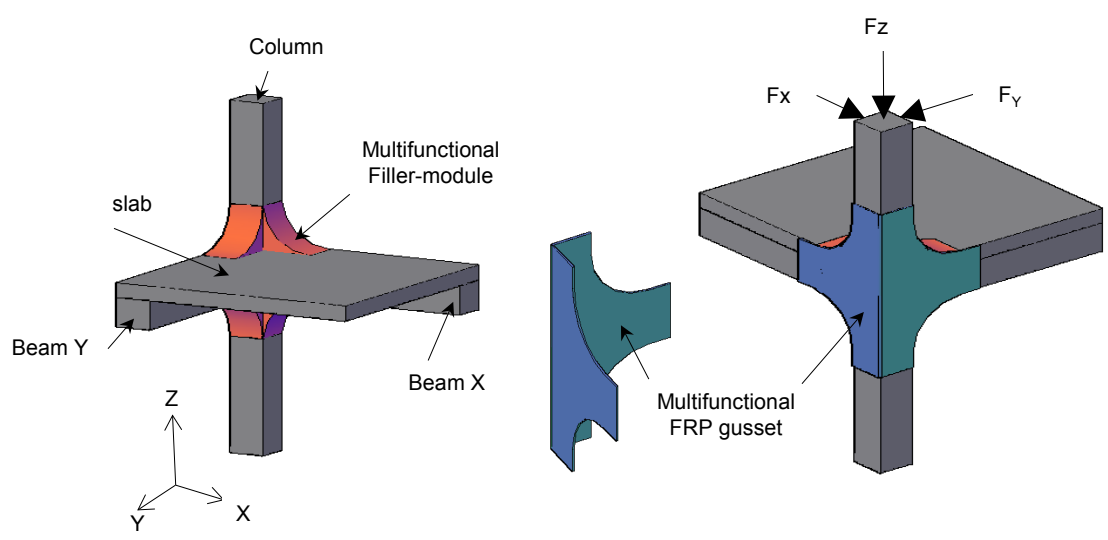

Figure 1-4: Proposed Retrofit System Installed on a Building System (Majjigapu 2019)
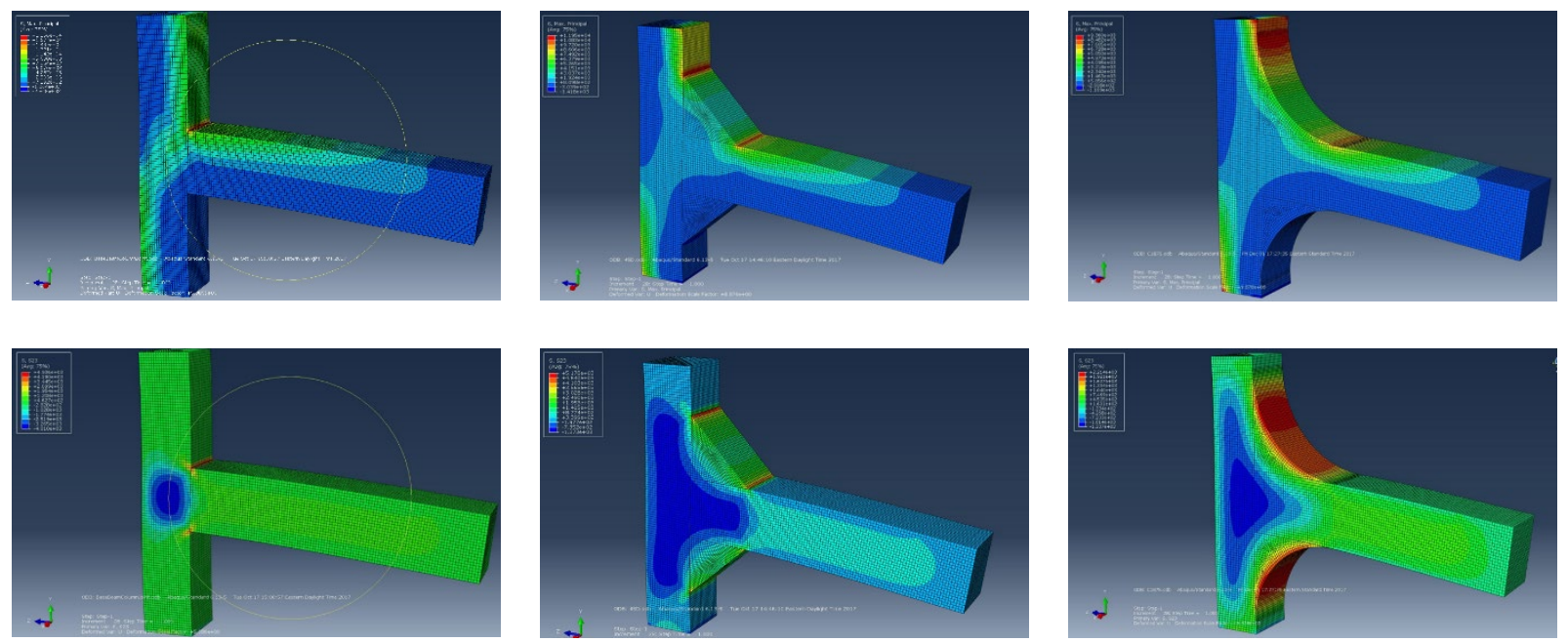

Figure 1-5: Finite Element S imulations S howing Principle $S$ tress (Top Row) and S hear S tress (Bottom Row) Concentration Effect on Varying Filler-Module Shapes Due to Transverse Loading

Throughout the entirety of this study varying joining schemes are used to study their effect on the bending behavior of the timber joints retrofitted with filler-modules and gussets. The shape of the filler-module will be examined to determine if a curve or a wedge can improve on distributing stresses and modify the failure to improve load carrying capacity and energy absorption. A gusset instillation is studied in terms of ease of field installation, when compared to a FRP wrap installation. FRP gusset material and configuration (fiber architecture) will be modified during this study to determine which composite configuration (as described in 
CHAPTER 3) provides the largest increase in strength, ductility, and energy absorption. Lastly reinforcing dowels will be installed on one joint to see if the dowels are able to contribute to a better force transfer.

\subsection{Objectives}

The main objective of this study is to complete static bending test on timber mortise and tenon joints, with and without the proposed retrofit scheme, and determine the behavior and failure modes to set up future research in this field.

- Determine what configuration of the proposed retrofit scheme gives the largest increase in strength, ductility, and energy absorption

- Review the current practices of timber framing and the available retrofitting techniques

- Evaluate the behavior and failure modes of the retrofitted joints

\subsection{Scope}

- Static bending test on mortise and tenon timber joints with and without the proposed retrofit system/scheme

○ 2 control specimens

○ 1 specimen with only filler-modules

○ 2 specimens with different gusset materials

○ 5 specimens with varying combinations of filler-modules and gussets

- Analys is of joint behavior with varying retrofit schemes

- To minimize catastrophic failures. discussion on failure modes with the proposed retrofit schemes is provided with emphasis on failure initiation, failure location, failure type, ductility limit states including peak load resistance and energy absorption 
- Make recommendations for future research using the WVU retrofit scheme

\subsection{Report Organization}

- Chapter 1 introduces the current need for moment resisting retrofit techniques and the WVU retrofit scheme

- Chapter 2 reviews current literature

- Chapter 3 discusses the materials used and explains the testing methodology

- Chapter 4 provides an analysis of the experimental data as a part of this test program collected and an in-depth look into failure modes

- Chapter 5 discusses conclusions and future work 


\section{CHAPTER 2 LITERATURE REVIEW}

This chapter focuses on a review of timber construction. Furthermore, this chapter provides background information pertaining to the selected jointing systems and their response to loading.

\subsection{Timber Construction Introduction}

Wood-based products are excellent as construction materials, because they have a high strength to weight ratio and they are green, i.e. renewable source. The use of timber quality is not as high as it used to be due to the depletion of virgin forests and accelerated growth mechanisms of southern yellow pine trees. Timber does not have the attributes in regard to reliability, serviceability, and durability that a designer will get from steel, concrete, and even masonry. Designing with timber takes someone with a significant amount of expertise to work with the highly complex transversely isotropic material (Köhler 2007).

\subsubsection{Potential Damages}

Structural timber systems are subjected to fire, wind, decay due to moisture and fungi attacks and many other reasons. A few of these adverse effects of reaction of timber to nature's vagaries are given below.

\subsubsection{Fire}

Fire can be a catastrophic event to happen to any building material due to the prolonged exposure to high temperatures. Timber degrades when exposed to the elevated temperatures that fire can produce. At temperatures below $212{ }^{\circ} \mathrm{F}$, the immediate effects of temperature on wood properties are reversible. Under prolonged exposure to temperatures above $150^{\circ} \mathrm{F}$, timber will undergo permanent losses in strength properties (Ross et. al 2005). 
Timber does have some natural fire resistance. Wood members can retain some load capacity if the charring effect does not reach a critical depth. Charred wood does not have any residual load capacity; therefore, the new capacity is dependent on the wood beneath the char layer. Figure 2-1 shows how charring effects the outer layers of a wooden member but can still have a solid core.

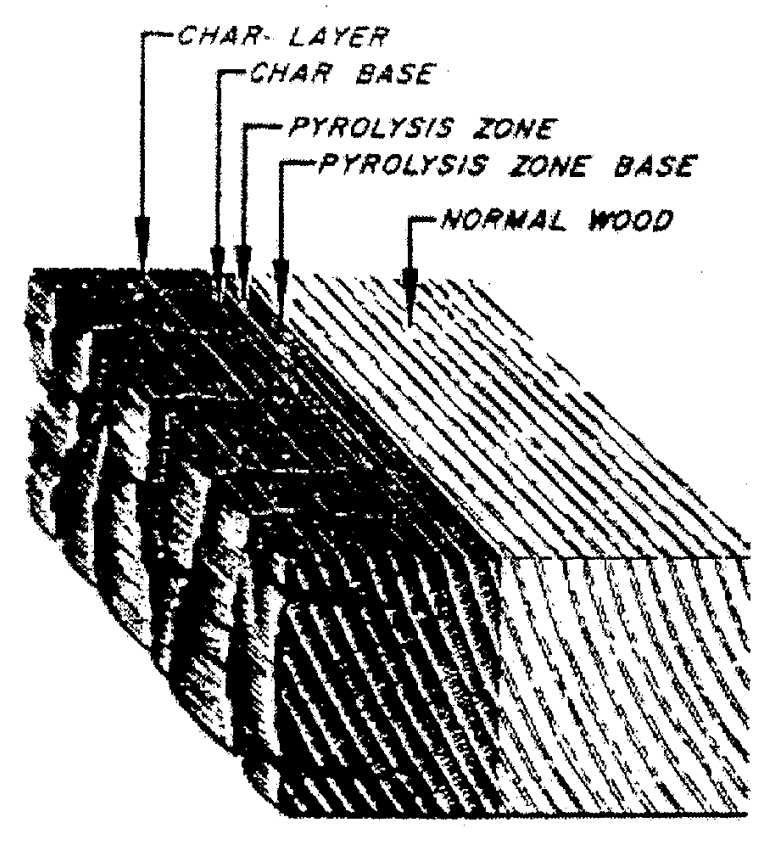

Figure 2-1: Depiction of Fire Damage on a Timber Cross Section (Ross et. al 2005)

\subsubsection{Wind}

High winds such as hurricanes and tornados cause billions of dollars in damage and hundreds of lives lost each year in the United States. Most damages are on structures that are non-engineered due to dry-rot, terminate attacks and others. These buildings are common residential dwellings or office or school buildings. Normally it takes winds over $100 \mathrm{mph}$ to cause widespread damage to buildings, but there have been many instances where structures have been damaged or destroyed by winds of lower speeds due to improper or inadequate joining schemes. Texas Tech University has conducted a large number of investigations due to wind 
damage over the last forty years and have made significant impacts on how buildings are designed (Liu et. al 1989). Design codes should be followed to avoid premature failure due to wind damage, like the building in Figure 2-2.

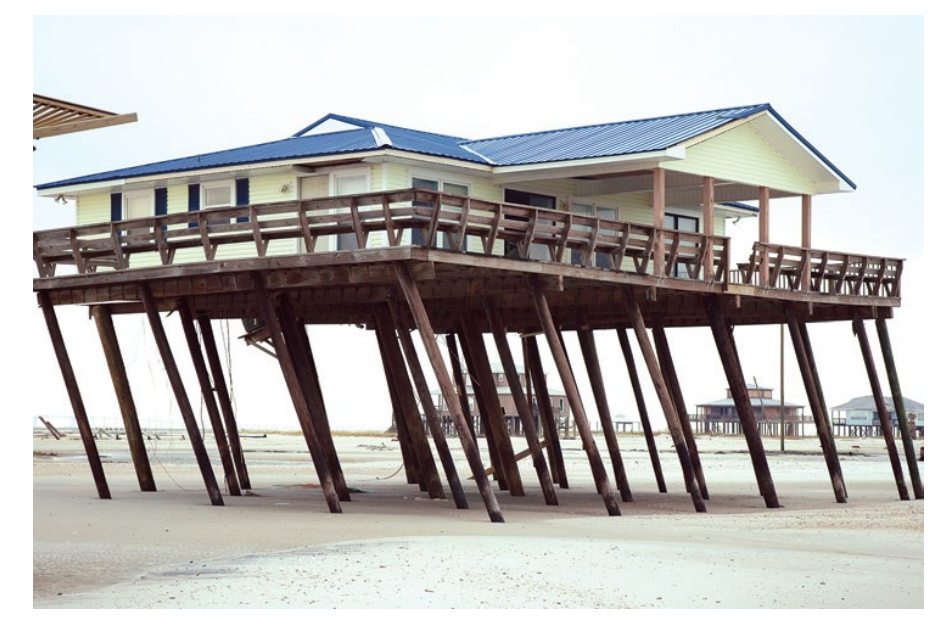

Figure 2-2: High Winds Causing a Building to Tilt (FEMA 2006)

\subsubsection{Decay}

Timber is an organic material, which makes it a great source of energy for microorganisms. Many organisms that can be found in buildings such as mold, fungi, bacteria, and insects are always searching for food. It is easier for these living creatures to survive on timber members when the wood is especially exposed to moisture. The factor that will keep a building from decaying is keeping the timber dry (Singh and White 1997). Decay can be prevented by allowing the timber members to be in a well-ventilated area with low humidity and making sure that the member is protected from leaks (Houspect WA 2015). Chemical treatment of wood with products such as pesticides will also further delay decay actions.

Structural members that are afflicted by decay must be treated immediately or run the risk of needing replacement or a building collapse. As seen in Figure 2-3 a structural member will lose cross sectional area due to micro-organisms eating away at the periphery of wood members. 
Once a member reaches its critical load because of the reduced area due to decay damage, then the structure supported that member can collapse, if it can't find alternate load path.

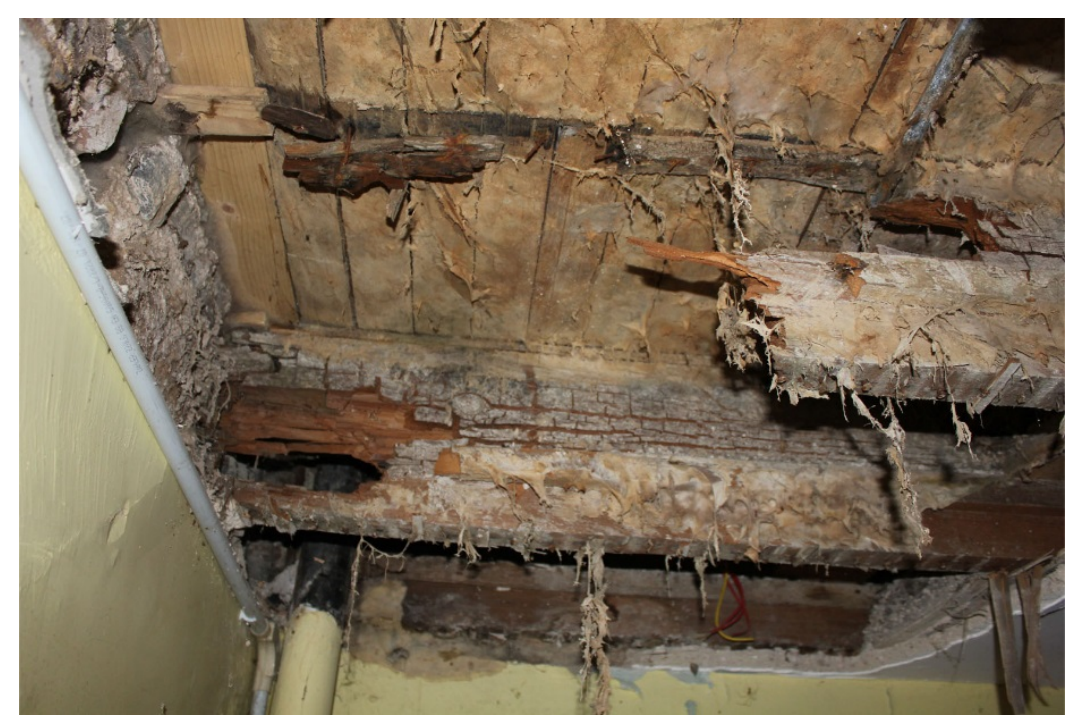

Figure 2-3: Example of Timber Decay on Beam Members (Houspect WA 2015)

\subsection{Timber Moment Connections}

Since typical timber construction is used on non-engineered structures, i.e. houses, schools, and offices, there are standards to connect beams to columns to roof trusses. A typical timber building can have several connection types, which are illustrated in Figure 2-4. The joint that is considered to be vital in any structure is the beam-column joint. The beam-column joint is important, because it is responsible for transferring loads from the flooring system to the column. Figure 2-5 displays a few typical beam-column connections in timber framing systems. Structures that will encounter a large amount of lateral forces will need to be constructed with moment connections, and therefore will be the focus of this study. A rigid joint, or moment connection, must have the ability to fully transfer bending moments and shear forces. The ability to transfer bending moment through a timber connection has been a difficult task due to their fiber orientation. Characteristics of timber such as volume change, low tensile strength 
perpendicular to the grain, and low fastener stiffness make timber connections easier to design as pinned supports. Moment connection designs are available (Moses et. al 2016) for timber structures but many modern solutions to timber joint design under seismic and other unusual loads are not code approved currently and can be difficult to acquire.
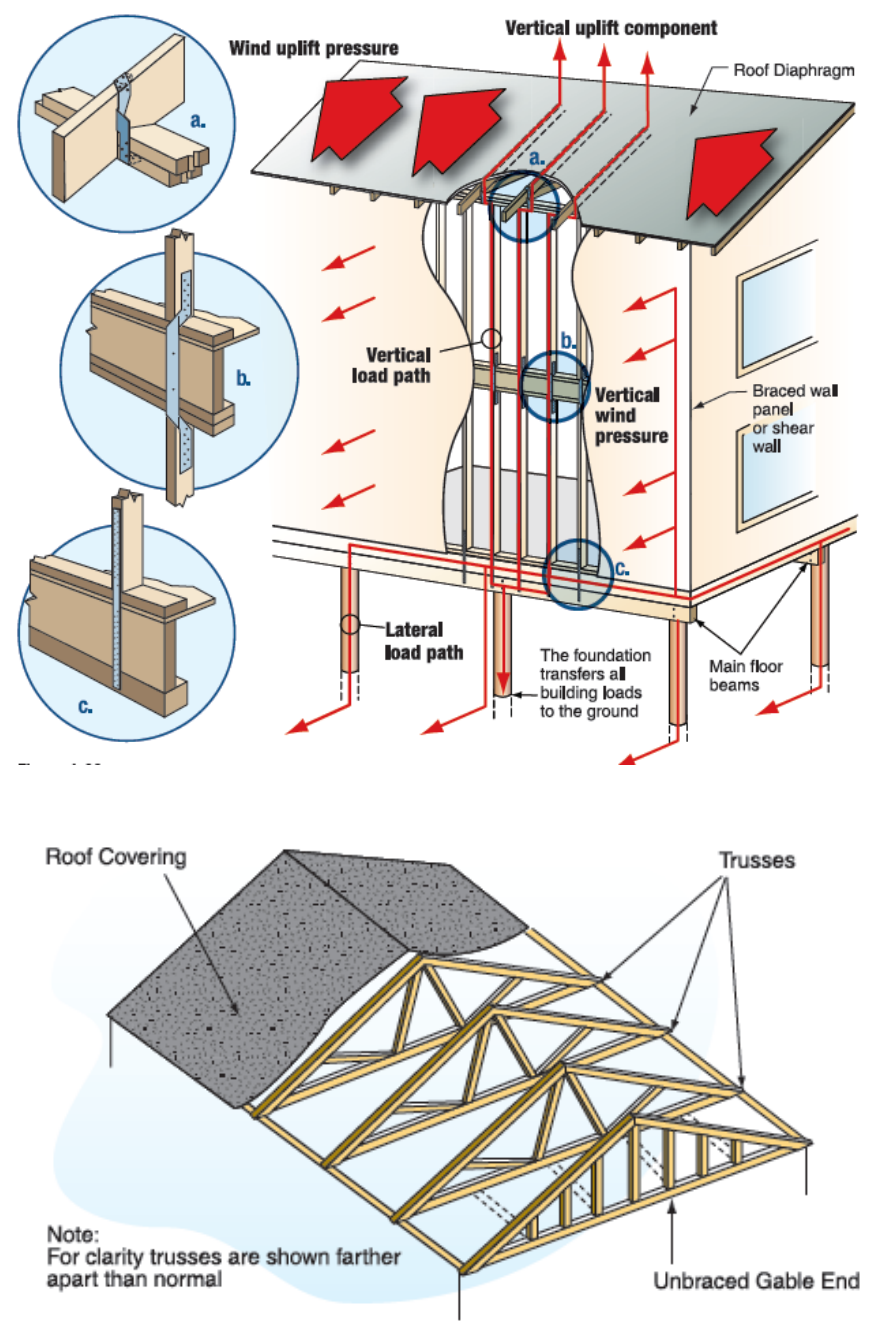

Figure 2-4: Typical Timber Connection Methods on a Residential Building (FEMA 2006) 

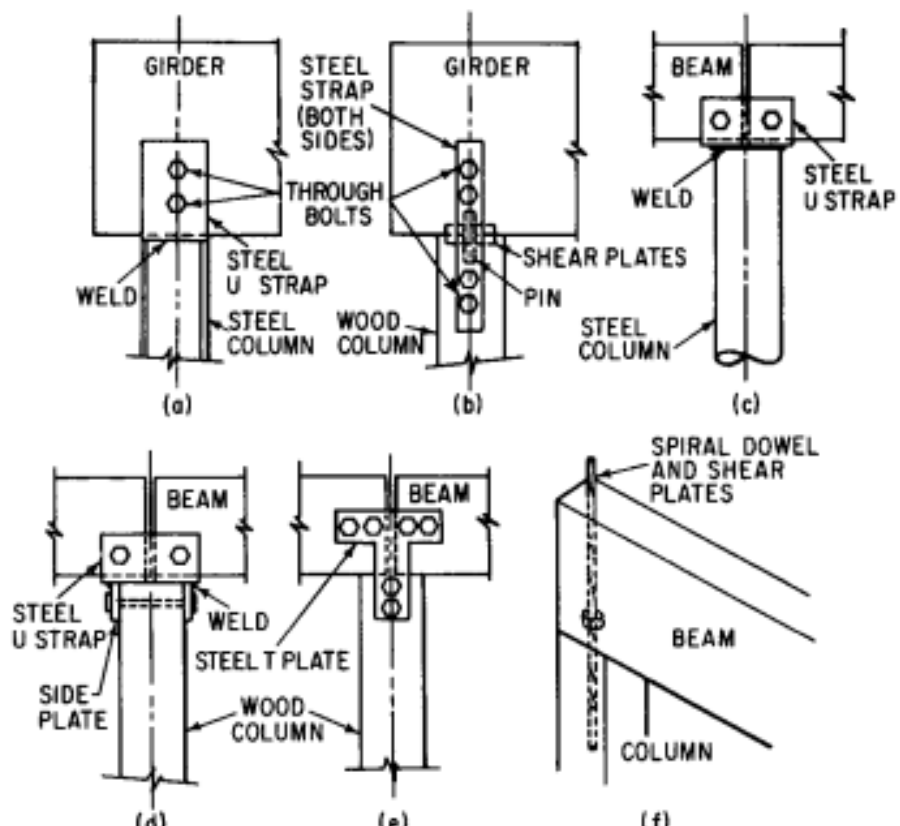

(d)

(e)

(f)

Figure 2-5: Typical Timber Beam/Girder Connections to Columns: (a) Girder to Steel Column; (b) Girder to Timber Column; (c) Beam to Pipe Column; (d) Beam to Wood Column, with S teel Trap Welded to Steel Side Plates; (e) Beam to Wood Column, with a T-Plate; (f) Beam-Column Connection with Spiral Dowel and S hear Plates (Merritt and Ricketts 2001)

\subsubsection{Dowel-Type Fasteners}

Dowel type fastener is a general term that covers nails, screws, dowels, and bolts that transfer load perpendicular to the longitudinal axis. These connections transfer load through connected members by a combination of flexure and shear in the fasteners and shear and bearing in the timber (Gocál 2014). Connections must be looked at both the local and global levels. At the local level, a single fastener must have a sufficient load carrying capacity with the timber it is embedded into. At the global level, spacing and distance between fasteners must be enough to withstand the forces being transferred (Pedersen 2002). 

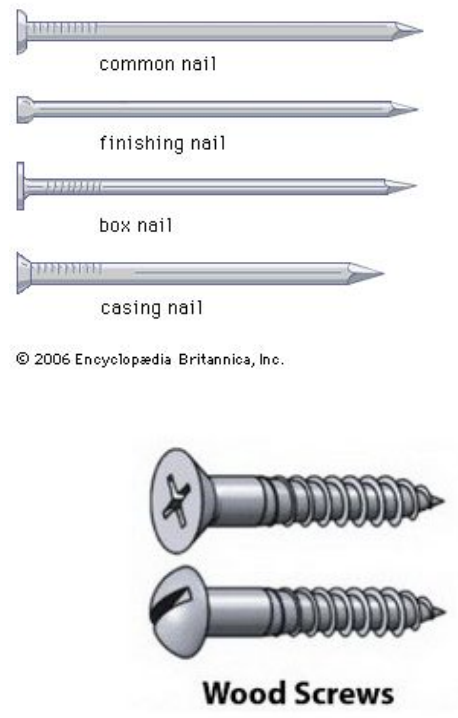
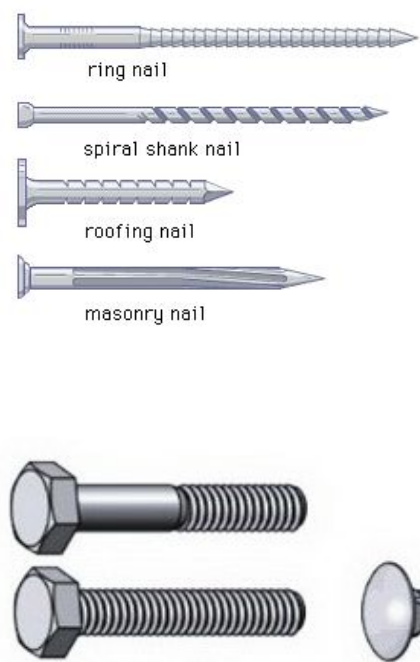

Hex Bolts
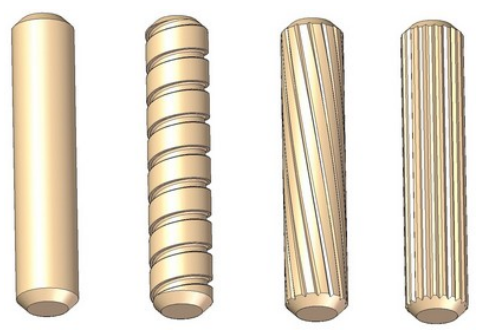

Wooden Dowels

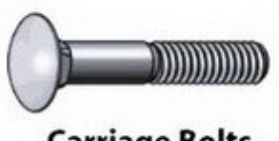

Carriage Bolts

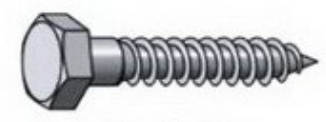

Lag Bolts

Figure 2-6: Examples of Dowel Type Fasteners: Nails (Top Left) (Encyclopedia Britannica n.d.), Wooden Dowels (Top Right) (Craftsmanspace n.d.), and S crews/Bolts (Bottom) (DIY Extra n.d.)

\subsubsection{Behavior}

The ductile behavior of dowel-type fasteners is based on the strength and stiffness of the connection type and its ability to transfer forces without getting suddenly loosened under repetitive loads, or impact loads resulting in jerking actions. The strength of the connection is modeled based on the dowel effect (the contact pressure between the fastener and the members), friction between connected members, and axial tension force in the fastener. The ultimate carrying capacity will be the summation of those three factors. The stiffness can be determined by many different types of tests, since there is no standard on calculating stiffness in a fastener. Research from many different tests has provided an empirical equation that is only valid for finding the initial stiffness per shear plane for fasteners, which can be seen in Equation 2-1. Another common approach for finding stiffness is an analytical method considering the fastener as a beam on a foundation. Bernoulli's theory (Haukaas 2014) can be applied assuming that the foundation is linear elastic. Kuenzi (Kollmann et. al 1975) applied the elastic foundation theory 
on laterally loaded dowel-type fastener connections. Kuenzi determined that the stiffness based off of this theory is depended on the modulus of the timber, the fastener diameter and the force transfer length of the fastener. The stress length is difficult to determine and must be done independently for each test specimen. Van der Put (van der Put and Leijten 2000) used Holographic Interferometry technique to prove that the beam on an elastic foundation method is a potential method to determine the stiffness of the moment connection (Fokkens 2017).

$$
\begin{aligned}
K_{\text {ser }}= & \rho_{m}{ }^{1.5} * \frac{d}{23} \\
& \text { With: } \\
& K_{\text {ser }}, \text { instantaneous slip modulus }[\mathrm{N} / \mathrm{mm}] ; \\
& \rho_{m}, \text { mean density of the timber }\left[\mathrm{kg} / \mathrm{m}^{3}\right] ; \\
& d, \text { fastener diameter }[\mathrm{mm}] .
\end{aligned}
$$

Equation 2-1

\subsubsection{Failure Modes}

Determining the failure mode for dowel-type fasteners can be done by using Johansen's yield theory (Johansen 1962). According to Johansen the load carrying capacity is dependent on the geometry of the connection, the bending resistance of the fastener, and the embedding strength of the timber material. The design equations used for dowel type fasteners are based on a rigid-plastic behavior of both the fastener under bending moments and the wood under embedding stresses, while also taking into account the plastic moment capacity of the fastener (Aicher and Reinhardt 2000).

There are several possible failure modes, outlined in

Figure 2-7, that happen in a timber joints depending on the connection type and materials used. Mode I is a wood bearing failure that happens in the timber member; mode II is a fastener 
rotation without bending; mode III is a combination of bearing failure with a plastic hinge formation; and mode IV is the same as mode III but with more plastic hinges forming. The modes are true for the assumption that the fastener and wood are both perfectly plastic. Axial force on the fastener and friction between members are ignored for these models, since they can significantly increase the capacity. Design of dowel-type fasteners is to be treated as the failure mode that results in the lowest load, i.e. which failure more would occur first when loading is applied (Rammer 2016).
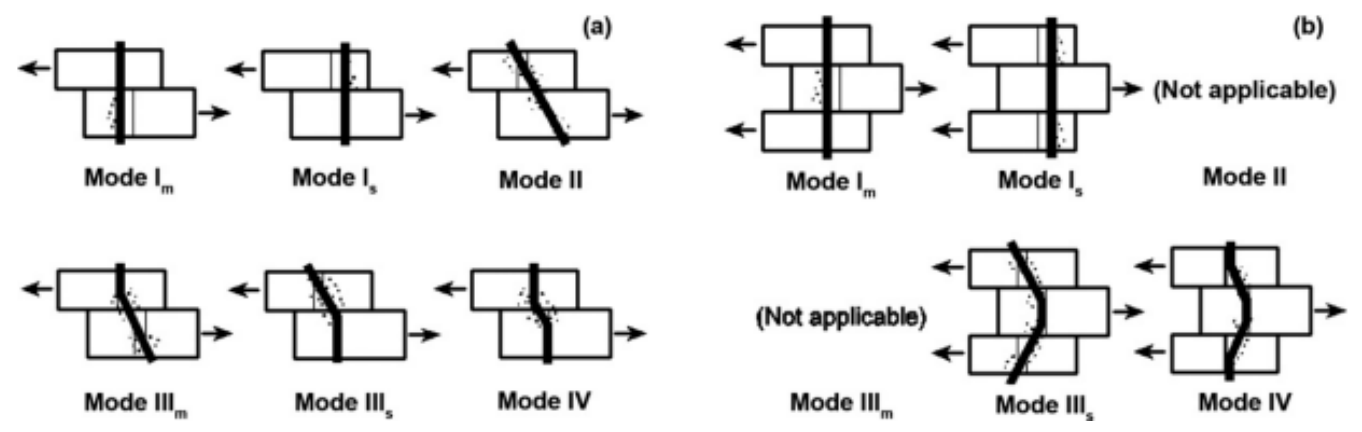

Figure 2-7: Failure Modes for Dowel-Type Fasteners in (a) Two Member Connections and (b) Three Member Connections (Rammer 2016)

\subsubsection{Mortise and Tenon}

Mortise and tenon connections have been used for centuries around the world in timber framing. The connections are made entirely out of wood, and therefore were a common joining method before metal fasteners were introduced in timber construction, which can be seen in Figure 2-8. The mortise (grove end) is secured to the tenon (tongue end) with the use of a dowel, as seen in Figure 2-9. Without the dowels, the tenon will slip right out of the mortise and not transfer any load. The two dowel connections will help transfer bending moment, because the tenon will be restricted from rotation by the second dowel (Schmidt and Daniels 1999); thus partially converting bending forces into axial and/or shear forces in the dowels. 


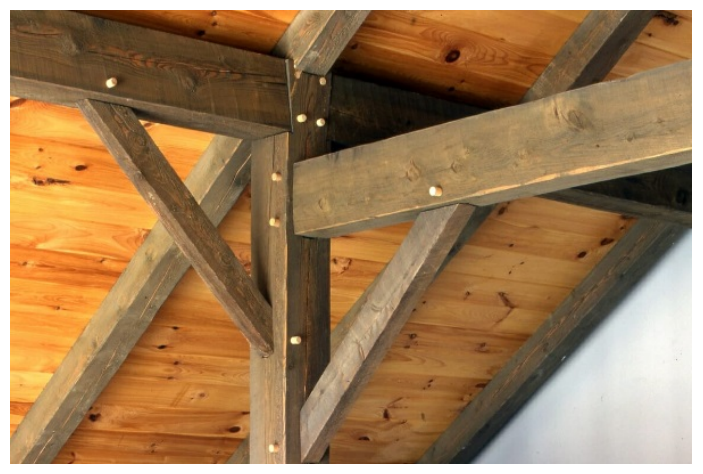

Figure 2-8: Mortise and Tenon Connection in a Building System (Vermont Timber Works n.d.)
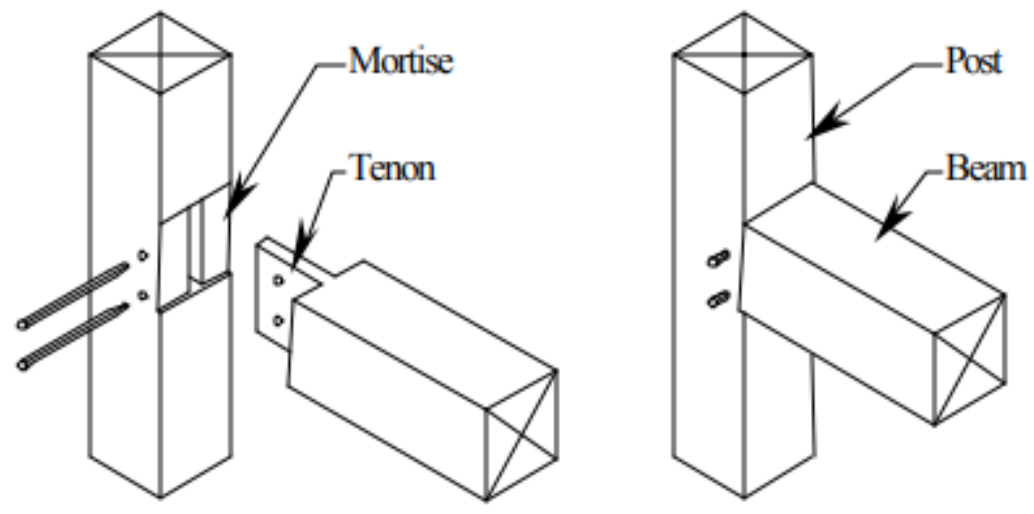

Figure 2-9: Beam Column Mortise and Tenon Connection (S chmidt and Daniels 1999)

\subsubsection{Behavior}

The behavior of a mortise and tenon connection is once again based on the strength and stiffness of the materials. The connection will behave as a semi-rigid joint, until a bearing or dowel failure initiates, at which point some of the rigidity is lost. The connection will lose all rigid ity when the ultimate failure occurs, which can be a ductile or brittle behavior depending on the controlling failure mode (Schmidt and Daniels 1999). 


\subsubsection{Failure Modes}

Mortise and tenon connections can experience three different failure modes. The first being a mortise split. A mortise can split if the wall thickness is inadequate to restrict bending/tensile force transfer from column to beam because the dowel material is stiffer than the bearing of the timber. The second mode that could occur is a tenon split. Tenons can split when there is not a sufficient edge distance between the dowel and the end of the beam. The dowel bending or shearing is the third failure mode. This behavior is the same action that is described in section 2.2.1.2 (Schmidt and Daniels 1999).

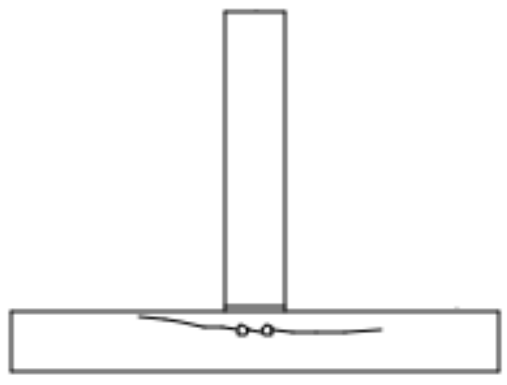

Mortise Split

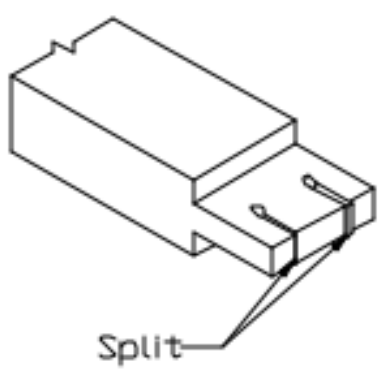

Tenon Split

Figure 2-10: Mortise and Tenon Split (S chmidt and Daniels 1999)

\subsubsection{Available Retrofit Methods}

Current retrofitting techniques focus on the entire structure, rather than addressing the weak link of beams and columns which is the joint. The practice that many retrofit engineers use to fix weak structures include installing shear walls and adding moment resisting steel frames (Partner Engineering and Science, Inc. n.d.). Figures 2-11 and 2-12 illustrate how invasive a global 
retrofit is. The steel frame and shear wall installation are effective retrofit schemes, because they add a higher strength material or more material to transfer lateral loads. FRP rehabilitation is becoming a promising alternative to conventional methods due to the lower cost of repair, $\sim 10 \%$ cheaper. A new material proves to be difficult not only for designers to use, but also for the workers installing the system. A new retrofit system that is able to be low cost while maintaining high structural efficiency that is also an easy installation process would integrate into current practices rapidly.

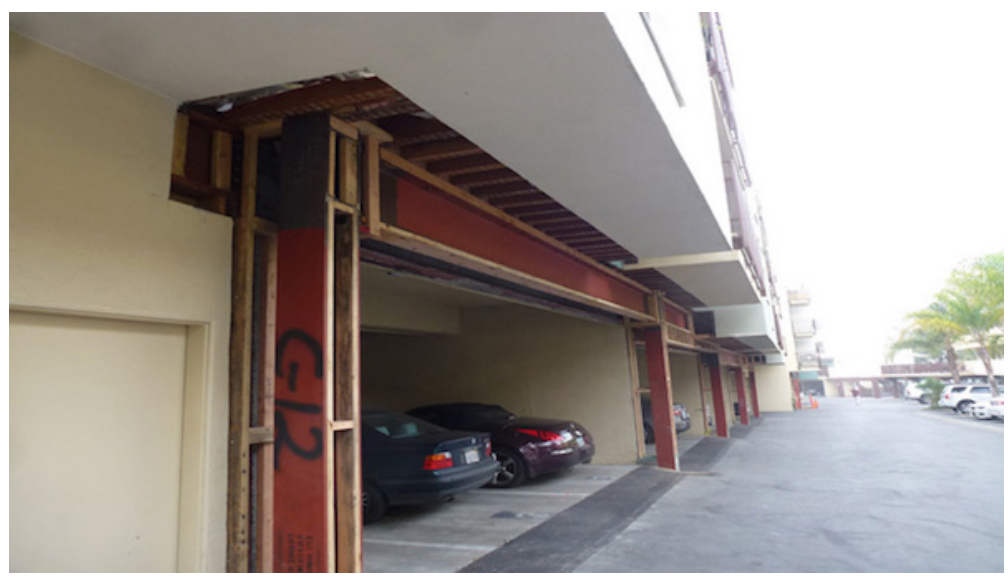

Figure 2-11: Installation of a S teel Moment Resisting Frame on a S oft S tory Building (City of S anta Monica n.d.)

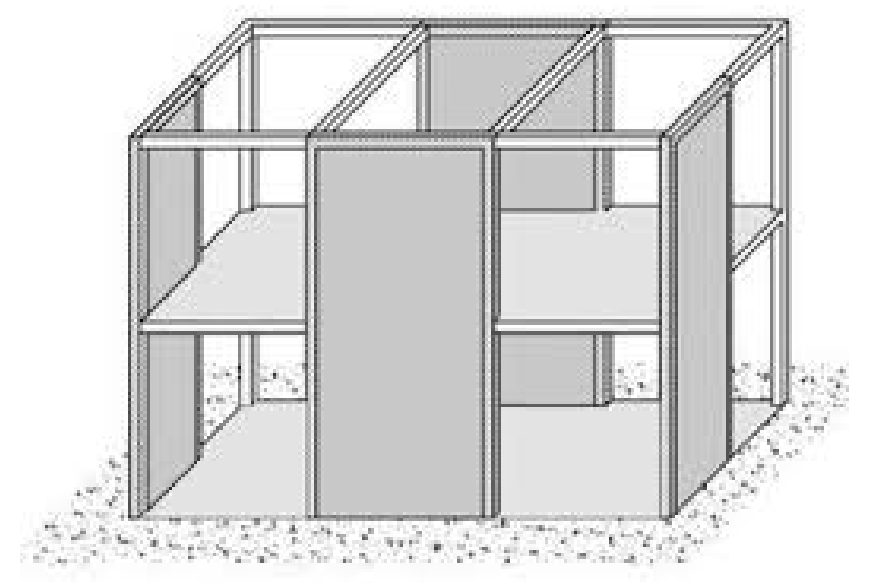

Figure 2-12: Shear Wall Layout on a Building (Civilengineer 2017) 


\section{CHAPTER 3 EXPERIMENTAL MATERIALS AND}

\section{METHODOLOGY}

\subsection{Testing Materials}

This section will go over the materials used and the size of throughout the testing. Test specimen, filler-module, and gusset fabrication will be outlined within this section as well. Standard building timber will be used for the joints to simulate a real building system. Engineered wood will be used for the filler modules, due to the higher strength and controlled properties. The FRP gussets will be made out of glass FRP (GFRP) due to the lower cost and high strength-to-weight ratio.

\subsubsection{Joint Materials}

Testing samples were made using readily available building materials. All timber (yellow pine) were obtained from the local lumber company (Lowe's). Severe Weather Ground Contact pressure treated 6" 6 " posts were used to create the joint seen in Figure 3-1. Note that 6" 6 " is the nominal size of the southern yellow pine (SYP) timber post, while the actual post dimensions are 5.5" x 5.5". The pressure treated wood was made of \#2 grade SYP. Dimensions for the test specimens are laid out on Figure 3-1. The length of the beam was limited due to the restrictions of the loading bay. To easily install the test specimens into the loading frame a 20 " long beam was used. Mortise and tenons were cut to a very tight tolerance for a very tight fit mortise and tenon joint and were joined together using wood glue. Using Schmidt and Daniels' paper for recommended dowel spacing, Figure 3-2 shows the layout used on all test samples. Dowels were $3 / 4$ " diameter oak rods that were cut to 6 " length then glued and hammered into a slightly 
undersized hole. Timber material properties used for this study were gotten from Southern Pine Reference Design Value and are reported in Table 3-1.

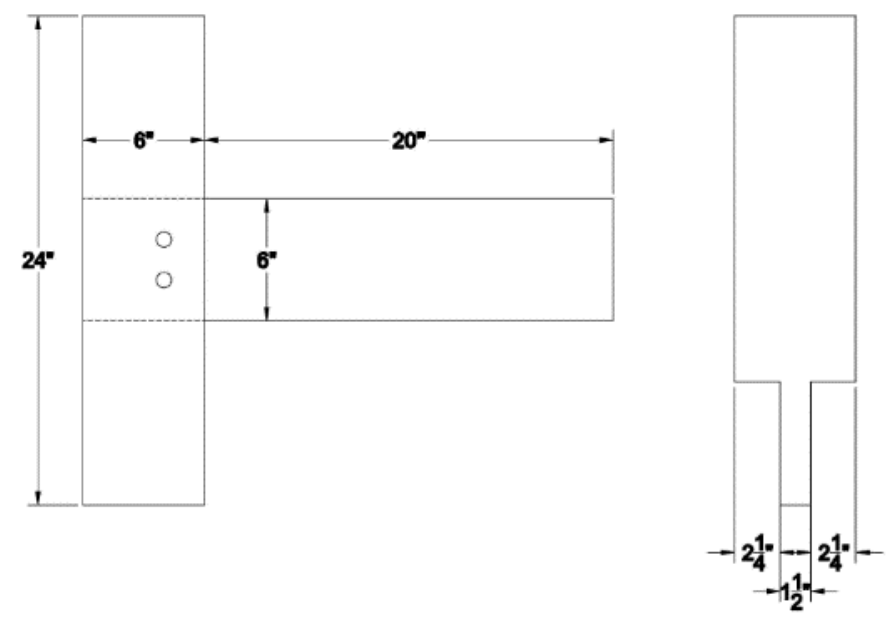

Figure 3-1: Mortise and Tenon Timber Joint Dimensions
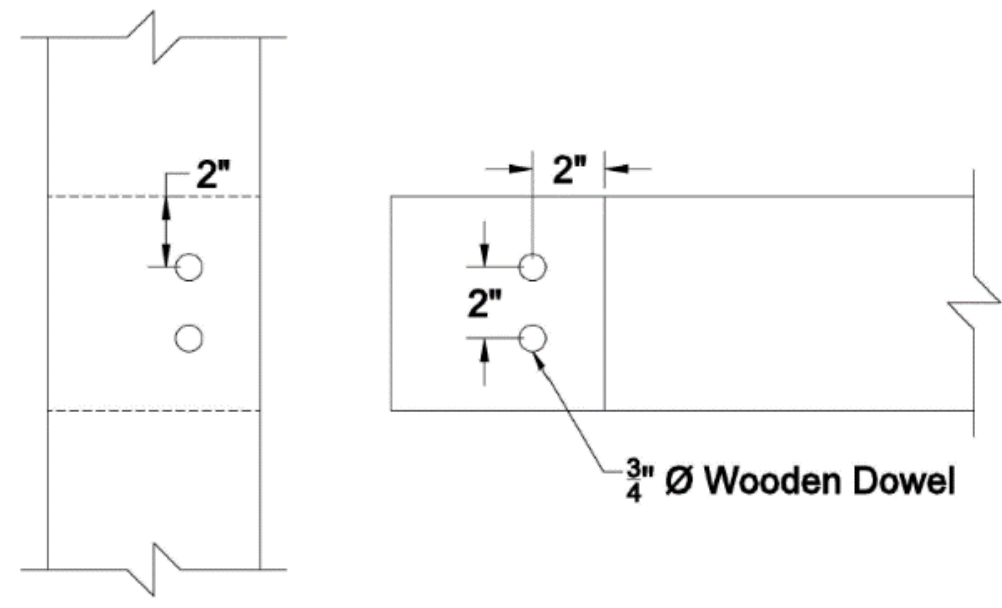

Figure 3-2: Mortise and Tenon Dowel Layout 
Table 3-1: Design Values for \#2 Southern Yellow Pine (Southern Forest Products Association 2013)

\begin{tabular}{|c|c|c|c|c|c|c|}
\hline & $\begin{array}{l}\text { Tension } \\
\text { Strength }\end{array}$ & $\begin{array}{c}\text { Shear } \\
\text { Strength }\end{array}$ & $\begin{array}{c}\text { Compression } \\
\text { Strength }\end{array}$ & $\begin{array}{l}\text { Compression } \\
\text { Strength }\end{array}$ & Modulus & $\begin{array}{l}\text { Minimum } \\
\text { Modulus }\end{array}$ \\
\hline Flexural & Parallel to & Parallel to & Perpendicular & Parallel to & of & of \\
\hline Strength & Grain & Grain & to Grain & Grain & Elasticity & Elasticity \\
\hline $\mathrm{F}_{\mathrm{b}}(\mathrm{psi})$ & $\mathrm{F}_{\mathrm{t}}(\mathrm{psi})$ & $\mathrm{F}_{\mathrm{V}}(\mathrm{psi})$ & $\mathrm{F}_{\mathrm{c} \perp}$ & $\mathrm{F}_{\mathrm{c}}(\mathrm{psi})$ & $\mathrm{E}(\mathrm{psi})$ & $\mathrm{E}_{\min }(\mathrm{psi})$ \\
\hline 850 & 550 & 165 & 375 & 525 & $1,200,000$ & 440,000 \\
\hline
\end{tabular}

\subsubsection{Filler-Module Materials}

Filler-modules were cut out of 40" x 25 " x 5" parallel strand lumber (PSL) modules from Trus Joist Corporation. On testing samples that required a FRP gusset, a 1/4" wood veneer was glued onto each side of the filler-module to close the gap between the gusset and joint, as seen in Figure 3-3. The veneer fillers are important, because the gussets will not be able to bond to the joint if the $1 / 4$ " remained, and would lead to a premature failure. Modules are attached to the joint by applying Sikadur ${ }^{\circledR}-31$ Hi-Mod Gel to the contact areas and using screws as a clamping force. A select amount of test specimens had $1 / 2$ " GFRP dowels to secure the filler-module to the timber. The material properties for the PSL module and Sikadur ${ }^{\circledR}-31$ can be found in Table 3-2 and Table 3-3 respectively. 


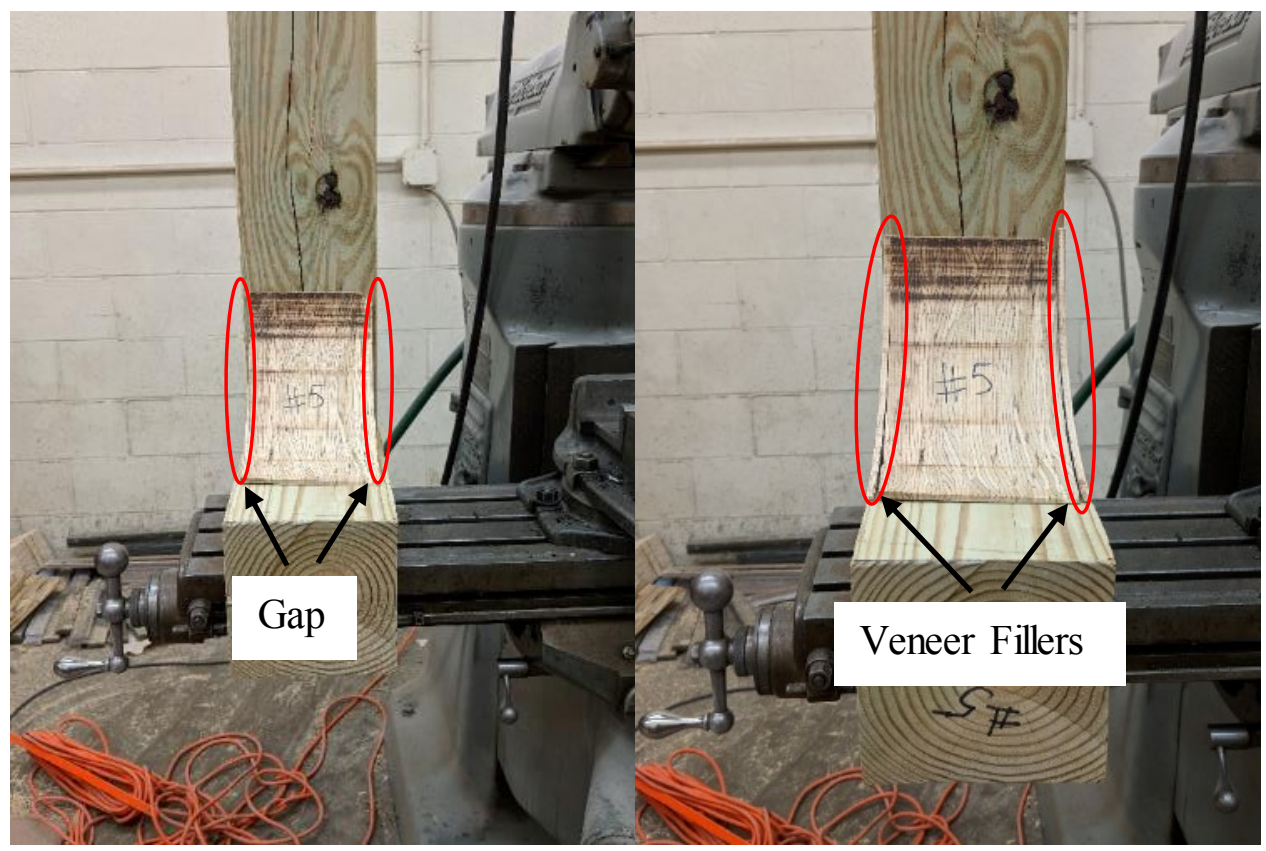

Figure 3-3: Before and After Attaching Wood Veneer to Filler-Module

Table 3-2: Design Values for PS L (Trus Joist 2018)

\begin{tabular}{|c|c|c|c|c|c|c|}
\hline & $\begin{array}{c}\text { Shear } \\
\text { Modulus }\end{array}$ & $\begin{array}{c}\text { Shear } \\
\text { Strength }\end{array}$ & $\begin{array}{l}\text { Compression } \\
\text { Strength }\end{array}$ & $\begin{array}{c}\text { Compression } \\
\text { Strength }\end{array}$ & Modulus & $\begin{array}{l}\text { Minimum } \\
\text { Modulus }\end{array}$ \\
\hline Flexural & & Parallel to & Perpendicular & Parallel to & of & of \\
\hline Strength & Elasticity & Grain & to Grain & Grain & Elasticity & Elasticity \\
\hline $\mathrm{F}_{\mathrm{b}}(\mathrm{psi})$ & $G(p s i)$ & $\mathrm{F}_{\mathrm{v}}(\mathrm{psi})$ & $\mathrm{F}_{\mathrm{c}} \perp$ & $\mathrm{F}_{\mathrm{c}}(\mathrm{psi})$ & $\mathrm{E}(\mathrm{psi})$ & $\mathrm{E}_{\min }(\mathrm{psi})$ \\
\hline 2,900 & 137,500 & 290 & 625 & 2,900 & $2,200,000$ & $1,118,190$ \\
\hline
\end{tabular}

Table 3-3: Design Values for Sikadur ${ }^{\circledR-31}$ (Resin) (Sika 2018)

\begin{tabular}{|c|c|c|c|c|c|c|}
\hline $\begin{array}{c}\text { Modulus of } \\
\text { Elasticity in }\end{array}$ & $\begin{array}{c}\text { Modulus } \\
\text { of }\end{array}$ & & & & \\
Compression & Stexural & Elasticity & Tensile & & Shear & Pull-off \\
$\mathrm{E}_{\mathrm{c}}(\mathrm{psi})$ & $\mathrm{F}_{\mathrm{b}}(\mathrm{psi})$ & $\mathrm{E}_{\mathrm{f}}(\mathrm{psi})$ & $\mathrm{F}_{\mathrm{u}}(\mathrm{psi})$ & at Break & $\mathrm{F}_{\mathrm{v}}(\mathrm{psi})$ & $\begin{array}{c}\text { Strength } \\
(\mathrm{psi})\end{array}$ \\
\hline 795,000 & 6,100 & $1,670,000$ & 3,300 & $0.9 \%$ & 4,600 & 420 \\
\hline
\end{tabular}




\subsubsection{FRP Gusset Materials}

Three different fabrics were used to manufacture gussets. The first set of gussets were made using SikaWrap ${ }^{\circledR}$ Hex-106 G bi-directional fabric while the second set were made using SikaWrap ${ }^{\circledR}$ Pre-saturated 430G. The final set of gussets were made of SikaWrap ${ }^{\circledR}$ Hex-100 G. The fabrics were all wet with Sikadur ${ }^{\circledR}-300$ epoxy resin. Before curing started, weight was applied on the fabric to ensure that the gusset would be flat while squeezing out extra resin. Gussets were bonded to the test specimens using Sikadur $®-330$ and Sikadur ${ }^{\circledR}-300$. \#8 x 1" long self-tapping wood screws were used to apply a clamping force onto the gusset. Screws were patterned out such that the gussets were in full contact with the joint. Material properties for the fabrics and resins can be found in Table 3-4 and Table 3-5, respectively.

Table 3-4: Design Values for Glass Fabric (Sika 2018) (Sika n.d.) (Sika 2018)

\begin{tabular}{|c|c|c|c|c|}
\hline Fabric Name & $\begin{array}{c}\text { Area } \\
\text { Density } \\
\left(\mathrm{oz} \mathrm{yd}^{2}\right)\end{array}$ & $\begin{array}{l}\text { Tensile } \\
\text { Strength } \\
\mathrm{F}_{\mathrm{u}}(\mathrm{psi})\end{array}$ & $\begin{array}{l}\text { Modulus of } \\
\text { Elasticity } \\
\text { E (psi) }\end{array}$ & $\begin{array}{c}\text { Elongation at } \\
\text { Break }\end{array}$ \\
\hline SikaWrap ${ }^{\circledR}$ Hex-106 G & 9.6 & 65,600 & $4,240,000$ & $1.45 \%$ \\
\hline $\begin{array}{c}\text { SikaWrap }{ }^{\circledR} \text { Pre-saturated } \\
430 \mathrm{G}\end{array}$ & 13 & 51,328 & $4,357,548$ & $1.4 \%$ \\
\hline SikaWrap ${ }^{\circledR}$ Hex-100 G & 27 & 78,400 & $3,970,000$ & N/A \\
\hline
\end{tabular}

Table 3-5: Design Values for Sikadur ${ }^{\circledR}$ Resins (Sika 2018) (S ika 2018)

\begin{tabular}{|c|c|c|c|c|c|}
\hline Resin Name & $\begin{array}{l}\text { Flexure } \\
\text { Strength } \\
\mathrm{F}_{\mathrm{b}}(\mathrm{psi})\end{array}$ & $\begin{array}{l}\text { Modulus of } \\
\text { Elasticity in } \\
\text { Flexure } \\
\mathrm{E}_{\mathrm{f}}(\mathrm{psi})\end{array}$ & $\begin{array}{c}\text { Tensile } \\
\text { Strength } \\
\mathrm{F}_{\mathrm{u}}(\mathrm{psi})\end{array}$ & $\begin{array}{l}\text { Modulus of } \\
\text { Elasticity } \\
\text { E (psi) }\end{array}$ & $\begin{array}{c}\text { Elongation at } \\
\text { Break }\end{array}$ \\
\hline Sikadur®-300 & 11,500 & 500,000 & 8,000 & 250,000 & $3 \%$ \\
\hline Sikadur ${ }^{\circledR}-330$ & 8,800 & 506,00 & 4,900 & N/A & $1.2 \%$ \\
\hline
\end{tabular}




\subsection{Filler-Module/Gusset Retrofit Schemes}

Simplicity is key when retrofitting existing buildings. Real world applications were taken into consideration when deciding what schemes would be tested.

\subsubsection{Filler-Module Schemes}

Filler-modules are designed based on the beam depth at the joint which is being reinforced for improved energy absorption and enhanced load capacity. The length of a beam that is most susceptible to shear failure is equal to the depth of the beam away from the face of the column. Since the nominal depth of the timber beam is six inches, the minimum filler-module leg length should be equal to that depth. Seen in Figure 3-4, the filler-module dimensions for both the curve and wedge are provided. Note for the curve module that there is a $1 / 8^{\text {th }}$ inch lip, which is provided for added stiffness to the tip. Fiber orientation of the PSL was considered for this study, i.e., if the module would be rotated to a sub-optimal direction the module will split along the glue lines which is the weak plane of failure. It was determined that placing the fibers on the $45^{\circ}$ would be the optimal orientation. Figure 3-5 shows an engineered wood wedge module cut to size and rotated to the correct angle. For specimens that included dowels, one $5 / 8$ " hole is drilled in the center of each face of the filler-module, as seen in Figure 3-6. Note that the holes do overlap on the long side of the module, but the reinforcing dowels are cut $1 / 4$ " shorter than the entire length of the hole, to ensure that once the first reinforcing dowel is installed it would not interfere with the installation of the second dowel. 

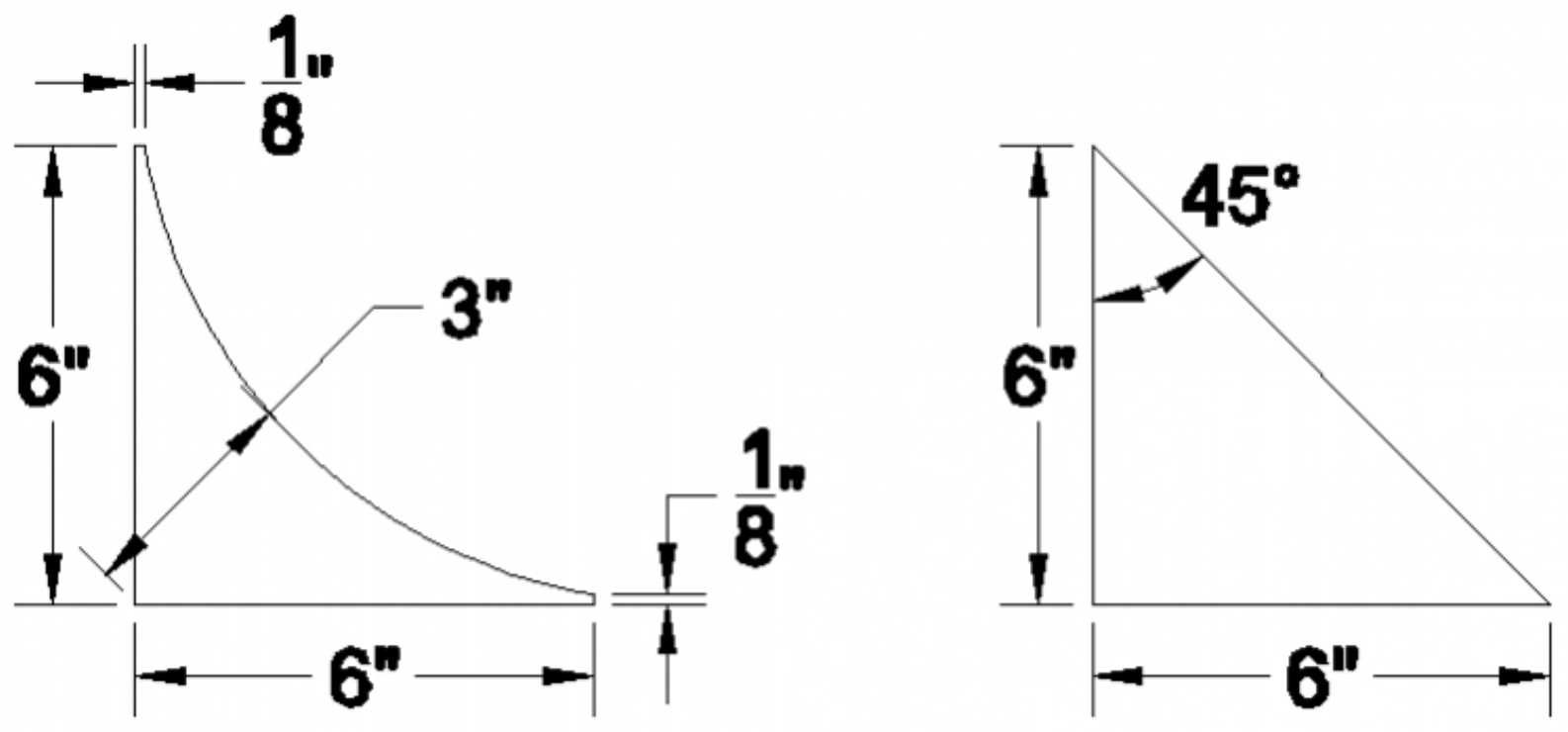

Figure 3-4: Filler-Module Dimensions

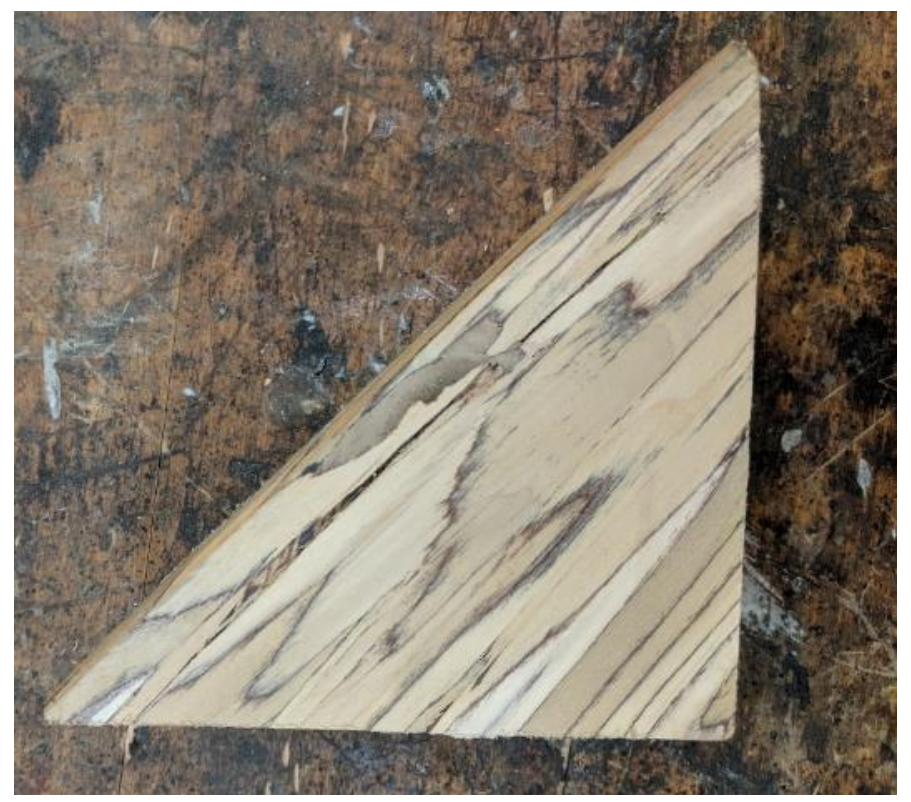

Figure 3-5: Wedge Shaped Filler-Module $\left(45^{\circ}\right)$ - Engineered Wood 


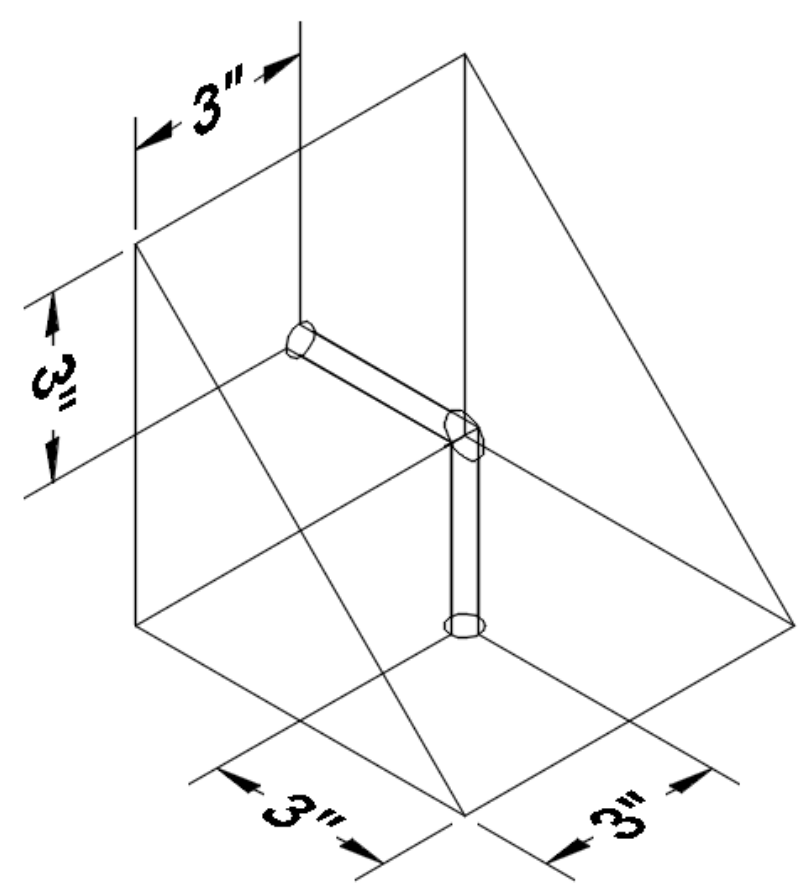

Figure 3-6: FRP Dowel Layout on Filler-Module

\subsubsection{FRP Gusset Schemes}

The gussets were made in three stages, making improvements after every stage. The first stage consisted of two layers of SikaWrap ${ }^{\circledR}$ Hex-106 G placed in the $\pm 45^{\circ}$ orientation rather than the $0 \% 90^{\circ}$. The second set of gussets were made using SikaWrap® Pre-saturated $430 \mathrm{G}$. Needing fibers in more directions, the second set consisted of a layer in the $0^{\circ} / 90^{\circ} / 45^{\circ} /-45^{\circ}$, making a quadriaxial lamina. The third set of gussets had the same fiber architecture as gusset set 2, but differed due to the use of SikaWrap ${ }^{\circledR}$ Hex-100 G fabric. Figure 3-7 shows an enlarged layout of the fiber architecture for all the gussets. Gussets were cut to 3" past the tip of the joint area. Figure 3-8 shows the dimensions for all gusset shapes. 


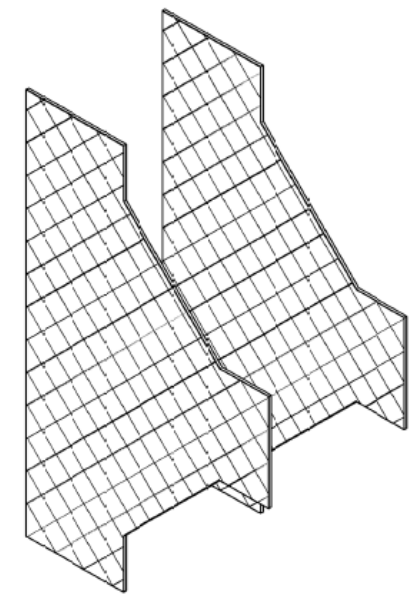

Gusset Set 1

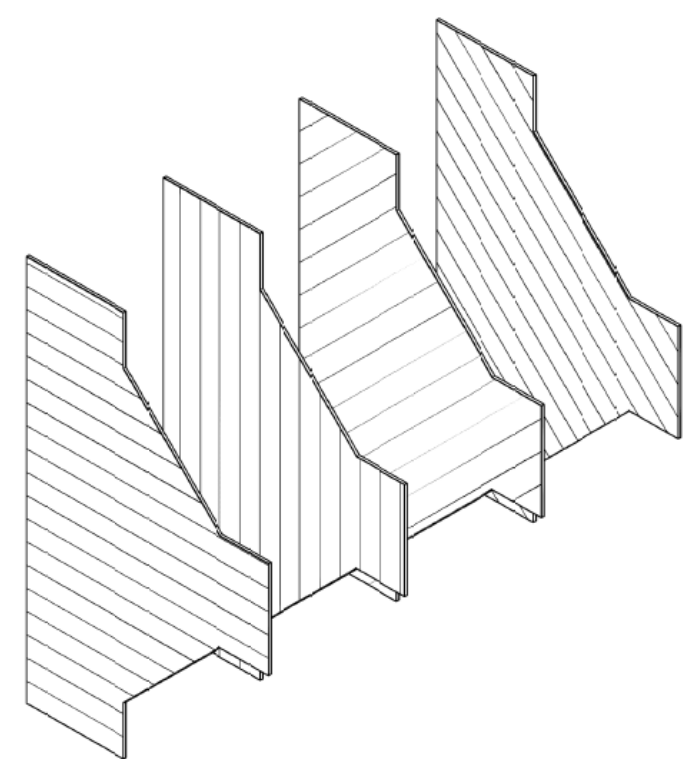

Gusset Set 2 \& 3

Figure 3-7: FRP Gusset Fiber Orientation
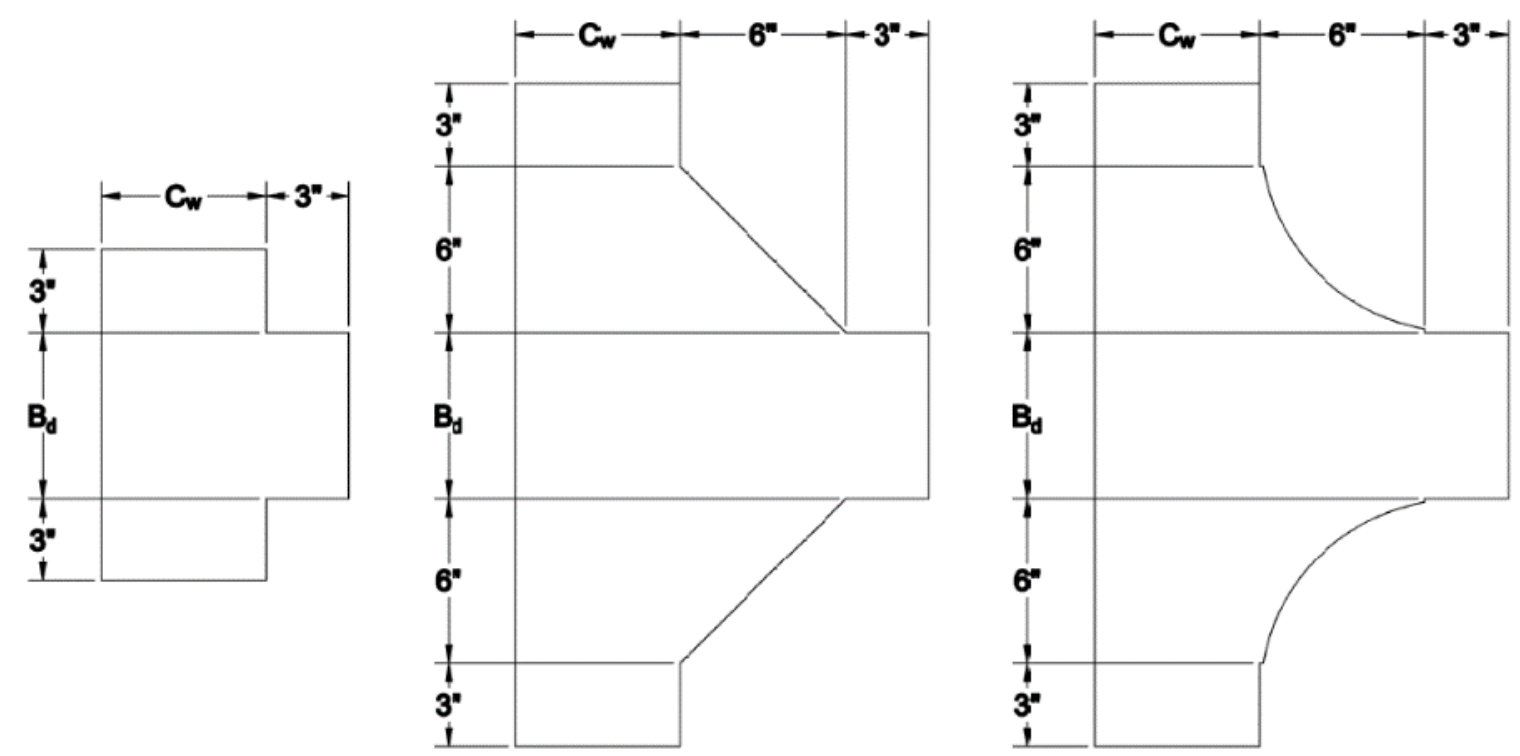

Figure 3-8: Dimensions of all Gusset Sizes

Additional layers of FRP were added depending on the testing scheme. Anchors are an important addition onto this system, because they provide confinement of the gusset to structural members (columns and beams) while also providing extra protection from gusset debond. Every 
specimen that had a gusset bonded to it, also had a beam anchor attached, as seen in Figure 3-9. Beam anchors are a 3" strip of FRP that wrap around the beam twice at the tip of the fillermodule overlapping the beam element and the composite. Figure 3-10 shows the layout when filler-module anchors are added. The filler-module anchor is a piece of FRP cut to width of the arc length/hypotenuse of the module and wrapped around the back. There is one layer of fabric on both the top and bottom modules. Two layers of longitudinal wrap can be applied on joints starting at an end of the column working its way over the filler-module and ending on the beam, as seen in Figure 3-11. Two layers of FRP are used as longitudinal wraps and are applied to both the top and bottom faces of the beam. When a longitudinal wrap is bonded onto a specimen, column anchors are also attached to the top and bottom 3" of the column. Column anchors are similar to beam anchors, because they both wrap around their member twice. The hand layup of FRP glass fabric layers are made with the same materials as the gussets, and orientated in the $0^{\circ}$ direction for the highest confinement effect.
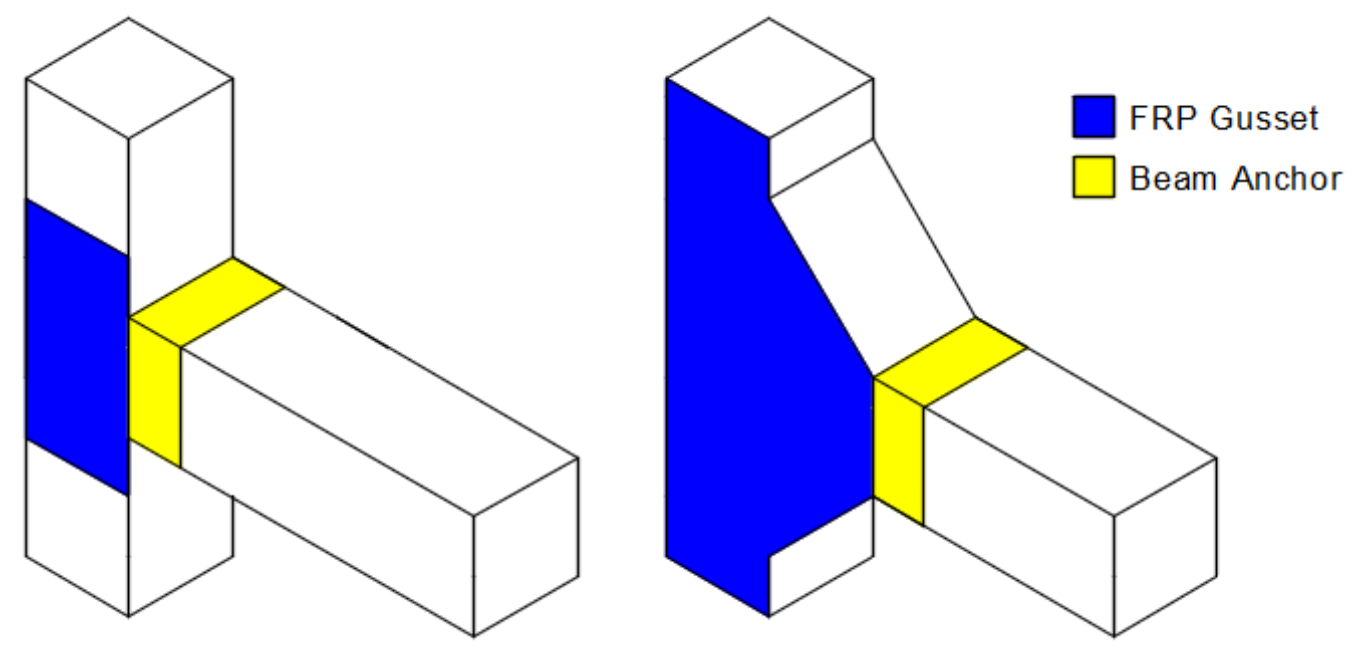

Figure 3-9: Beam Anchor Setup 


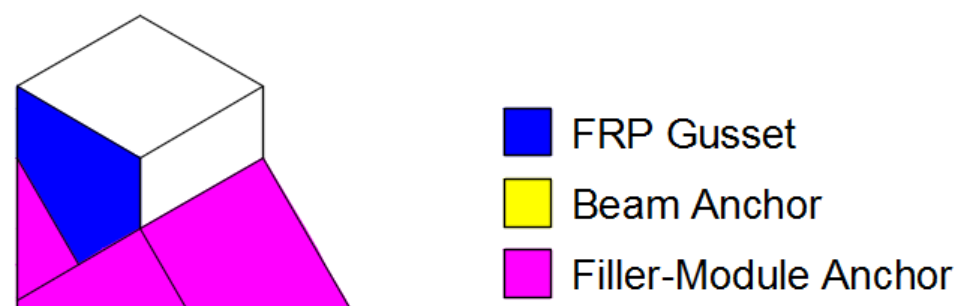

Figure 3-10: Filler-Module Wrap S etup

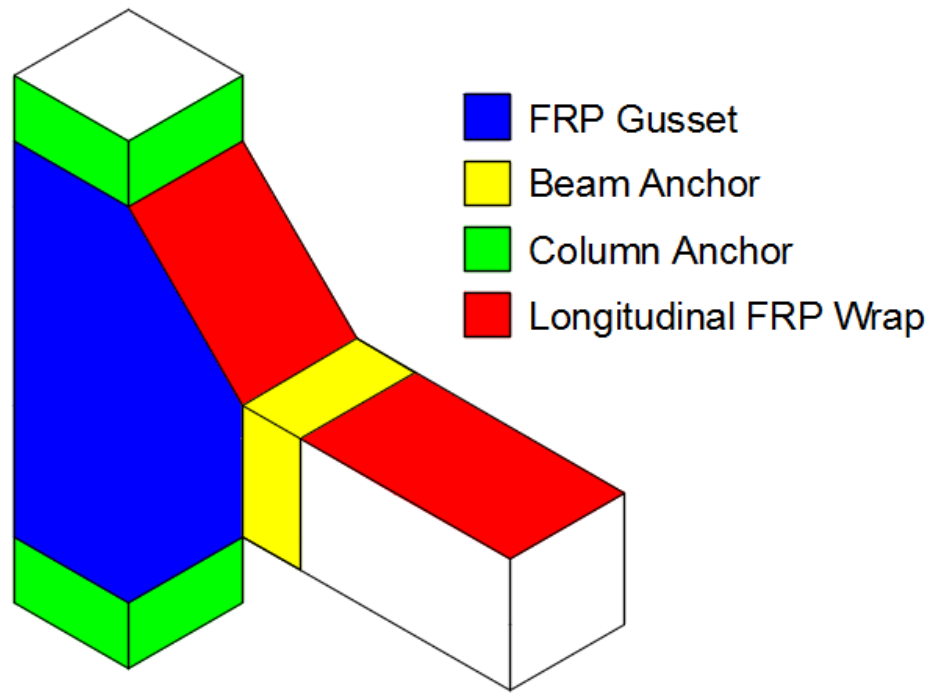

Figure 3-11: Longitudinal FRP Wrap Setup

\subsection{Testing Specimens}

The testing specimens will have varying retrofitting schemes. Table 3-6 outlines the 10 testing samples, and why they are being tested. 
Table 3-6: Testing S pecimen Breakdown

\begin{tabular}{|c|c|c|c|}
\hline Specimen Number & Filler-Module (Shape) & FRP Gusset (Fabric) & Reason for Testing \\
\hline 1 & No & No & Control \\
\hline 2 & No & No & Control \\
\hline 3 & Yes (Curve) & No & Filler-Module Effect \\
\hline 4 & No & $\begin{array}{c}\text { Yes (SikaWrap }{ }^{\circledR} \\
\text { Hex-106 G) }\end{array}$ & Gusset Effect \\
\hline 5 & Yes (Curve) & $\begin{array}{c}\text { Yes (SikaWrap }{ }^{\circledR} \\
\text { Hex-106 G) }\end{array}$ & $\begin{array}{l}\text { Filler-Module and } \\
\text { Gusset Effect }\end{array}$ \\
\hline 6 & Yes (Curve) & $\begin{array}{c}\text { Yes (SikaWrap }{ }^{\circledR} \\
\text { Hex-106 G) }\end{array}$ & $\begin{array}{l}\text { Filler-Module, Gusset, } \\
\text { and Filler-Module } \\
\text { Anchor Effect }\end{array}$ \\
\hline 7 & Yes (Wedge) & $\begin{array}{c}\text { Yes (SikaWrap }{ }^{\circledR} \\
\text { Pre-saturated } 430 \mathrm{G})\end{array}$ & $\begin{array}{c}\text { Filler-Module and } \\
\text { Improved Gusset } \\
\text { Effect }\end{array}$ \\
\hline 8 & No & $\begin{array}{c}\text { Yes (SikaWrap }{ }^{\circledR} \\
\text { Hex-100 G) }\end{array}$ & $\begin{array}{l}\text { Improved Gusset } \\
\text { Effect }\end{array}$ \\
\hline 9 & Yes (Wedge) & $\begin{array}{l}\text { Yes (SikaWrap }{ }^{\circledR} \\
\text { Hex-100 G) }\end{array}$ & $\begin{array}{l}\text { Filler-Module, } \\
\text { Improved, and } \\
\text { Longitudinal Wrap } \\
\text { Gusset Effect }\end{array}$ \\
\hline 10 & Yes (Wedge) & $\begin{array}{l}\text { Yes (SikaWrap }{ }^{\circledR} \\
\text { Hex-100 G) }\end{array}$ & $\begin{array}{c}\text { Filler-Module, } \\
\text { Improved, } \\
\text { Longitudinal Wrap } \\
\text { Gusset, and Filler- } \\
\text { Module Dowels Effect }\end{array}$ \\
\hline
\end{tabular}

\subsection{Test Setup}

The joint specimens were placed into a steel testing frame that is attached to a strong floor of WVU's Major Units Lab, as seen in Figure 3-12. Two hydraulic hand pump actuators applied the load onto the beam and column. A forty and ten kip load cells were placed on the beam and column respectively under their actuator. The beam load was applied 18 " from the face of the column, or 2" from the end of the beam. 18 " was selected as the loading distance, because that is about the distance to an inflection point on an $8^{\prime}$ beam. 

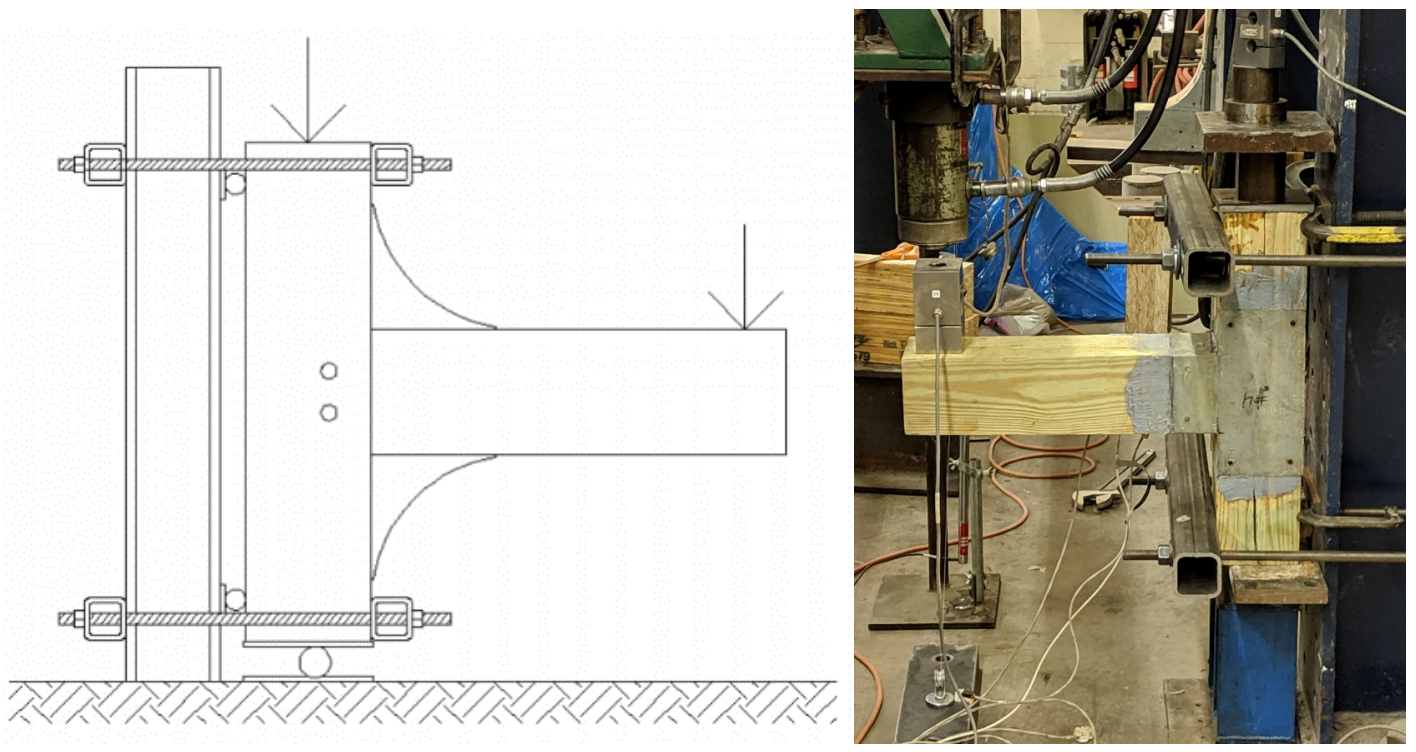

Figure 3-12: Beam-Column Joint Testing Setup

\subsection{Instrumentation}

A combination of strain gages and linear variable differential transformers (LVDT) were used throughout this study. Strain gages, obtained from Micro-Measurements, were applied on the FRP gusset and on the filler-module. Three $1 / 4$ " strain gages were applied on to the FRP gusset in the $0^{\circ} / 45^{\circ} / 90^{\circ}$ directions (rosette setup) on the tip of the joint area, as seen in Figure $3-13$, to obtain the principal strains at that location. The tip of the joint area is an important location to study, because of its high stress concentration from the applied loads. For test specimens that had filler-modules, a 1" strain gage was put on the center of each module as seen in Figure 3-14. For specimens that had an FRP layer on top of the filler-module a quarter inch gage was used, while a one inch long gage was used when it was applied directly onto the PSL surface. The strain gage on the filler-module will help indicate when the filler-module debonds and how it is behaving before debonding occurs. A 4" LVDT was placed directly under the beam 
at or near the vertical load application to measure vertical deflections. For joints that had no FRP gussets attached, two 1" spring loaded LVDTs were attached onto the timber surface, as shown in Figure 3-15.
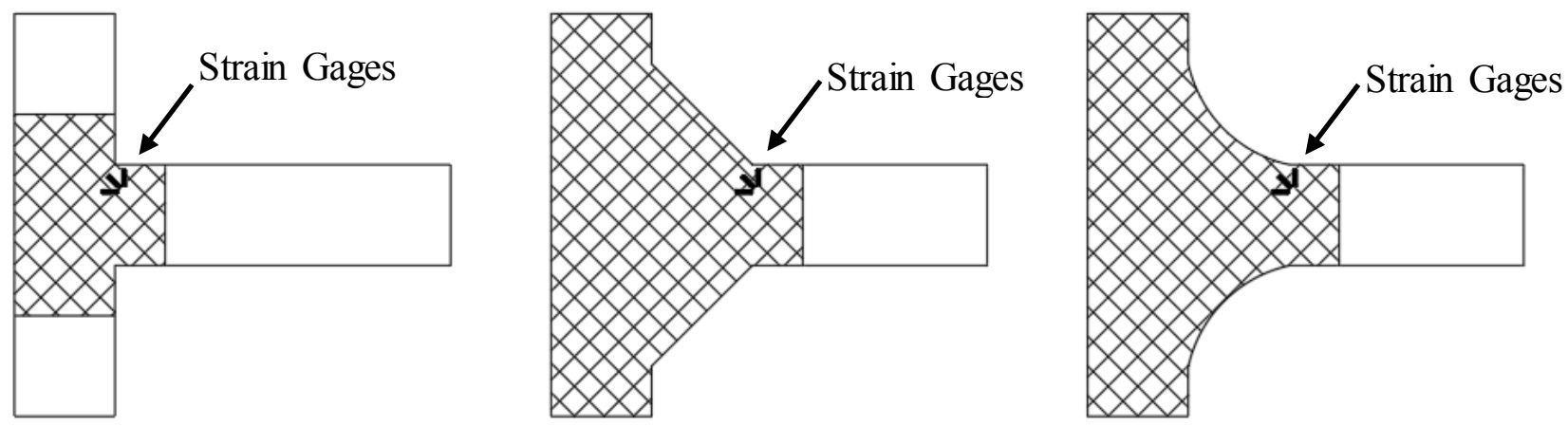

Figure 3-13: Strain Gage Location and Orientation on the FRP Gusset
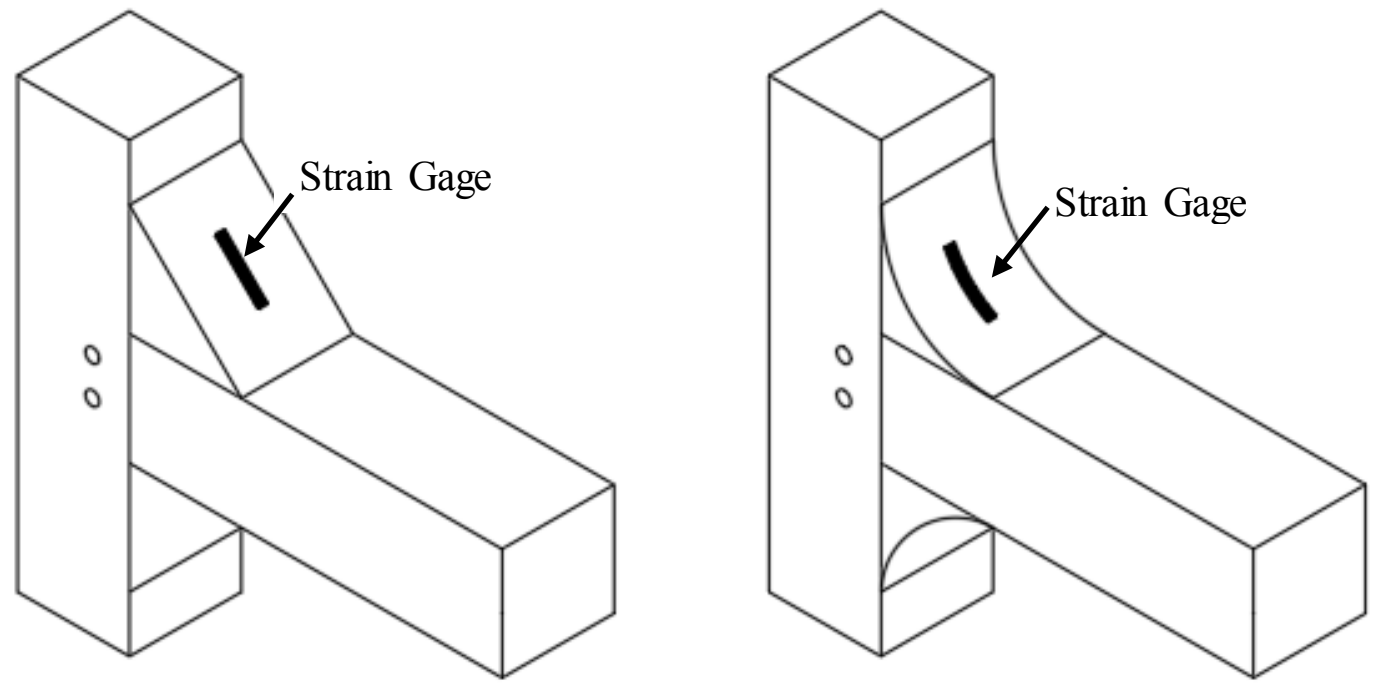

Figure 3-14: Strain Gage Location on the Filler-Modules 

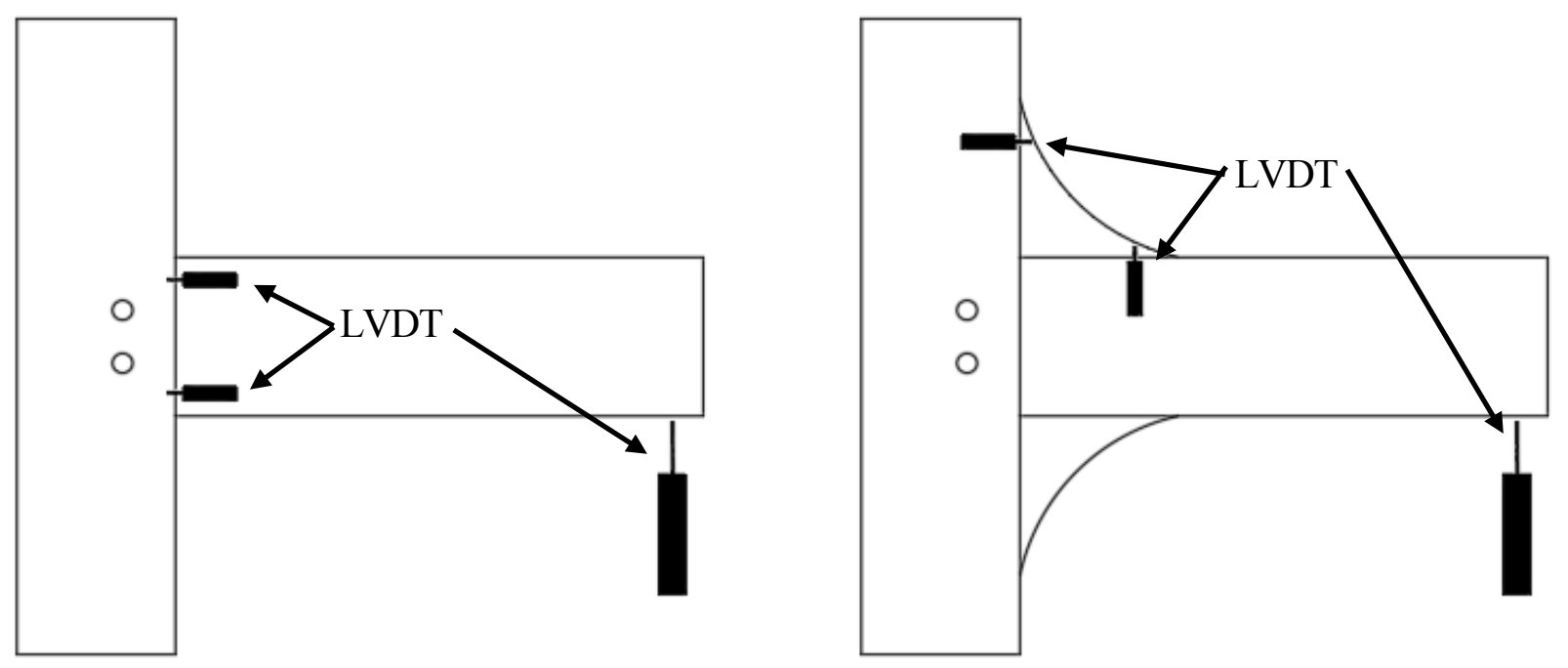

Figure 3-15: LVDT Locations

\subsection{Loading}

A two-step loading process was used for the duration of this study. The first step consisted of applying a load to the column. The column load is important, because it simulates the realworld action of load transfer from other stories. Seven thousand pounds of load was applied onto the column to simulate the transfer of load through a building system. The column load was found by taking $\sim 10 \%$ of the failure load of SYP. The second loading step was the beam load. Loading is completed when the joint fails. Load rate was not at a set speed, because lading was applied thru hand pump and it is difficult to achieve a constant rate of loading. 


\section{CHAPTER 4 TEST RESULTS AND EVALUATION}

\subsection{Introduction}

This chapter presents the test data in terms of load versus strains or deflections, and discussion of data in terms of strength, ductility, and energy absorption. Since this is a preliminary study, a detailed evaluation of failure modes will be the emphasis of the limited testing conducted as a part of this study to help future research in establishing more accurate design and ultimate joint failure values resisting beam and column loads. However, preliminary analyses is carried out to find theoretical failure load values. Appendix A contains load vs strain and load vs deflection plots for each test specimen.

\subsection{Test Specimens}

A total of ten specimens have been tested within this study. Two joints were un-retrofitted (base line) to compile control results. The remaining eight joints have varying configurations of filler-module and FRP gusset schemes. The dimensions and layout of retrofitting schemes are detailed in CHAPTER 3. A detailed breakdown of test specimens is presented in Table 4-1. 
Table 4-1: Testing S pecimen Breakdown

\begin{tabular}{|c|c|c|c|}
\hline Specimen Number & Filler-Module (Shape) & FRP Gusset (Fabric) & Additional Information \\
\hline 1 & No & No & N/A \\
\hline 2 & No & No & N/A \\
\hline 3 & Yes (Curve) & No & N/A \\
\hline 4 & No & $\begin{array}{l}\text { Yes (SikaWrap }{ }^{\circledR} \\
\text { Hex-106 G) }\end{array}$ & $\begin{array}{c}\text { Beam anchor using } \\
\text { SikaWrap® Hex-106 } \\
\text { G }\end{array}$ \\
\hline 5 & Yes (Curve) & $\begin{array}{c}\text { Yes (SikaWrap }{ }^{\circledR} \\
\text { Hex-106 G) }\end{array}$ & $\begin{array}{c}\text { Beam anchor using } \\
\text { SikaWrap® Hex-106 } \\
\text { G }\end{array}$ \\
\hline 6 & Yes (Curve) & $\begin{array}{l}\text { Yes (SikaWrap® } \\
\text { Hex-106 G) }\end{array}$ & $\begin{array}{c}\text { Beam and filler- } \\
\text { module anchors using } \\
\text { SikaWrap }{ }^{\circledR} \text { Hex-106 } \\
\text { G }\end{array}$ \\
\hline 7 & Yes (Wedge) & $\begin{array}{c}\text { Yes }\left(\text { SikaWrap }{ }^{\circledR}\right. \\
\text { Pre-saturated } 430 G)\end{array}$ & $\begin{array}{c}\text { Beam anchor using } \\
\text { SikaWrap® Hex-106 } \\
\text { G }\end{array}$ \\
\hline 8 & No & $\begin{array}{l}\text { Yes (SikaWrap }{ }^{\circledR} \\
\text { Hex-100 G) }\end{array}$ & $\begin{array}{c}\text { Beam anchor using } \\
\text { SikaWrap® Hex-100 } \\
G\end{array}$ \\
\hline 9 & Yes (Wedge) & $\begin{array}{l}\text { Yes (SikaWrap }{ }^{\circledR} \\
\text { Hex-100 G) }\end{array}$ & $\begin{array}{l}\text { Longitudinal wrap, } \\
\text { beam anchor, and } \\
\text { column anchors using } \\
\text { SikaWrap }{ }^{\circledR} \text { Hex-100 } \\
\text { G }\end{array}$ \\
\hline 10 & Yes (Wedge) & $\begin{array}{l}\text { Yes (SikaWrap }{ }^{\circledR} \\
\text { Hex-100 G) }\end{array}$ & $\begin{array}{l}\text { Longitudinal wrap, } \\
\text { beam anchor, and } \\
\text { column anchors using } \\
\text { SikaWrap }{ }^{\circledR} \text { Hex-100 } \\
\text { G. GFRP dowels used }\end{array}$ \\
\hline
\end{tabular}

\subsection{Results}

The results from the loading process, outlined in Section 3.6, are presented in Table 4-2. The loading was stopped once the joint failed. Failure was defined as an increase in deflection while gradual decrease or plateau in the applied beam load. Comparison plots for load vs deflection, joint strains (from the rosette strain gages that were described in CHAPTER 3), and filler-module strains can be seen below in Figure 4-1 through Figure 4-7. Principal strain was 
calculated using Equation 4-1 (Garmoll n.d.) and the collected data from the rosette strain gages. Principal strain was found to study the combined effect of loading. For the first specimen, the LVDT (deflection monitor) malfunctioned and therefore the deflection readings have been left out of this report.

Table 4-2: Joint Test Results - Failure Load vs Deflection

\begin{tabular}{|c|c|c|}
\hline Specimen Number & Max Beam Load (lbs) & Beam Deflection at Max Load (in) \\
\hline 1 & $2,935.18$ & N/A \\
\hline 2 & $2,820.01$ & 0.29 \\
\hline 3 & $7,420.20$ & 0.58 \\
\hline 4 & $2,796.97$ & 0.36 \\
\hline 5 & $8,094.77$ & 0.48 \\
\hline 6 & $7,663.71$ & 0.51 \\
\hline 7 & $11,691.35$ & 0.69 \\
\hline 8 & $4,708.79$ & 0.64 \\
\hline 9 & $15,166.15$ & 0.96 \\
\hline 10 & $15,932.87$ & 0.96 \\
\hline
\end{tabular}

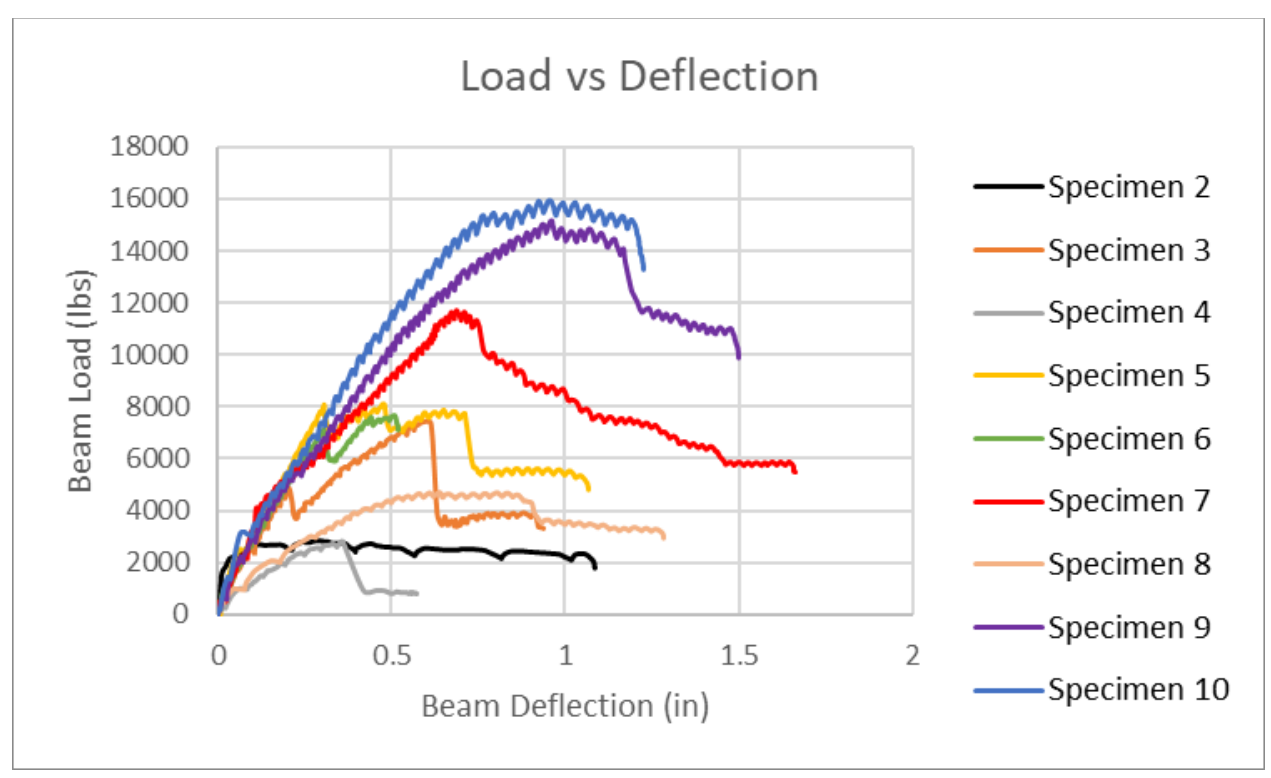

Figure 4-1: Load vs Beam Deflection under Beam Loading 


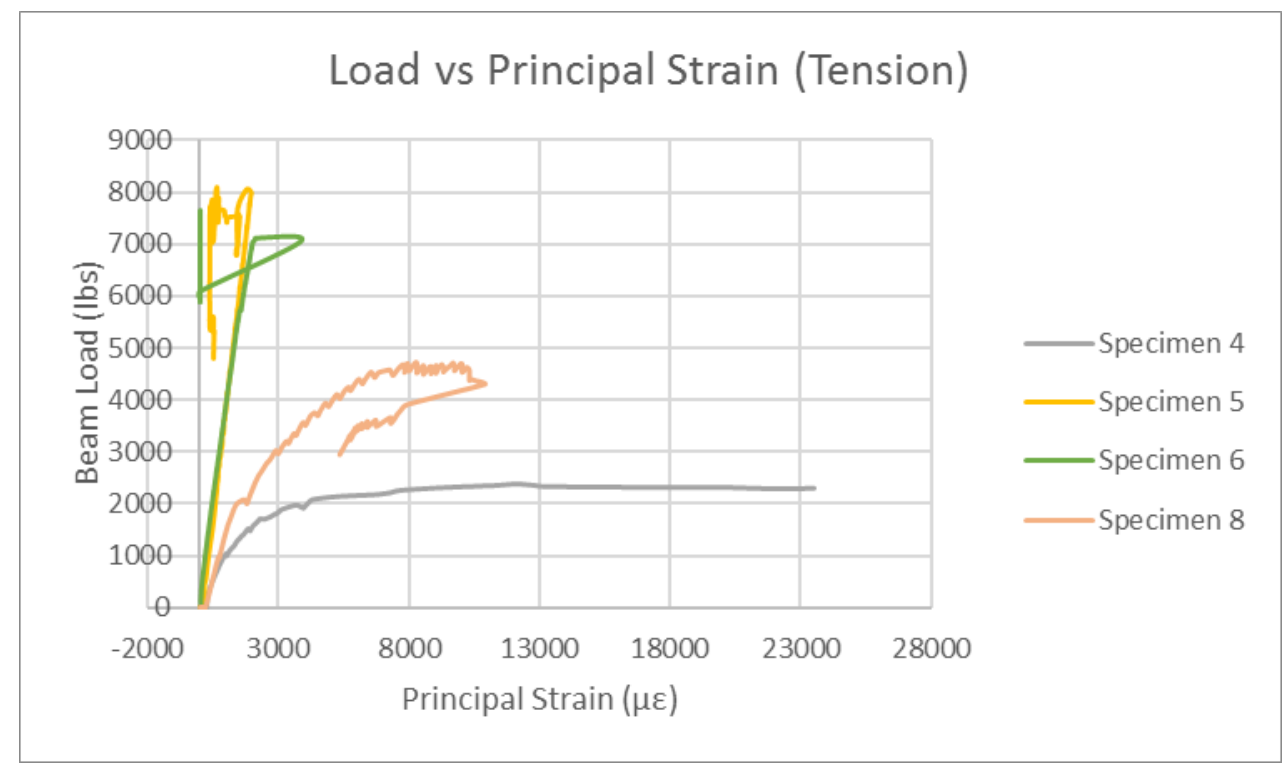

Figure 4-2: Load vs Principal $S$ train (Tension) for $\mathrm{S}$ pecimens 4, 5, 6, and 8

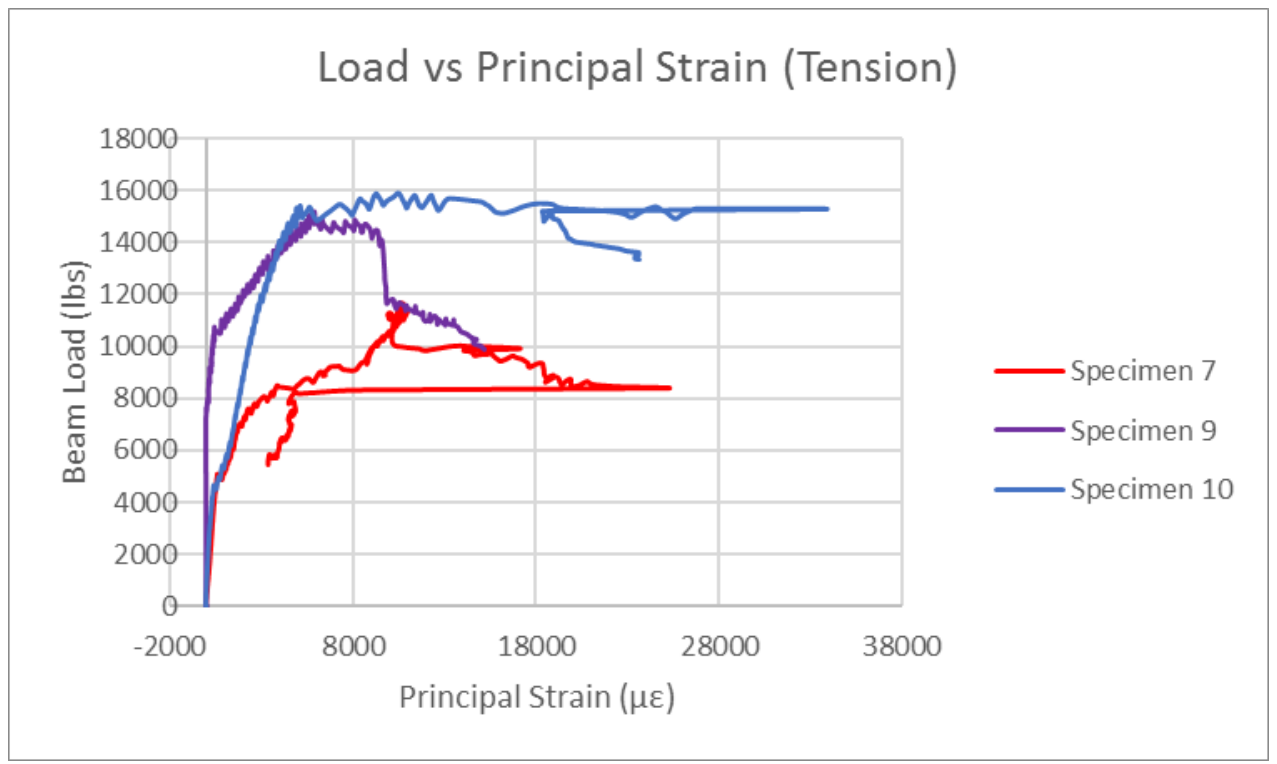

Figure 4-3: Load vs Principal Strain (Tension) for $S$ pecimens 7, 9, and 10 


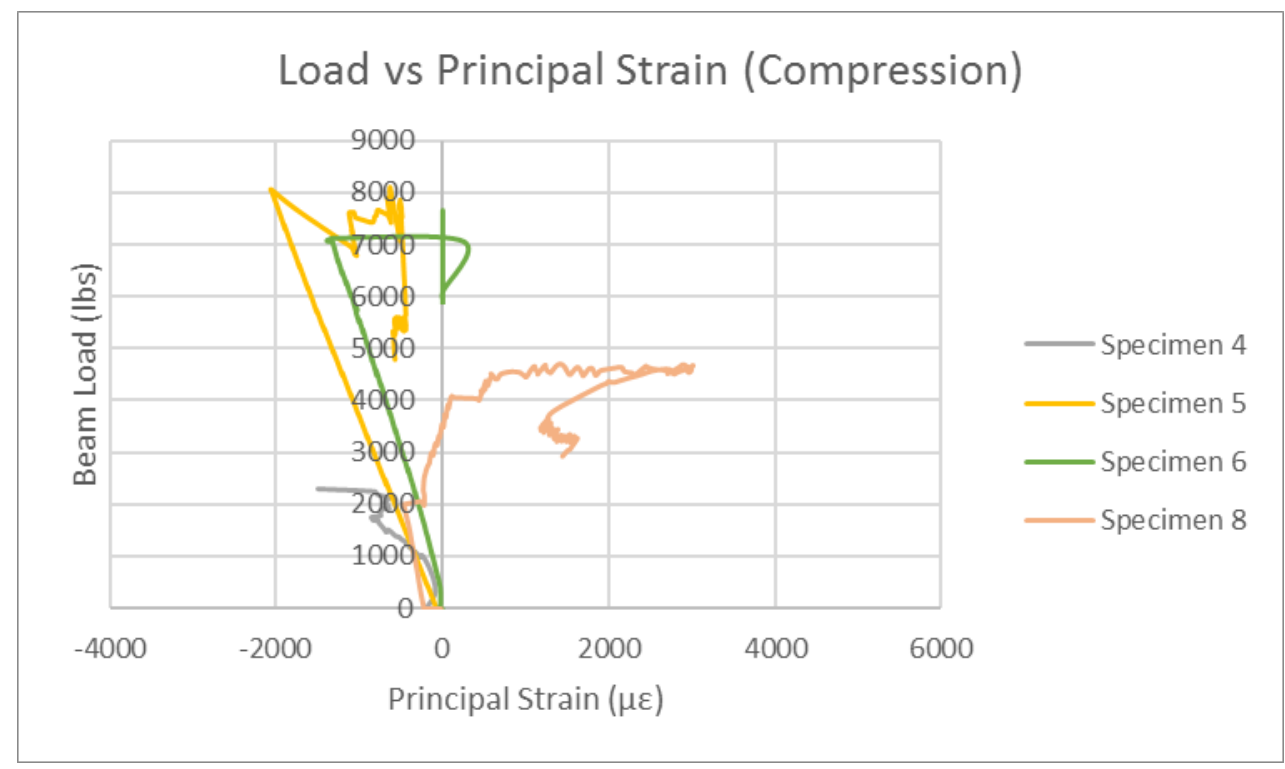

Figure 4-4: Load vs Principal Strain (Compression) for Specimens 4, 5, 6, and 8

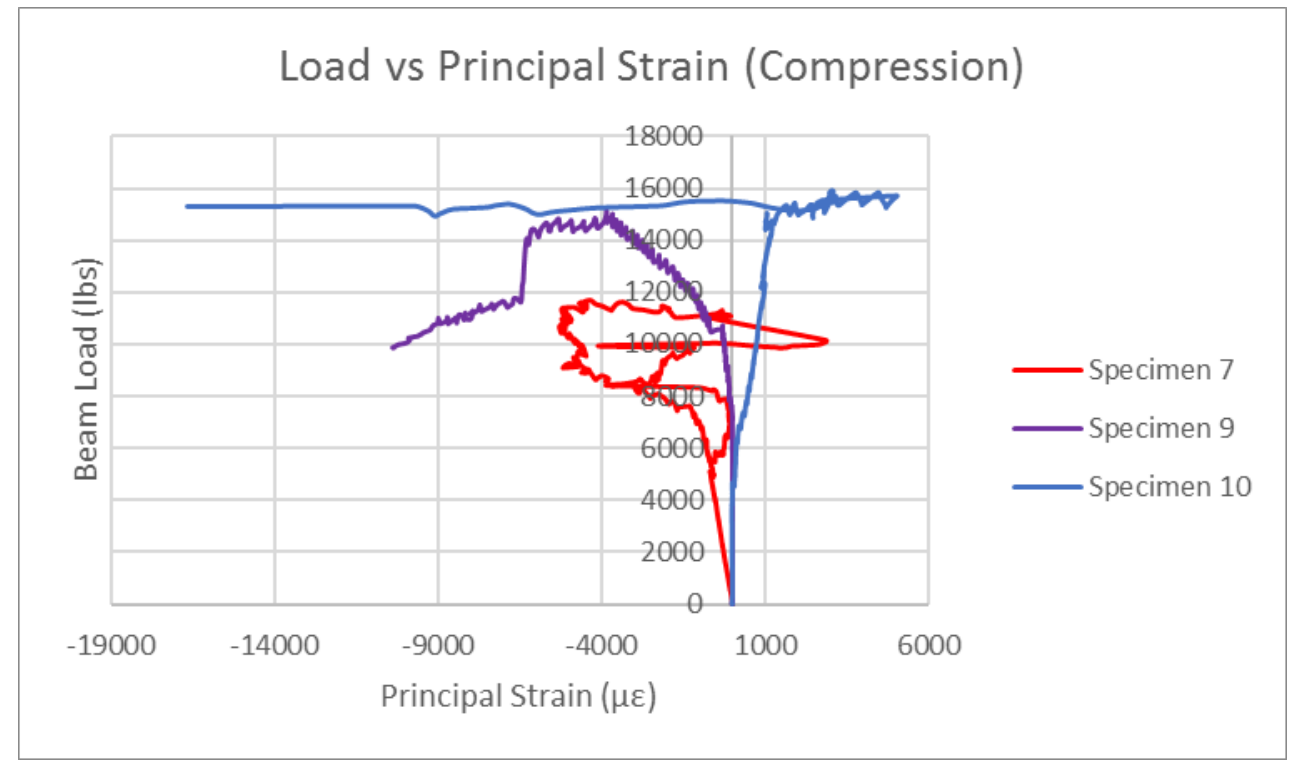

Figure 4-5: Load vs Principal Strain (Compression) for Specimens 7, 9, and 10

$\varepsilon_{1,2}=\frac{\varepsilon_{0}+\varepsilon_{90}}{2} \pm \frac{1}{\sqrt{2}} \sqrt{\left(\varepsilon_{0}-\varepsilon_{45}\right)^{2}+\left(\varepsilon_{45}-\varepsilon_{90}\right)^{2}}$

Equation 4-1 (Garmoll n.d.) 


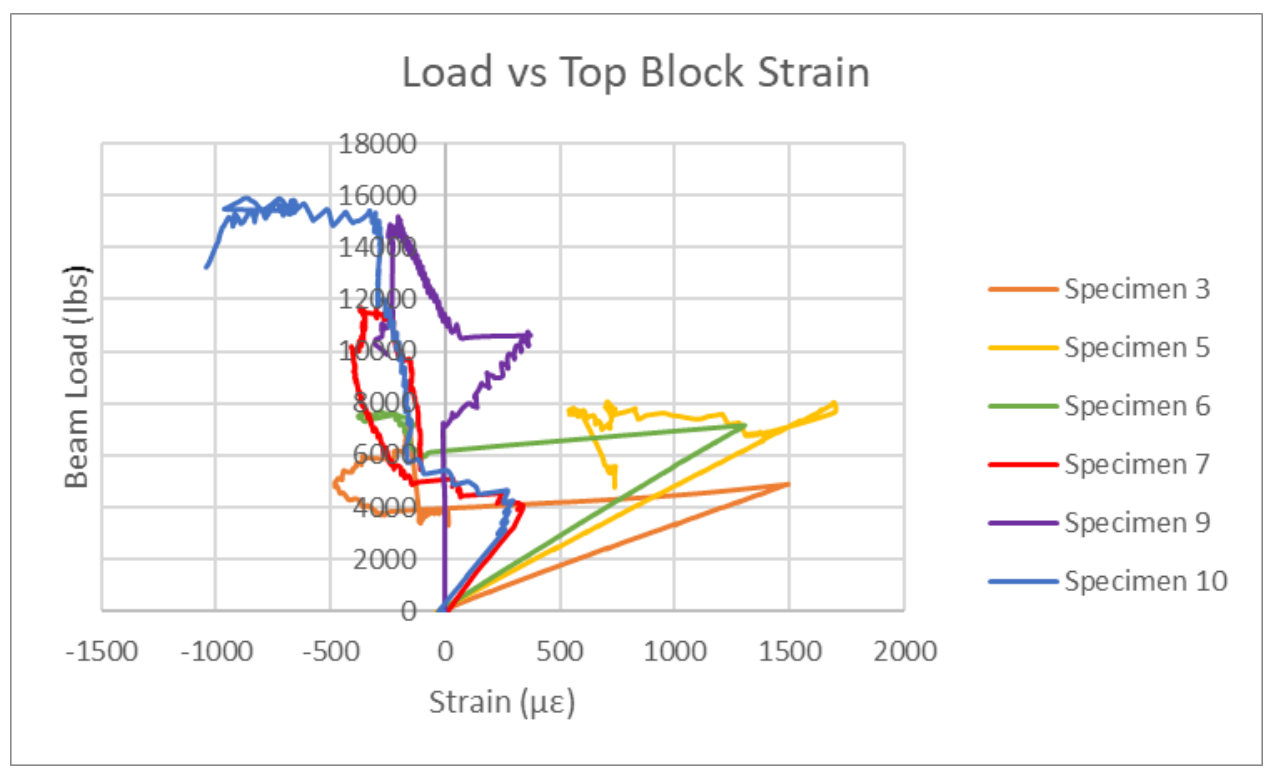

Figure 4-6: Load vs Top Filler-Module Strain

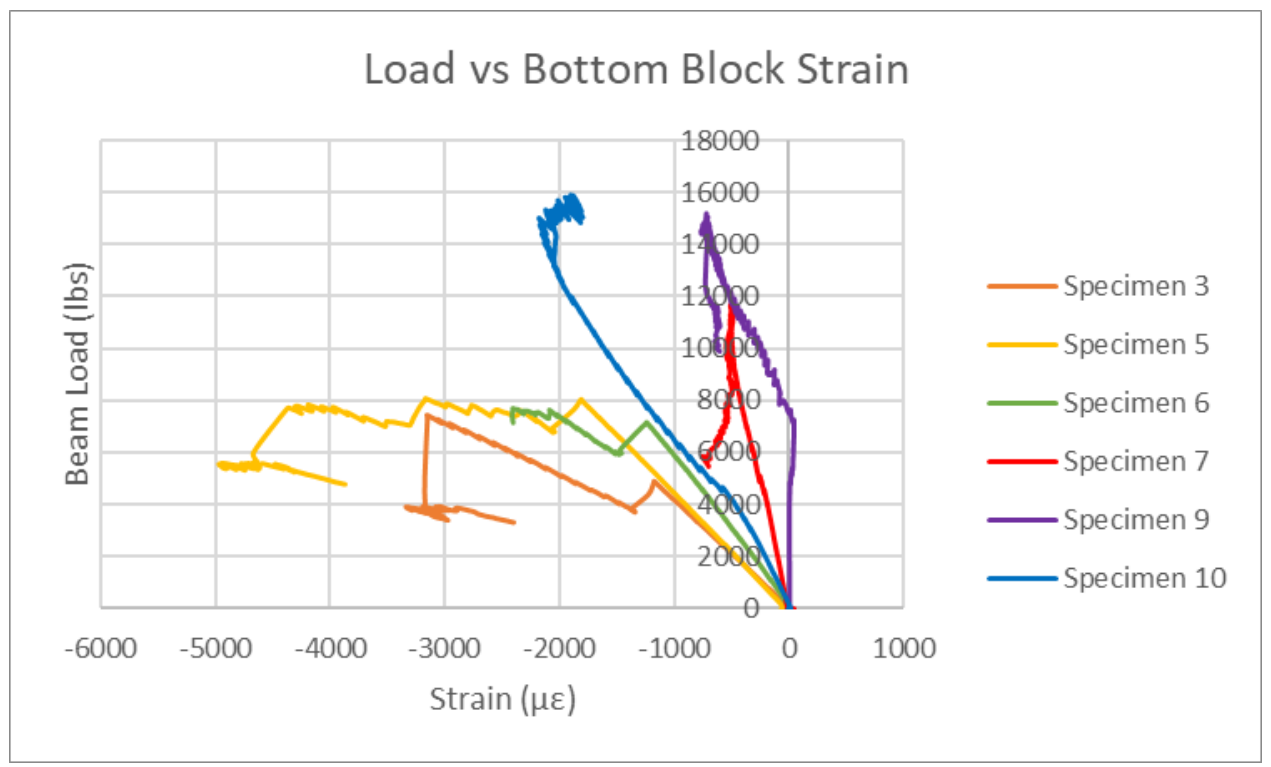

Figure 4-7: Load vs Bottom Filler-Module S train 


\subsection{Discussions}

This section discusses the joint behavior based on strength, ductility, and energy absorption. A comparison to the control specimens will show improvements made by the retrofitting technique. Strength, ductility, and energy absorption are all important factors when designing and retrofitting a structure, and therefore the proposed system should show improvements in all three categories.

\subsubsection{Strength}

Strength is an important factor when designing structures. A designer needs to know how much force a structural system can take before it fails to transfer any more load. Table 4-3 shows the strength increase for all specimens compared to the average control strength.

Table 4-3: S trength Comparison for All Specimens

\begin{tabular}{|c|c|c|}
\hline Specimen Number & Max Beam Load (lbs) & Percent Increase (\%) \\
\hline 1 & $2,935.18$ & N/A \\
\hline 2 & $2,820.01$ & N/A \\
\hline 3 & $7,420.20$ & 158 \\
\hline 4 & $2,796.97$ & -3 \\
\hline 5 & $8,094.77$ & 181 \\
\hline 6 & $7,663.71$ & 166 \\
\hline 7 & $11,691.35$ & 306 \\
\hline 8 & $4,708.79$ & 64 \\
\hline 9 & $15,166.15$ & 427 \\
\hline 10 & $15,932.87$ & 454 \\
\hline
\end{tabular}

The percent increase in strength varied greatly during the testing. Samples with the SikaWrap ${ }^{\circledR}$ Hex-106 G gusset did not show a large increase in strength compared to the other two gusset materials. Specimen 4 is within $3 \%$ of the max load compared to the control specimen, and specimens 5 and 6 are within $8 \%$ of specimen 3 . Figure $4-1$ shows how the specimens with the SikaWrap ${ }^{\circledR}$ Hex-106 G gusset do not gain strength, when compared to 
similar retrofit schemes without gussets. The FRP of these plates rupture at the high stress concentration area of the joint's tip (re-entrant corner location), but no delay in failure (or increase in failure load) was achieved by adding these thin plates. Such minimal strength increase led to conclude that the SikaWrap ${ }^{\circledR}$ Hex-106 G gussets did not contribute enough reinforcement to the joint to justify adding a very thin FRP gusset; therefore a stiffer gusset would be needed to improve joint strength.

Specimen 7 showed an increase of $306 \%$ over the control specimens. The stiffer gusset worked better than the gusset in Specimens 5 and 6, but the increase was still lower than expected, so another adjustment was made. Specimens 9 and 10 were adjusted from the strengthstiffness response in the earlier samples; thus another major increase of strength was obtained with increase in gusset stiffness. The maximum increase in strength obtained during this study was $453 \%$. Specimen 7,9 , and 10 displayed the largest increase in strength, and it is evident from Figure 4-1 where their respective load-deflection responses exhibit maximum loads. The failure mode seen in these specimens is the same as the ones with thinner gussets. Using the same gussets that gave the highest strength increase, a sample without filler-modules was tested to see how best gusset alone would help. Specimen 8 shows a $64 \%$ increase in strength over the control specimen, which is a great step up from the control samples. The stiffer gusset also was able to change the failure mode and help delay the joint from failing. The failure still occurred at the tip of the joint area, which is to be expected since that is a high stress concentration area.

The reinforcing dowels inserted on Specimen 10 did not add strength to the system. There was only a $5 \%$ increase of strength from Specimen 9 to Specimen 10, which shared the same retrofit scheme except for the inclusion of reinforcing dowels. The shape of the filler- 
module also did not add much strength to the system, because the failure of the specimens was not on the filler-module.

After the testing was concluded, we can clearly see that filler-modules contributed to the increase of strength. The addition of FRP gussets works best when in tandem with the modules. Figure 4-1 shows the specimens with filler-modules had a taller curve than those without modules, but the tallest curves were those of specimens with both stiff gussets and fillermodules.

\subsubsection{Ductility}

Ductility is an important factor to study, because a ductile failure does not lead to a sudden collapse. To find the ductility of the test specimens, deflection at the maximum deformation capacity for a minimum residual load resistance. Specimens were not tested to their maximum deformation capacity, so Table 4-4 was put together for deflection $25 \%$ past the peak load.

Table 4-4: Ductility Comparison for All Specimens (*Did Not Reach 25\% Past Peak Load)

\begin{tabular}{|c|c|c|}
\hline Specimen Number & Ductility (in) & Percent Increase (\%) \\
\hline 1 & N/A & N/A \\
\hline 2 & 0.36 & 103 \\
\hline 3 & 0.73 & 22 \\
\hline 4 & 0.44 & 67 \\
\hline 5 & 0.60 & 44 \\
\hline 6 & $0.52^{*}$ & 161 \\
\hline 7 & 0.94 & 119 \\
\hline 8 & 0.79 & 233 \\
\hline 9 & 1.20 & 233 \\
\hline 10 & 1.20 & \\
\hline
\end{tabular}

All retrofitted specimens saw an increase in ductility. Specimens 4 and 8 , joints retrofitted with gussets only, showed that the gussets help improve the ductility response of a 
joint. An enhanced stiffness of gusset would greatly increase the ductility, an $80 \%$ increase of ductility from Specimen 4 to Specimen 8. Filler-modules added almost the same amount of ductility as a stiff gusset would. Specimen 8 only had an $8 \%$ increase of ductility when compared to Specimen 3.

Specimens that had both gussets and filler-modules showed the largest increase in ductility. A maximum of $233 \%$ increase in ductility was achieved by using filler-modules with a high stiffness gusset. Since the proposed retrofit scheme was able to delay the internal failure of the tenon on a conventional joint, the system was able to have a higher deflection at the peak load.

The shape of the filler-module and the inclusion of reinforcing dowels did not contribute to the ductility of the system. Gusset material on the other hand did greatly improve the ductility. The ductility increases in this study can be attributed to the ability of the retrofit system delaying the failure, and pushing the failure mode onto the system instead of locally affecting the joint.

\subsubsection{Energy Absorption}

Energy absorption is a good indication of how well a structure can resist until the ultimate failure. Energy absorption can be found as the area under the load-deflection curve. Since failure was not well defined at the start of this study, not all specimens were able to reach their own ultimate failure. Because of this the energy absorption for this report will be limited to $25 \%$ past the peak load. Table $4-5$ displays the energy absorption for each testing specimen and the percent increase from the control specimen. Energy absorption was found in Excel using the trapezoidal method for finding the area under the curve. 
Table 4-5: Energy Absorption Comparison for All Specimens (*Did Not Reach 25\% Past Peak Load)

\begin{tabular}{|c|c|c|}
\hline Specimen Number & Energy Absorption (lbs-in) & Percent Increase (\%) \\
\hline 1 & N/A & N/A \\
\hline 2 & 923.48 & 263 \\
\hline 3 & $3,347.71$ & -13 \\
\hline 4 & 804.45 & 289 \\
\hline 5 & $3,594.10$ & 192 \\
\hline 6 & $2,700.10^{*}$ & 658 \\
\hline 7 & $7,253.79$ & 195 \\
\hline 8 & $2,721.21$ & 1,243 \\
\hline 9 & $12,400.04$ & 1,364 \\
\hline 10 & $13,516.36$ & \\
\hline
\end{tabular}

The majority of joints showed an increase in energy absorption. The one outlier is Specimen 4 , which lost $13 \%$ of its energy absorption abilities. This could be expected, since Specimen 4 behaved like the control joints. Another joint that had a lower energy absorption than expected is Specimen 6, but this can be contributed to the test being concluded before reaching $25 \%$ deflection past the peak load. The specimens with the SikaWrap® Hex-106 G all behaved as if no gussets were attached.

Specimen 7 saw the first large jump in energy absorption, with a $658 \%$ increase over the control specimens. Knowing that a stiffer gusset is needed, Specimen 8 was tested to see how only an improved gusset would behave. With almost a $200 \%$ increase in energy absorption over conventional joints, Specimen 8 demonstrated how FRP is an excellent retrofitting material.

The improved specimens of 9 and 10 once again show the highest change. Over 1,350\% more energy absorption than that of the control specimen, and an $86 \%$ increase compared to a similar testing scheme in specimen 7. The enhanced stiffness of the gussets and the inclusion of the longitudinal wrap on specimens 9 and 10 are the reasons why the system was able to absorb more energy than the conventional (control) joints. 
Energy absorption comparison for this study was not perfect since the testing did not go to the ultimate failure, but the $25 \%$ method illustrates that a strong FRP gusset paired with fillermodules drastically increases the absorption ability.

\subsection{Failure Modes}

The main goal of this research is to investigate failure modes for future development/improvement of joint integrity, energy absorption, and avoiding catastrophic failures of structures. Thus, this section will go into great details to narrow down the failure mode for every specimen.

\subsubsection{Control Specimens}

The control joints behaved as expected. The "two-dowel" connection was reacting as a rigid joint, until the dowels started to bend. The peg bending is not the ultimate failure, because the joint was still reacting as a semi-ridged connection, and thus would continue to transfer load. It was until the ultimate failure of the tenon that the connection acted as a hinge. No more load beyond $\sim 2,800 \mathrm{lbs}$ was transferred through the connection, but deflection was continuing to increase without any load increase. Figure 4-8 and Figure 4-9 show the beam cross-section pullout away from the column by a large horizontal displacement. In those figures there is an almost infinite slope when loading begins and a change in slope until the joint fails. The ultimate failure of the joints happened due to shear failure on the tenon. As seen in Figure 4-10 the tenon splits and is no longer restrained by the dowels. 


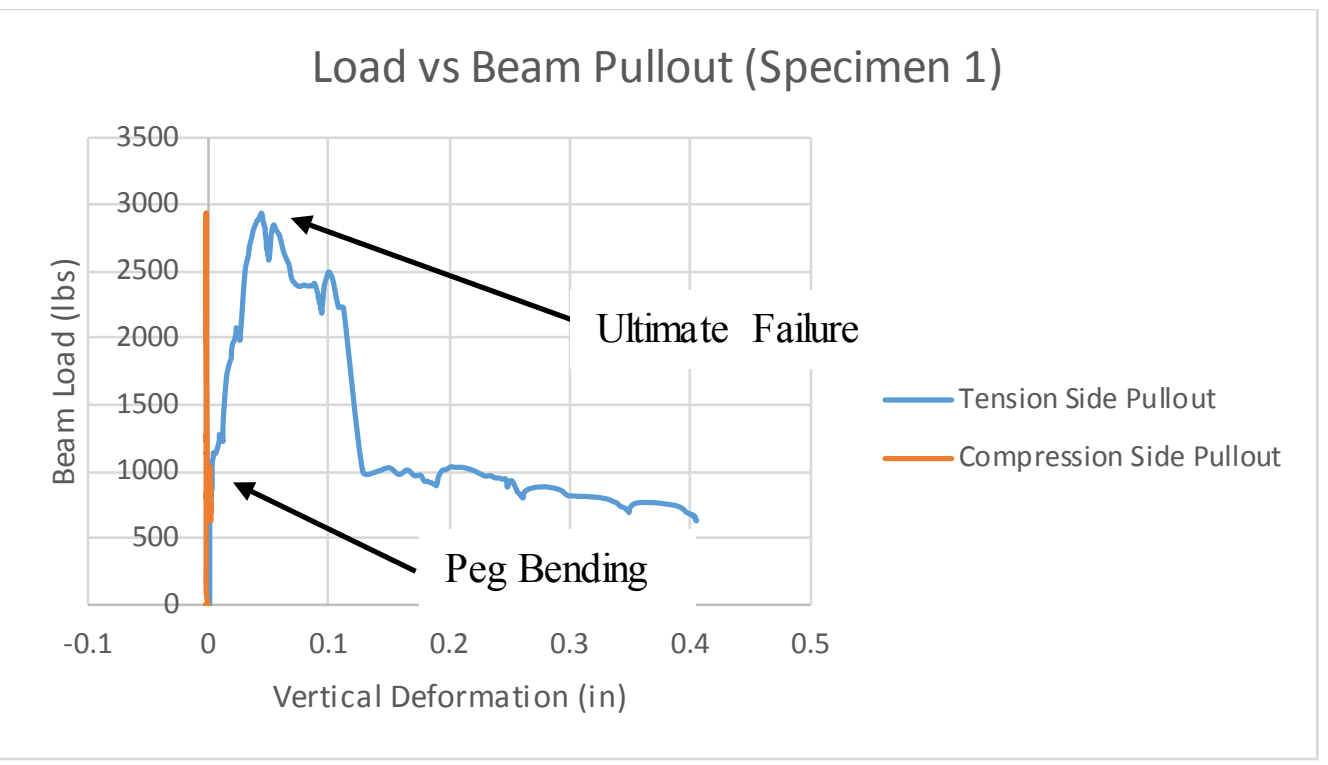

Figure 4-8: Load vs Tenon Pullout for Specimen 1

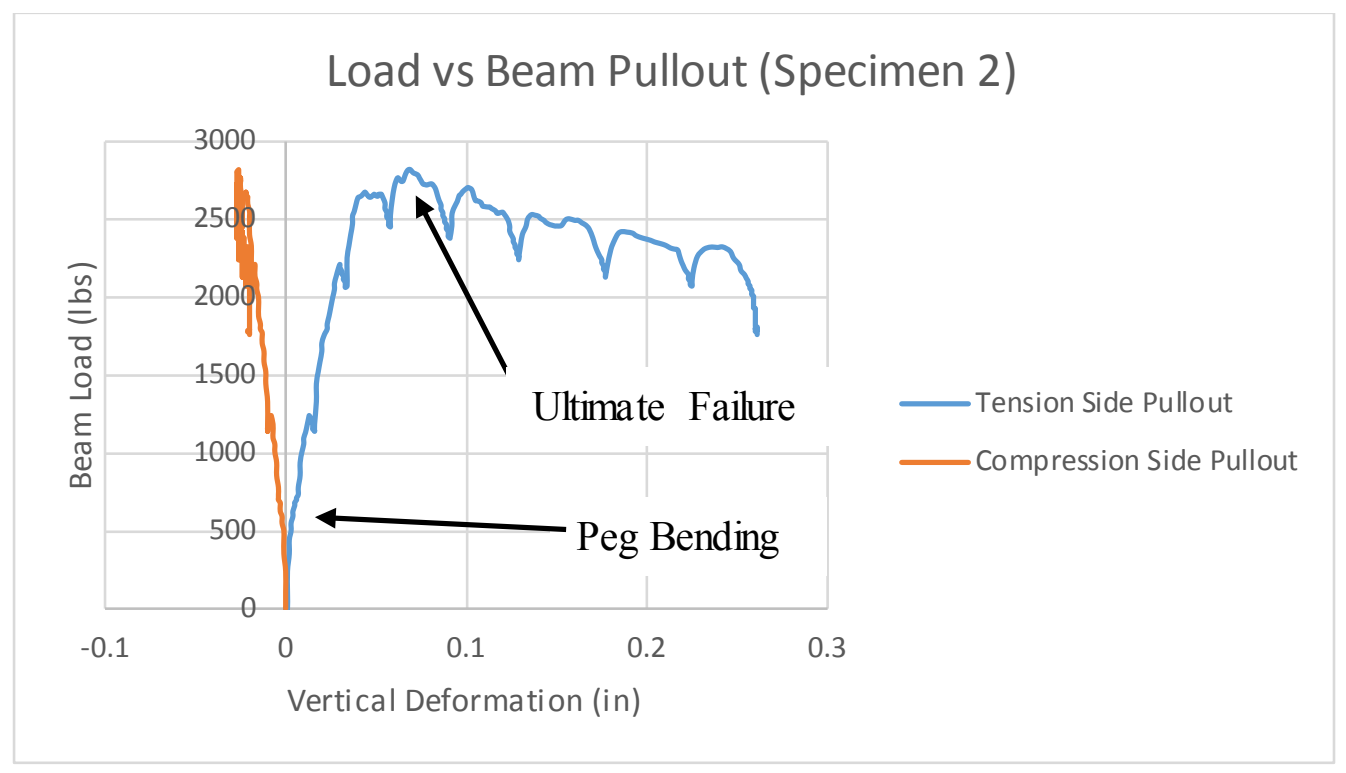

Figure 4-9: Load vs Tenon Pullout for Specimen 2 


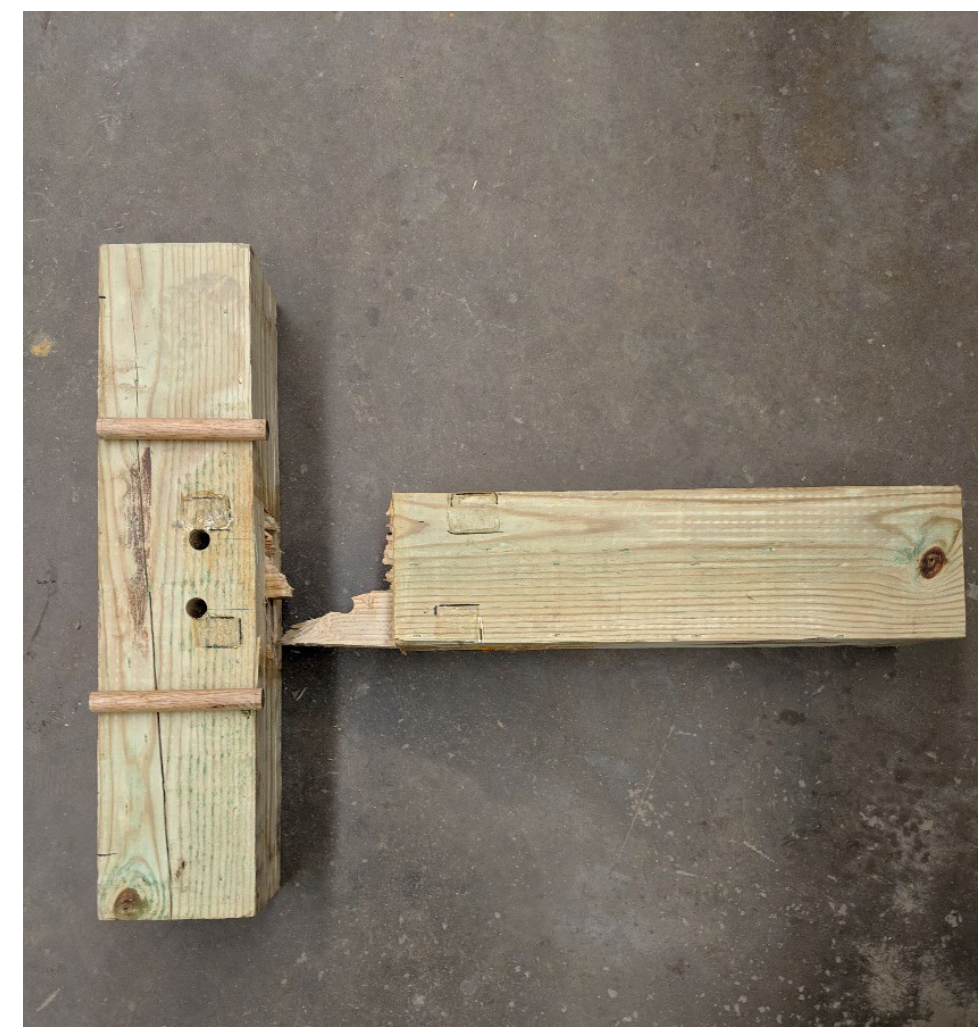

Figure 4-10: Failure Mode for the Control S pecimens (S pecimen 2)

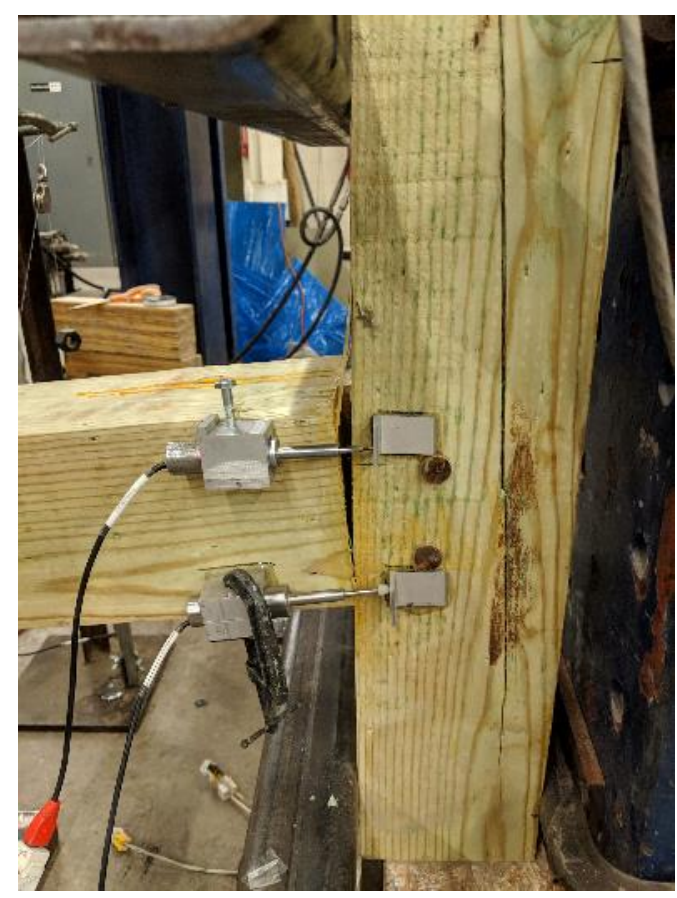

Figure 4-11: Specimen 1 after Testing 


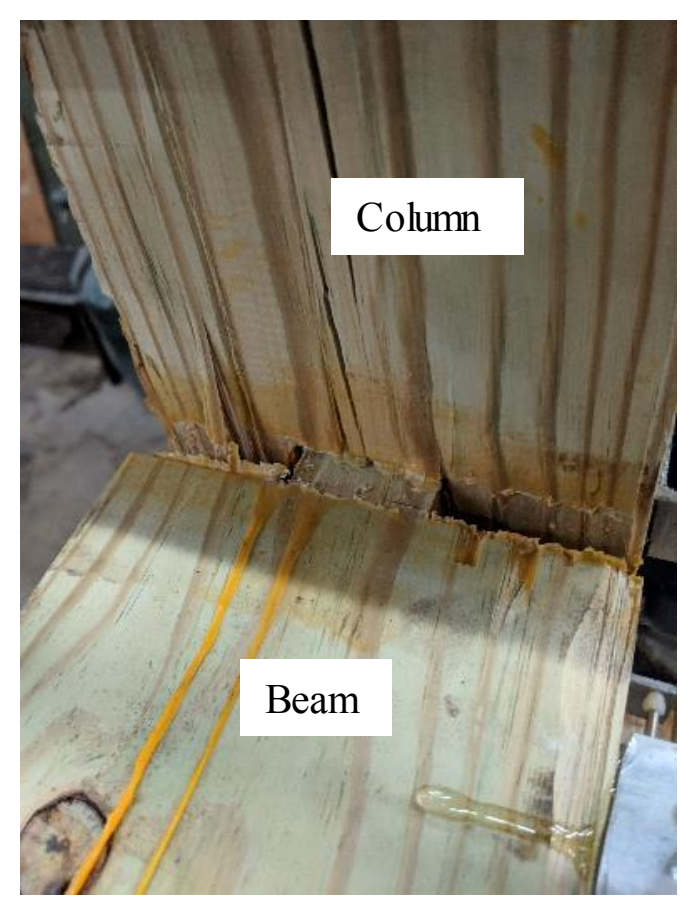

Figure 4-12: Close up of the Tenon Pull Away from Mortise on Specimen 2

\subsubsection{Retrofitted Specimens}

\subsubsection{Specimen 3}

Upon continuous increase in loading, joint 3 went through a two-step failure process. The initial failure occurs when the top filler-module starts to peel off from the beam which occurred at $\sim 5,000 \mathrm{lbs}$, which can be seen in Figure 4-14. The peel off starts at the tip of the module and continues to grow towards the face of the column. The joint acted as a rigid connection up until the filler-module pull off from the column at the maximum load. The filler-module was able to pull off from the column because the module was not fully debonded from the beam and was still acting as a single unit. Once the top filler-module pulled off from the column, the joint acted as a conventional connection and deflection continued to grow while the load plateaued at $\sim 4,000 \mathrm{lbs}$. Figure 4-13 shows the final failure of specimen 3. 


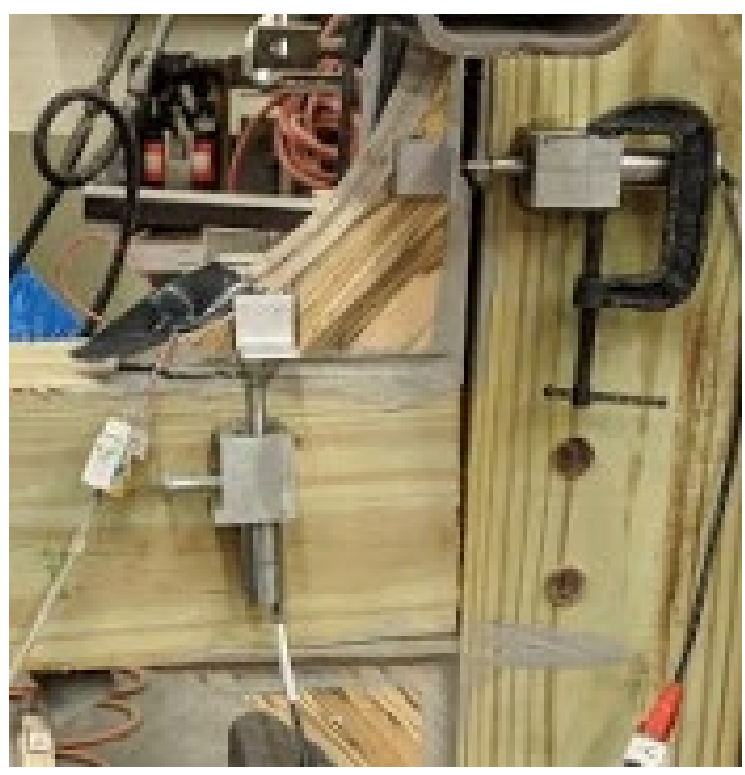

Figure 4-13: Failure Mode of Specimen 3

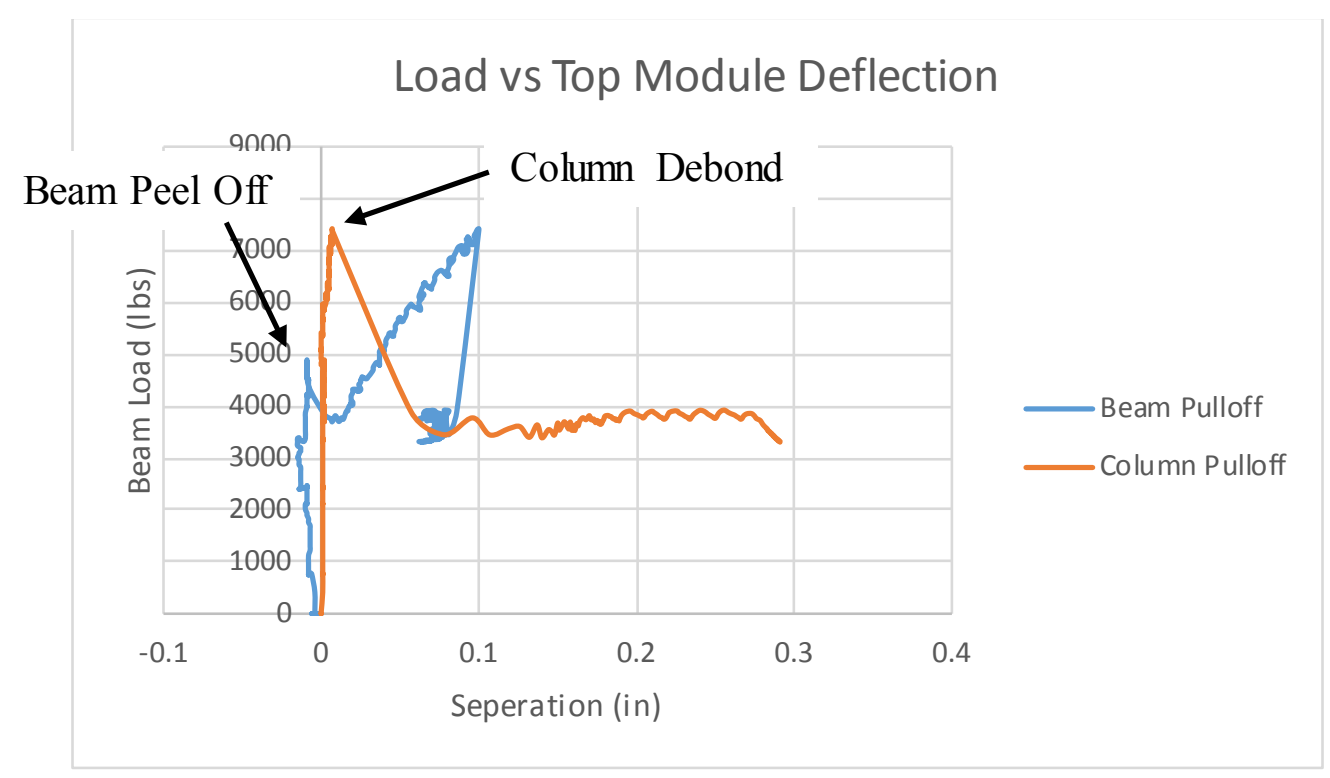

Figure 4-14: Load vs Top Module Deflection for Specimen 3

\subsubsection{Specimen 4}

Specimen 4 showed an external failure in the joint's top corner on the FRP gusset, as seen in Figure 4-15. As discussed in section 4.4 the FRP gusset used in this test did not contribute to any noticeable property, such as strength, ductility, or energy absorption. Therefore, 
the joint behaved just like the conventional specimens and had an internal failure on the tenon with the added failure of FRP rupture. The failure of the tenon was consistent with that of the control specimens.

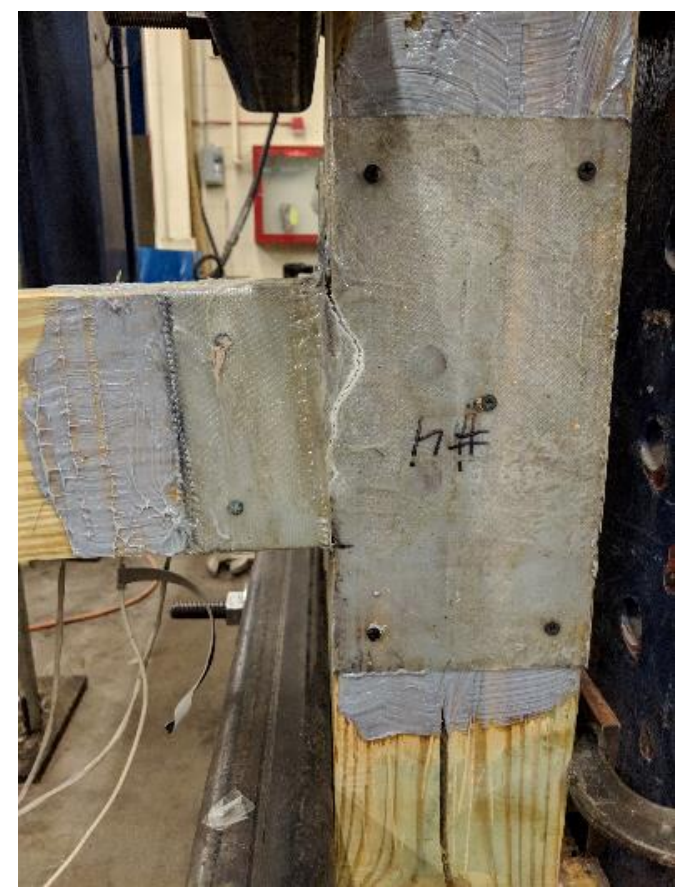

Figure 4-15: Failure Mode of Specimen 4

\subsubsection{Specimen 5}

Specimen 5 had rupture similar to specimen 3 on the FRP gusset as well. The gusset rupture occurred at the center of the tension side filler-module, as seen in Figure 4-16. The crack in the gusset happens on the module rather than the tip of the module, because there was no bond between the gusset and the tip of the module at the time of the initial module peel off, so the filler module was able to peel off with no resistance from the gusset. Then the peel off stops when it reaches a point where the FRP gusset is well bonded to the module. When the module still had some integrity with the beam thru bond forces, then the FRP ruptured. Similarly to the beam side, there was no bond between the filler-module and gusset near the tip on the column. Finally, once the loading reaches the peak value the filler-module pulls off from the column and 
the joint fails and no longer behaves as a near rigid connection. This failure mode could be pushed back to the tip of the filler-module if better bond between filler-module and gusset was achieved.

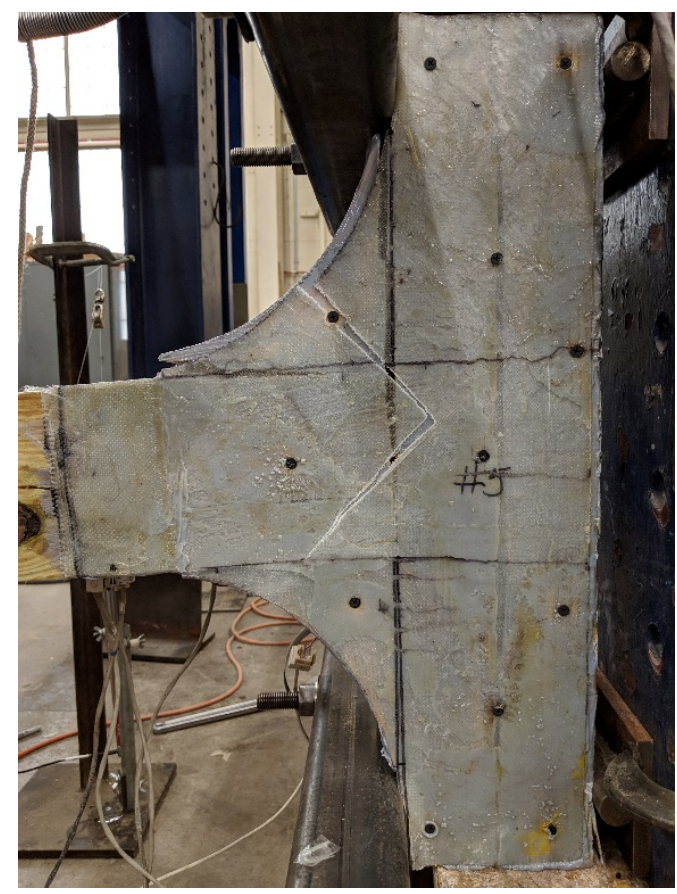

Figure 4-16: Failure Mode of Specimen 5

\subsubsection{Specimen 6}

Specimen 6 had an FRP rupture failure at the tip of the top filler-module which can be seen in Figure 4-17. The addition of filler-module anchors on Specimen 6 was able to delay the filler-module peel off until a higher load of $\sim 7,000 \mathrm{lbs}$ is obtained, as seen in Figure 4-18. During testing, the joint acted as a rigid connection. The FRP ruptured at the 7,000 lbs level and the filler-module started to peel off. The test was concluded before the crack in the FRP gusset could progress too far and thus the filler-module was not able to pull off from the column. The joint was able to behave as a near rigid connection through the entire testing. 
The joint did not have an increased strength when compared to Specimens 3 or 5, even though the module peel off was delayed until a higher load. This is due to the fact that the anchor wraps and gussets were very thin and did not have high stiffness to prevent failure in the wrap.

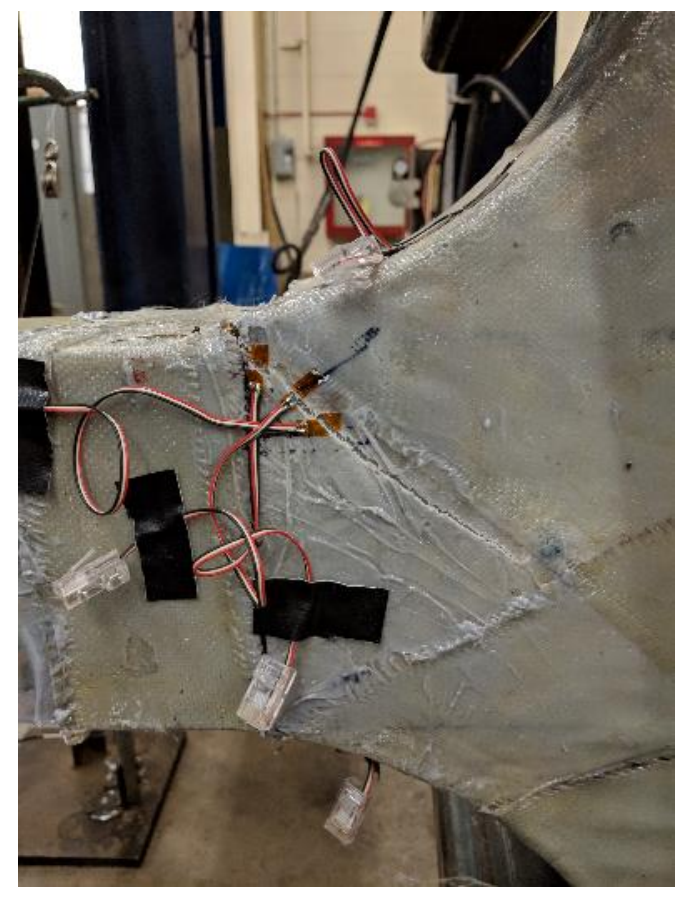

Figure 4-17: Failure Mode of Specimen 6

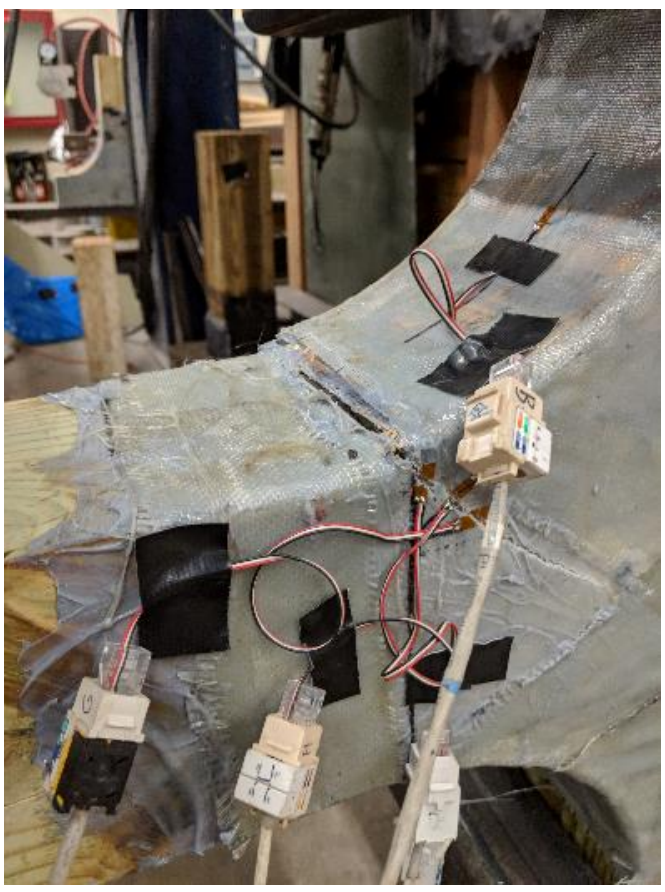

Figure 4-18: Module Debond on Specimen 6 


\subsubsection{Specimen 7}

Predominant failure mode of Specimen 7 was FRP rupture at the top filler-module's tip, as seen in Figure 4-19. The joint was rigid until the ultimate load is reached; then the specimen behaved as a hinge. The load-deflection curve shows a change of slope at $\sim 4,000 \mathrm{lbs}$, which correlates to the initiation of the top filler-module starting to peel off, which can be seen in Figure 4-20. The gussets transfer the load up to the peak load, which is the ultimate load capacity for the gussets. The filler-module did not pull off from the column, but the load decreased dramatically while still increasing in deflection. Thus, the filler-module must have peeled off completely from the beam and the joint no longer behaves as a rigid connection.

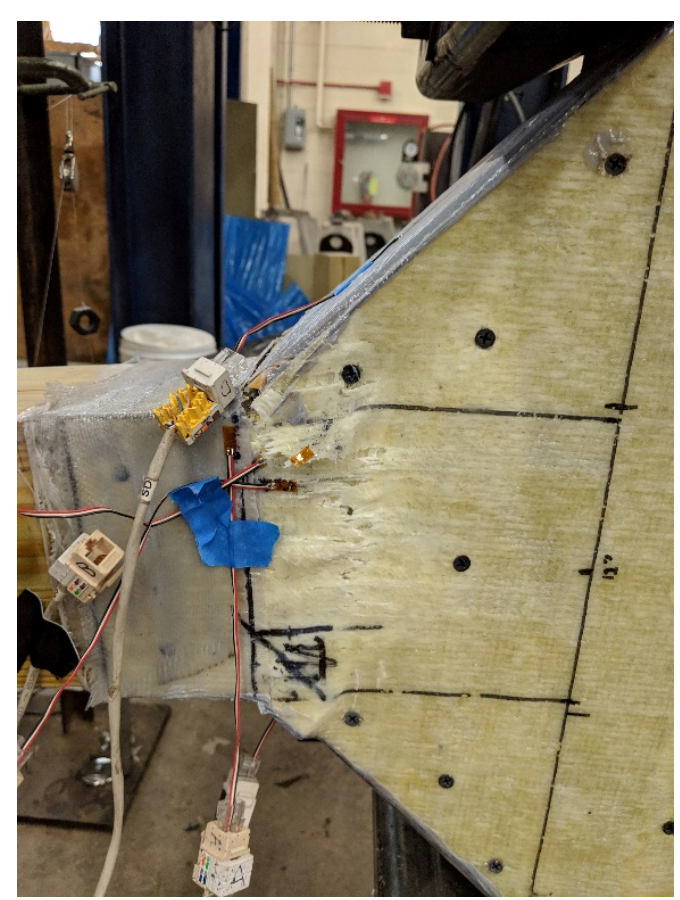

Figure 4-19: Failure Mode of Specimen 7 


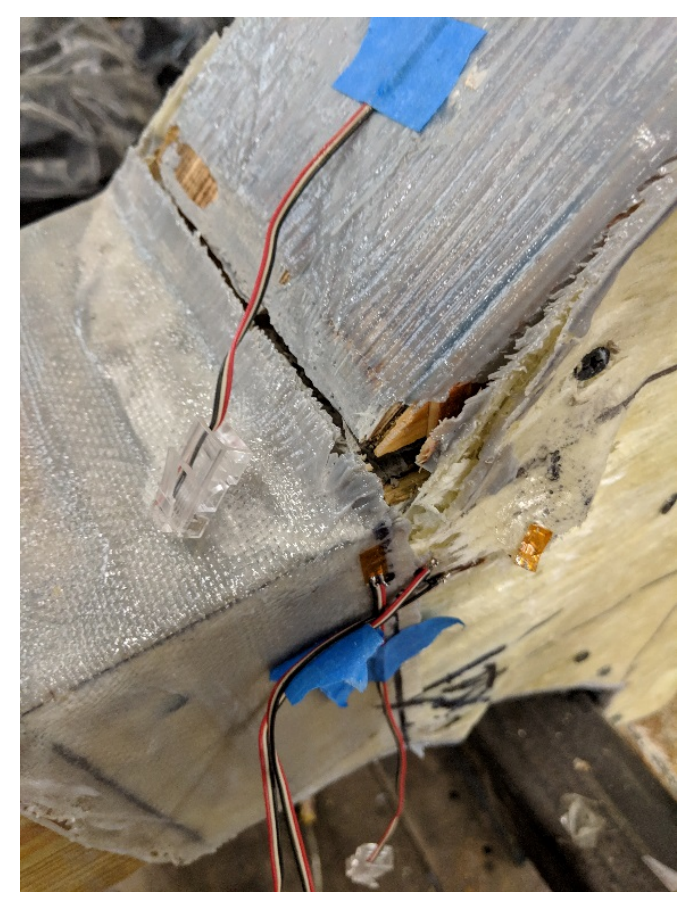

Figure 4-20: Top Filler-Module Tip Debond on Specimen 7

\subsubsection{Specimen 8}

Specimen 8 had a better behavior than that of Specimen 4, in terms of strength, ductility, and energy absorption. At $\sim 2,000 \mathrm{lbs}$ Specimen 8 is no longer rigid and switches to a semi-rigid connection. This can be seen in the joint strain plots, as a sudden change of slope is noted in the load-strain plots of Figure 4-2 and Figure 4-4. Then the joint will share the load with the FRP gussets and continued to act as a semi-rigid connection until the gussets rupture as displayed in Figure 4-21. At the ultimate load the gussets ruptured, refer to Figure 4-21, and the tenon can no longer support the load and fails internally at which point the connection turns into a hinge type mechanism. 


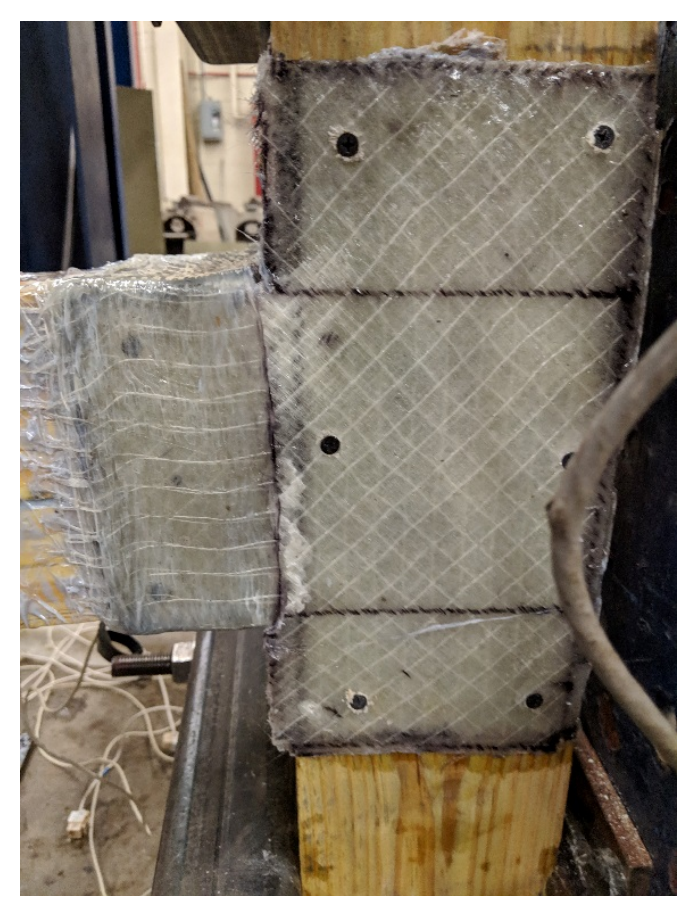

Figure 4-21: Failure Mode of Specimen 8

\subsubsection{Specimen 9}

Specimen 9 with wedge shaped filler-modules preformed the best out of all the samples. The results showed that Specimen 9 was very rigid until the $\sim 5,000 \mathrm{lbs}$ level, at which point the FRP gussets help distribute the load. The tension side filler-module does not start taking load until $\sim 7,000 \mathrm{lbs}$. The joint, still behaving as a single unit, and takes up to $\sim 10,500 \mathrm{lbs}$ before the filler-module starts to peel off from the column. Once the peel off initiates the FRP gussets take and distribute the load until the ultimate capacity of the gusset. The FRP gusset ruptures at the tip of the top filler-module, where a high stress concentration is located from the maximum load of $15,100 \mathrm{lbs}$. When the peak load is reached, then the load resistance drops to $\sim 10,000 \mathrm{lbs}$, and the crack in the FRP continues to grow at $\sim 45^{\circ}$ towards the bottom filler-module. The filler-module did not pull off from the column, therefore the joint would still be able to resist additional loads and moments. The failure mode of Specimen 9 can be seen in Figure 4-22. The increase in gusset stiffness helps keep the filler-module resist the pull off forces. 


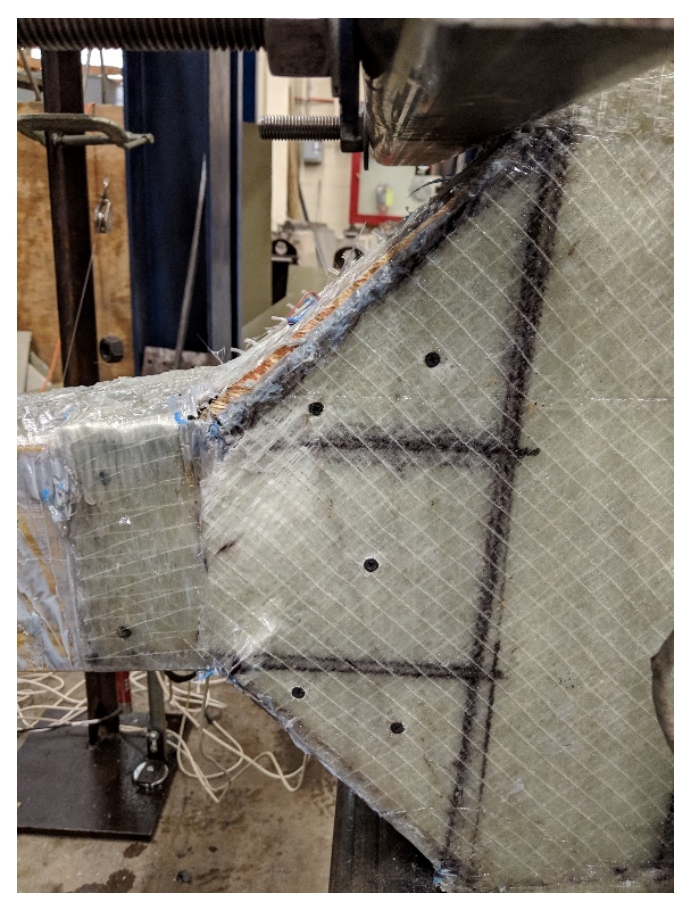

Figure 4-22: Failure Mode of S pecimen 9

\subsubsection{Specimen 10}

The behavior on Specimen 10 varied from that of Specimen 9. Both joints of specimens 9 and 10 acted as rigid connections until $\sim 40 \%$ of their maximum load, but on Specimen 10 , the top filler-module started taking load soon after applied load initiation. Since the filler-module had to distribute load sooner, the peel off also occurred at the lower level of loading, i.e. $\sim 5,000$ lbs. The reinforcing dowels in the filler-module could affect why the peel off occurred at an earlier load level. The dowels split the filler-module into section, and with the reduced area along the glue line, the filler-module peel off at a lower stress compared to a filler-module with no reinforcing dowels. The FRP gussets had to distribute the load until failure, at which point the FRP ruptured at the tip of the filler-module. Once again though the filler-module did not pull off from the column, which indicates that the joint still behaved as a rigid connection until the module fully peels off from the beam or the pulls off from the column occurs. Figure 4-23 shows 
the FRP rupture, but also an area where the gusset buckled after the initial failure, as seen in Figure 4-24. The lighter area on the bottom filler-module is where the gusset debonded from the joint due to inter-planar shear forces and resulted in a buckling effect.

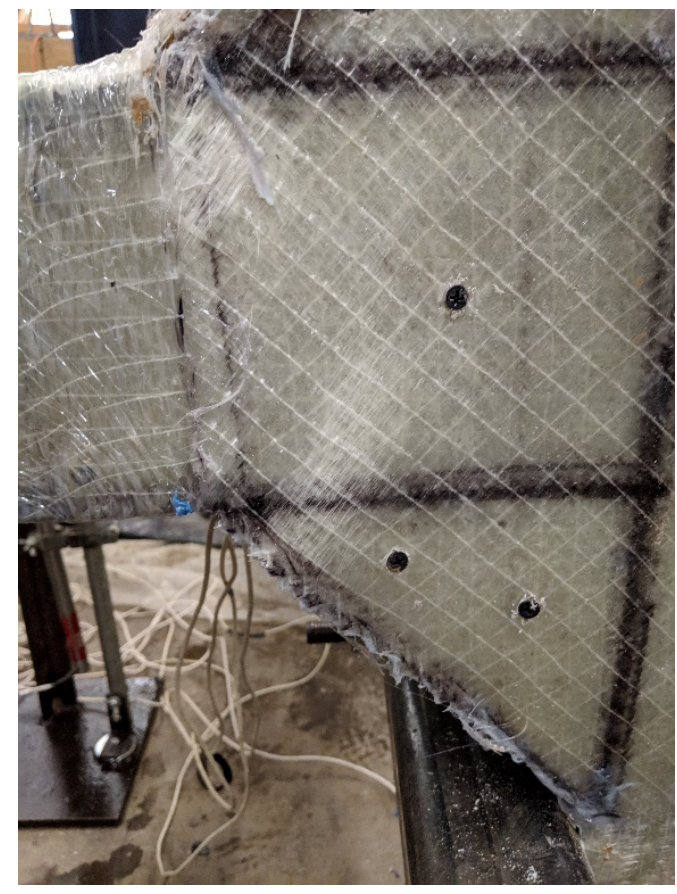

Figure 4-23: Failure Mode of Specimen 10 


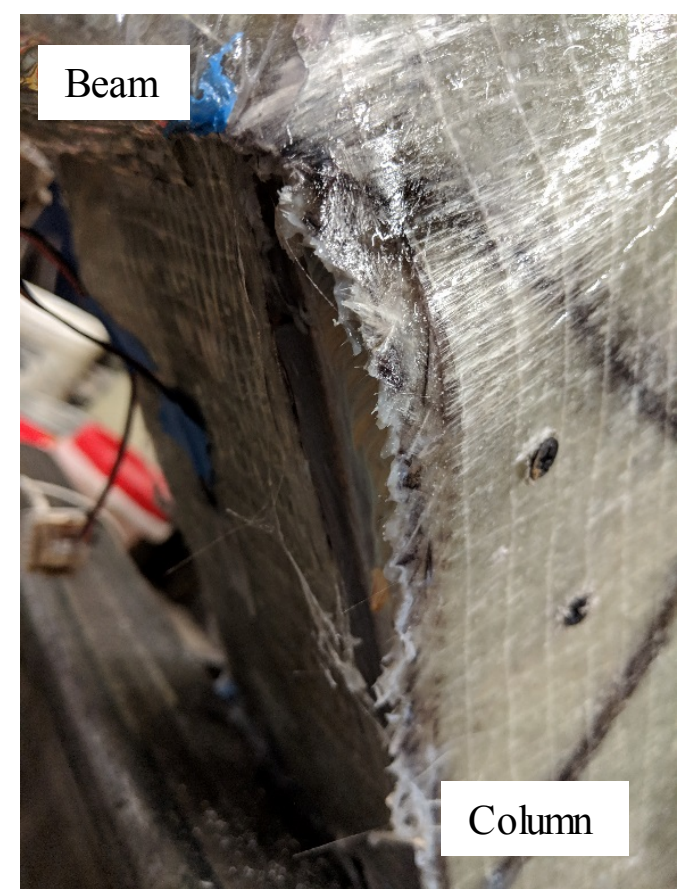

Figure 4-24: Buckling Effect on the Bottom Filler-Module of S pecimen 10

\subsection{Analytical Prediction}

This section deals with strength predictions using principal stress theory and compared these predictions with the experimental results. A comparison will be made to material properties especially with reference to the principal bending and shear stresses, and also bond stress based on the failure modes described in section 4.5.

Table 4-6 displays the predicted values for failure stress, which are described in sections 4.6.1 thru 4.6.4, based on their failure modes. These predicted failure stresses are compared to the failing member's ultimate strength in bending or bond. Analytical predictions for Specimens $2,3,7$, and 8 are examined in sections 4.6.1 thru 4.6.4 and compared with the experimental values. 
Table 4-6: Analytical Prediction of Joint S trength vs Material Property S trength

\begin{tabular}{|c|c|c|c|}
\hline Specimen Number & $\begin{array}{c}\text { Predicted Failure } \\
\text { Strength (psi) }\end{array}$ & $\begin{array}{c}\text { Material Failure } \\
\text { Strength (psi) (as per } \\
\text { manufacture) }\end{array}$ & Failure Mode \\
\hline 2 & $2,157.35$ & $1,500-1,600$ & Tenon Shear \\
\hline 3 & $1,136.19$ & $1,260-1,680$ & $\begin{array}{c}\text { Filler-Module Peel } \\
\text { off }\end{array}$ \\
\hline 7 & $25,721.6$ & $25,000-30,000$ & FRP Rupture \\
\hline 8 & $20,224.8$ & $25,000-30,000$ & FRP Rupture \\
\hline
\end{tabular}

\subsubsection{Conventional Joints}

The control specimens were subjected to a combined effect due to the loading. Bending, shear, and axial forces were all affecting the failure of the joints. To determine the combined effect of the bending and shear, the Mohr's circle approach was taken wherein principal stress are determined for our test specimens subjected to bending and shear loads as shown in Figure 3-12. Equation 4-2 thru Equation 4-4 (Doane 2018) were used to calculate the Mohr's circle using the input values from Table 4-7.

$$
\begin{gathered}
\sigma_{1,2}=\frac{M c}{2 I} \pm \sqrt{\left(\frac{M c}{2 I}\right)^{2}+\left(\frac{V Q}{I t}\right)^{2}} \\
\tau_{\text {max }}=\sqrt{\left(\frac{M c}{2 I}\right)^{2}+\left(\frac{V Q}{I t}\right)^{2}} \\
\theta=\frac{\tan ^{-1}\left(\frac{\frac{V Q}{I t}}{\frac{M c}{I}}\right)}{2}
\end{gathered}
$$

Equation 4-4

Table 4-7: Input Values for S pecimen 2 Prediction

\begin{tabular}{|c|c|c|c|c|}
\hline $\begin{array}{c}\text { Experimental } \\
\text { Failure Load } \\
\text { (lbs) }\end{array}$ & $\begin{array}{c}\text { Loading } \\
\text { Distance (in) }\end{array}$ & $\begin{array}{c}\text { Tenon Depth } \\
\text { (in) }\end{array}$ & $\begin{array}{c}\text { Tenon Thickness } \\
\text { (in) }\end{array}$ & $\begin{array}{c}\text { Stress Level } \\
\text { from Top of } \\
\text { Beam (in) }\end{array}$ \\
\hline $2,820.01$ & 18 & 5.5 & 1.5 & 1 \\
\hline
\end{tabular}


Table 4-8: Mohr's Circle Results for S ample 2

\begin{tabular}{|c|c|c|c|}
\hline$\sigma_{1}(\mathrm{psi})$ & $\sigma_{2}(\mathrm{psi})$ & $\tau_{\max }(\mathrm{psi})$ & $\theta$ (degrees) \\
\hline $4,293.01$ & -21.68 & $2,157.35$ & 2.04 \\
\hline
\end{tabular}

The results, seen in Table 4-7: Input Values for Specimen 2 Prediction

\begin{tabular}{|c|c|c|c|c|}
\hline $\begin{array}{c}\text { Experimental } \\
\begin{array}{c}\text { Failure Load } \\
\text { (lbs) }\end{array}\end{array}$ & $\begin{array}{c}\text { Loading } \\
\text { Distance (in) }\end{array}$ & $\begin{array}{c}\text { Tenon Depth } \\
\text { (in) }\end{array}$ & $\begin{array}{c}\text { Tenon Thickness } \\
\text { (in) }\end{array}$ & $\begin{array}{c}\text { Stress Level } \\
\text { from Top of } \\
\text { Beam (in) }\end{array}$ \\
\hline $2,820.01$ & 18 & 5.5 & 1.5 & 1 \\
\hline
\end{tabular}

Table 4-8, from the control specimens resulted in a shear stress that is higher than the ultimate value for SYP. On average SYP fails under shear at $\sim 1,500$ to 1,600 psi (Forest Products Laboratory 2010), roughly $46 \%$ lower than the shear stress obtained in this study. Three factors could contribute to the higher shear stress. Timber is a highly variable material, and the numbers in the Wood Handbook's Table 5-3b (Forest Products Laboratory 2010) are average values in shear stress failure. The timber used in the study could be a higher grade material. Secondly the moisture content of the test specimens could be lower than the $12 \%$ moisture content that the handbook reports on because of dry conditions in WVU's Major Units Lab. A lower moisture content, obtained by having the test specimens stored in a dry area, increases material properties of timber. Lastly the tenon could have experiencing a confinement effect from the mortise. The tight fit of the mortise and tenon connection due to good bond thru adhesive along with the applied axial load on the column helps keep the joint tight even with the reduced thickness of the tenon inside of the column. Once the tenon starts to pull out from the mortise, then the shear stress is able to act on the reduced area of the tenon. 


\subsubsection{Joints Retrofitted with Filler-Modules}

Since the specimen with filler-modules had a debond failure mode, the bending stress at the tip of the top module must be examined. The failure stress from the experimental results are compared with the bond strength of the bonding material (Sikadur®-31). Equation 4-5 will be used to find the bending stress, and Equation 4-6 is used to determine the stress concentration at the filler-module tip location.

$$
\begin{gathered}
\sigma=\frac{M c}{I} \\
k=\frac{\sigma_{b e a m}}{\sigma_{F M}}
\end{gathered}
$$

Equation 4-6

Using the results from Specimen 3, the analytical results are presented in Table 4-9. The stress was found on the top face of the beam, at the load when the filler-module starts to debond $(5,000 \mathrm{lbs})$.

Table 4-9: Specimen with Filler-Module Analytical Results

\begin{tabular}{|c|c|c|}
\hline$\sigma_{\text {beam }}(\mathrm{psi})$ & $\sigma_{\mathrm{FM}}(\mathrm{psi})$ & $\mathrm{k}$ \\
\hline $2,163.78$ & $1,893.65$ & 1.14 \\
\hline
\end{tabular}

That stress at the filler-module is well above the bond strength of Sikadur $\AA-31,420$ psi. The manufacturer's number is lower, because it is a design value and not an ultimate value. The ultimate value can be assumed to be 3-4 times larger than the design value. A stress distribution factor can be applied to the stress at the filler-module of $\sim 0.6$. Using Equation $4-7$, the stress is reduced to $1,136.19$ psi. The stress with the stress distribution factor is close to the assumed bond strength of the Sikadur $(-31,1,260-1,680$ psi. The predicted value is a bit lower could be due to 
the materials that the glue was bonded to. Sikadur $($ - 31 is recommended for concrete application, but for this study is was used to bond two timber materials together.

$$
\sigma=\sigma_{F M} * Z
$$

Equation 4-7

\subsubsection{Joints Retrofitted with FRP Gussets}

Since the failure occurred on the FRP gusset, the analytical strength should be compared to the failure stress of the gusset. Using Equation 4-5 with the values in Table 4-10 the predicted strength at the reentrant corner can be found.

Table 4-10: Input Values for $S$ pecimen 8 Prediction

\begin{tabular}{|c|c|c|c|}
\hline Load (lbs) & Loading Distance (in) & Beam Depth (in) & Beam Thickness (in) \\
\hline $4,708.79$ & 18 & 5.5 & 5.5 \\
\hline
\end{tabular}

GFRP has a typical ultimate tensile strength of $\sim 25,000-30,000$ psi (Creative Pultrusions 2004). The bending stress equation gives the maximum bending stress to be $3,056.65$ psi, but that is the stress on the beam and not the FRP. To convert the beam stress on to the FRP gusset the modular ratio must be used. Using Equation 4-8, a modular ratio of 3.308 was obtained, as seen in Table 4-11. Applying the modular ratio onto the bending stress, the stress on the gusset is 10,112.4 psi. A stress concentration factor is needed, since the change from beam to column is a $90^{\circ}$ angle. A right angle corner usually has a stress concentration factor of $\sim 2.0$, which when applied onto the predicted value would increase it to $20,224.8$ psi. The predicted value is now within $20 \%$ of the ultimate strength of the FRP. The difference can come from a handful of variable, such as voids in the gusset, uneven fiber distribution, bending modulus of wood higher than 1.2 Msi, etc. 


$$
n=\frac{E_{F R P}}{E_{\text {wood }}}
$$

Table 4-11: Modular Ratio Calculation for S pecimen 8

\begin{tabular}{|c|c|c|}
\hline EFRP (psi) & $\mathrm{E}_{\mathrm{wood}}(\mathrm{psi})$ & $\mathrm{n}$ \\
\hline $3,970,000$ & $1,200,000$ & 3.308 \\
\hline
\end{tabular}

\subsubsection{Joints Retrofitted with Filler-Modules and FRP Gussets}

Following the same method as the joints with just gussets, Equation 4-5 and Equation 4-8 were used to predict the failure stress of joints with filler-modules and FRP gussets. Specimen 7 was looked at for this section, because it had no other added variables such longitudinal wraps, reinforcing dowels, or filler-module anchors. Table 4-12 and Table 4-13 display the information needed to predict the failure strength of Specimen 7 .

Table 4-12: Input Values for $S$ pecimen 7 Prediction

\begin{tabular}{|c|c|c|c|}
\hline Load (bs) & Loading Distance (in) & Beam Depth (in) & Beam Thickness (in) \\
\hline $11,691.35$ & 12 & 5.5 & 5.5 \\
\hline
\end{tabular}

Table 4-13: Modular Ratio Calculation for Specimen 7

\begin{tabular}{|c|c|c|}
\hline EFRP (psi) & $\mathrm{E}_{\text {wood }}(\mathrm{psi})$ & $\mathrm{n}$ \\
\hline $4,357,548$ & $1,200,000$ & 3.63 \\
\hline
\end{tabular}

Using the bending stress equation (Equation 4-5) and the modular ratio from Table 4-13, the resulting bending stress at the tip of the filler-module on the FRP gusset is $18,372.57$ psi. A stress concentration factor is still needed, but it will be lower than the 2.0 used on a $90^{\circ}$ angle. Since wedge-shaped filler-modules were used on Specimen 7, the stress concentration factor can be used as 1.4. Applying that factor onto the bending stress, the resulting stress on the gusset is 
25,721.6 psi. The predicted failure value is right in line with the typical failure strength of GFRP (25,000-30,000 psi).

Specimens 6,9 , and 10 would follow the same process, but could have a higher failure stress than predicted. This is due to the fact that these three specimens had added FRP wraps, which would increase the failure strength.

\subsubsection{Conclusions}

Working with the experimental data and using standard analytical evaluation methods, the joints were behaving close to what would be expected. Some factors need to be studied more, i.e. stress concentration and stress distribution, to fully understand why the joint is failing a lower load value. A designer should always follow design specifications and manufacture properties, since they will always result in a lower failure load than the ultimate failure load. 


\section{CHAPTER 5 CONCLUSIONS AND FUTURE WORK}

\subsection{Conclusions}

Literature review revealed that timber has properties that are ideal for structural purposes but is limited due to the high variability within the material and its susceptibility to damages that other materials are not encountered typically. The uncertainty in moment connections in timber buildings can lead to possible premature failures and thus must be retrofitted. One such solution is the patented system of fiber reinforced polymer (FRP) composite gussets and filler-modules.

The purpose of this project was to study the behavior of timber beam-column moment connections with the invention created at West Virginia University. This was done through several key objectives:

- Design and fabrication of 10 mortise and tenon connections.

- Static load testing of control specimens until failure.

- Adding filler-modules and FRP gussets to increase load capacity, ductility, and energy absorption.

- Improving the retrofitting scheme(s), and achieving a higher capacity. Thru wraps, dowels and filler-modules.

- Improving the scheme once again to increase the ultimate load capacity.

- Analysis and comparison of strength, ductility, and energy absorption.

- A detailed evaluation into failure modes for all test specimens.

The retrofit system used in this work was able to achieve a $450 \%$ increase in strength, $1,200 \%$ increase in ductility, and a 500\% increase in energy absorption. The failure of retrofitted 
joints was not catastrophic and would result in huge energy absorption under the proposed retrofit scheme(s).

\subsubsection{Effect of Filler-Modules}

Filler modules were able to increase strength, ductility, and energy absorption while maintaining joint rigidity at a higher load.

\subsubsection{Effect of Filler-Module Shape}

Two filler-module shapes were tested throughout this study, a curve and a wedge. There was no noticeable increase in any joint characteristics due to filler-module shape, because the filler-module failure was linked to debond along the glue line. If the glue line was able to resist higher forces, then there could be a failure in the filler-module.

\subsubsection{Effect of Filler-Module Reinforcing Dowels}

Two similar test specimens were tested with the only difference being the addition of fillermodule reinforcing dowels. The two specimens, 9 and 10, peaked at almost identical loads, but behaved differently. Specimen 10 saw the tension side filler-module peel off at a lower load level than Specimen 9. The reduced contact area with the glue line and filler-module could be the reason for this occurrence. Therefore the dowels did not affect the ultimate load capacity, but did affect how the load was transferred.

\subsubsection{Effect of Longitudinal Wraps}

The longitudinal wrapped specimens (9 and 10) performed the best, and showed a later peel off of the tension side filler-module. The addition of longitudinal wraps is one solution to delay the peel off effect of the top filler-module. 


\subsubsection{Effect of Gusset Stiffness}

Three gusset sets were tested in this study. The gussets with the highest stiffness performed the best, while the gusset with the lowest stiffness did not contribute to the behavior of the joint.

\subsubsection{Analytical Work}

After testing was complete the experimental data was compared to principal stress theory. The predicted values for failure stress were close to the material failure strengths, and provide great insight on how the joint is behaving with the proposed retrofit shceme(s).

\subsection{Future Work}

- Investigate more variables such as filler-module material, confinement effect, filler-module dowel effect, and filler-module bonding methods.

- Testing and evaluation of joints under dynamic loading to understand behavior for extreme events like earthquakes and hurricanes.

- Full scale structure tests to study the combined effects a building provides under static, dynamic, and blast loading.

- Develop design equations based off of timber design codes and composite material standards. 


\section{REFERENCES}

Aicher, S. and Reinhardt, H. W. (2000). "Joints in Timber Structures." International RILEM Symposium, RILEM, Stuttgart, Germany.

Arroyo, N. (2015). “S.F.'s List of Quake-Vulnerable Homes Continues to Grow." San Francisco Public Press, <https://sfpublicpress.org/news/2015-02/sfs-list-of-quake-vulnerablehomes-continues-to-grow $>$.

Encyclopedia Britannica (n.d.) "Nail: Fastener." < https://www.britannica.com/technology/nailfastener $>$.

Craftsmanspace (n.d.). "Dowelling - Dowel joint." $<$ http://www.craftsmanspace.com/knowled ge/dowelling-dowel-joint.html >.

Chappell, C. (2019). "Natural disasters cost $\$ 91$ billion in 2018, according to federal report." CNBC, < https://www.cnbc.com/2019/02/06/natural-disasters-cost-91-billion-in-2018federal-report.htm $\triangleright$.

City of Santa Monica (n.d.). "Seismic Retrofit Program." Planning \& Community Development. $<$ https $/ /$ www.smgov.net/Departments/PCD/Programs/Se ismic-Retrofit/>.

Civilengineer (2017). "Difference Between Shear Wall and Column." $<$ https:/www.iamcivilengineer.com/difference-between-shear-wall-and-column/>.

Creative Pultrusions (2004). "The Pultex ${ }^{\circledR}$ Pultrusion Design Manual: of Standard and Custom Fiber Reinforced Polymer Structural Profiles.” Vol. 5, Rev.8.

DIY Extra (n.d.). “Guide to Screws and Bolts." < https://www.diy-extra.co.uk/guide-to-screwsand-bolts.html >. 
Doane, J (2018). “Combinded Stress and Mohr's Circle.” A SunCam online continuing education course.

FEMA (2006). "Hurricane Katrina in the Gulf Coast: Mitigation Assessment Team Report: Building Performance Observations, Recommendations, and Technical Guidance." FEMA 549 .

Ferris, R. (2018). "US disaster costs shatter records in 2017, the third-warmest year on record." CNBC, < https:/www.cnbc.com/2018/01/08/us-disaster-costs-shatter-record s-in-2017the-third-warmest-year.html>.

Fokkens, T. J. H. (2017). "Behaviour timber moment connections with dowel-type fasteners reinforced with self-tapping screws in seismic areas," thesis, presented to Eindhoven University of Technology, in partial fulfilment of the requirements for the degree of Masters of Science.

Forest Products Laboratory (2010). "Wood Handbook - Wood as an Engineering Material." Madison, WI.

GangaRao, H. V. S. and Majjigapu, P. K. R. (2017). 'Durable, fire resistant, energy absorbing and cost-effective strengthening systems for structural joints and members," U.S. Patent No. 9,611,667, April 4, 2017.

GangaRao, H. V. S. and Majjigapu, P. K. R. (2018). "Durable, fire resistant, energy absorbing and cost-effective strengthening systems for structural joints and members," U.S. Patent Application No. 10/100,542, October 16, 2018. 
GangaRao, H. V. S. and Majjigapu, P. K. R. (2019). 'Durable, fire resistant, energy absorbing and cost-effective strengthening systems for structural joints and members," U.S. Patent Application No. 16/133,337, January 17, 2019.

Gramoll, K. (n.d.). "Mechanics - Theory." < https://www.ecourses.ou.edu/cgibin/eBook.cgi?doc $=\&$ top $i c=$ me\&chap_sec $=08.1 \&$ page $=$ theory $>$

Gocál, J. (2014). “Load Carrying Capacity of Metal Dowel Type Connections of Timber Structures." Civil and Environmental Engineering, 10 (2), 51-69.

Haukaas, T. (2014). Beams on Elastic Foundation. University of British Columbia, Vancouver, Canada.

Hollaway, L. C. and Teng, J. G. (2008). Strengthening and Rehabilitation of Civil Infrastructure Using Fibre-Reinforced Polymer (FRP) Composites. Woodhead Publishing Limited, Cambridge, England.

Houspect WA (2015). "Timber Rot and How it Affects a Your Property." $<$ https://www.houspect.com.au/wa/blog/entry/timber-rot-and-how-it-affects-yourproperty.html>.

Johansen, K. W. (1962). Yield-line theory. Cement and Concrete Association.

Köhler, J. (2007). Reliability of Timber Structures. vdf Hochschulverlag AG, Zurich, Switzerland.

Kollmann, F. F. P., Kuenzi, E. W., and Stamm, A. J. (1975). Principles of Wood Science and Technology: II Wood Based Materials. Springer-Verlag, Berlin/Heidelberg, Germany. 
Liu, H., Saffir, H. S., and Sparks, P. R. (1989). "Wind Damage to Wood-Frame Houses:

Problems, Solutions, and Research Needs," Journal of Aerospace Engineering, 2 (2), 5770.

Majjigapu, P. K. R. (2019). "Structural Response of Reinforced Concrete Beam-Column Joints with Filler-Modules and FRP Composite Systems." disertation, presented to West Virginia University, in partial fulfilment of the requirements for the degree of Doctor of Philosophy.

Merritt, F. S. and Ricketts, J. T. (2001). Building Design and Construction Handbook. McGrawHill, New York, NY.

Moses, D., Magee, M., and DeStefano, J. (2016). "Moment Connections in Timber," Bulletin No. 2016-06, Timber Frame Engineering Council.

Pan, F. (2014). 'Damage Prediction of Low-Ride Buildings Under Hurricane Winds," dissertation, presented to Louisiana State University, in partial fulfilment of the requirements for the degree of Doctor of Philosophy.

Partner Engineering and Science, Inc. (n.d.) "Soft Story Retrofit." $<$ https://www.partneresi.com/services/building-engineering/structural-engineering/softstory-retrofit $>$.

Pedersen, M. U. (2002). “Dowel Type Timber Connections: Strength Modelling," thesis, presented to Technical University of Denmark, in partial fulfilment of the requirements for the degree of Doctor of Philosophy. 
Rammer, D. R. (2016). "Wood: Mechanical Fasteners.” Reference Module in Materials Science and Materials Engineering. Oxford: Elsevier, 1-10.

Rañoa, R., Xia, R., and Lin II, R.G. (2015) 'Look at how apartments can collapse during an

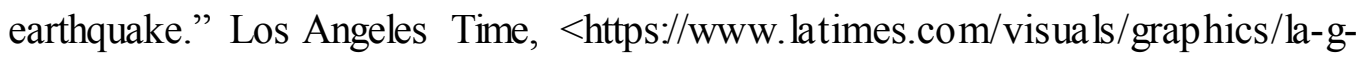
retrofiitting-wood-frame-soft-story-buildings-20151005-htmlstory.html .

Ross, R. J., Brashaw, B. K., Wang, X., White, R. H., and Pellerin, R. F. (2005). 'Post-Fire Assessment of structural Wood Members." Wood and Timber Condition Assesment Manual, (4), Madison, WI, 29-46.

Schmidt, R. J., \& Daniels, C. E. (1999). Design Considerations for Mortise and Tenon Connections. Laramie, WY.

Sika (2018). Product Data Sheet Sikadur ${ }^{\circledR}-300$. Lyndhurst, NJ, Sika Corporation.

Sika (2018). Product Data Sheet Sikadur®-330. Lyndhurst, NJ, Sika Corporation.

Sika (2018). Product Data Sheet Sikadur $®-31$ Hi-Mod Gel. Lyndhurst, NJ, Sika Corporation.

Sika (2018). Product Data Sheet SikaWrap ${ }^{\circledR}$ Hex-100 G. Lyndhurst, NJ, Sika Corporation.

Sika (2018). Product Data Sheet SikaWrap ${ }^{\circledR}$ Hex-106 G. Lyndhurst, NJ, Sika Corporation.

Sika (n.d.). Product Data Sheet SikaWrap ${ }^{\circledR}$ Pre-saturated 430G. Lyndhurst, NJ, Sika Corporation.

Singh, J and White N. (1997). "Timber Decay in Buildings: Pathology and Control." Journal of Performance of Constricted Facilities, 11(1), 3-12. 
Southern Forest Products Association (2013). "Southern Pine Reference Design Values." Southern Pine Use Guide: 2013 Edition.

The City and County of San Francisco (n.d). "Soft Story FAQ." Department of Building Inspection, <https://s fdbi.org/soft-story-faq $>$.

Trus Joist (2018). "Parallam® Plus PSL Beams, Headers and Columns.” Weyerhaeuser.

van der Put, T. C. A. M. and Leijten, A. J. M. (2000). Evaluation of Perpendicular to Grain Failure of Beams Caused by Concentrated Loads of Joints. Delft University of Technology, the Netherlands.

Vermont Timber Works (n.d.). "Traditional Timber Frame Joinery: Mortise \& Tenon Connections." < https://www.vermonttimberworks.com/learn/timber-framejoinery/traditional/s. 


\section{APPENDIX A - TESTING DATA PLOTS}

Presented in this appendix is the complete raw data used throughout this study. Each section is broken up by test specimen, and within the sections will be plots of load versus deflection, joint strain, module strain, beam pullout, and module pull off.

\section{A.1 Specimen 1 Data}

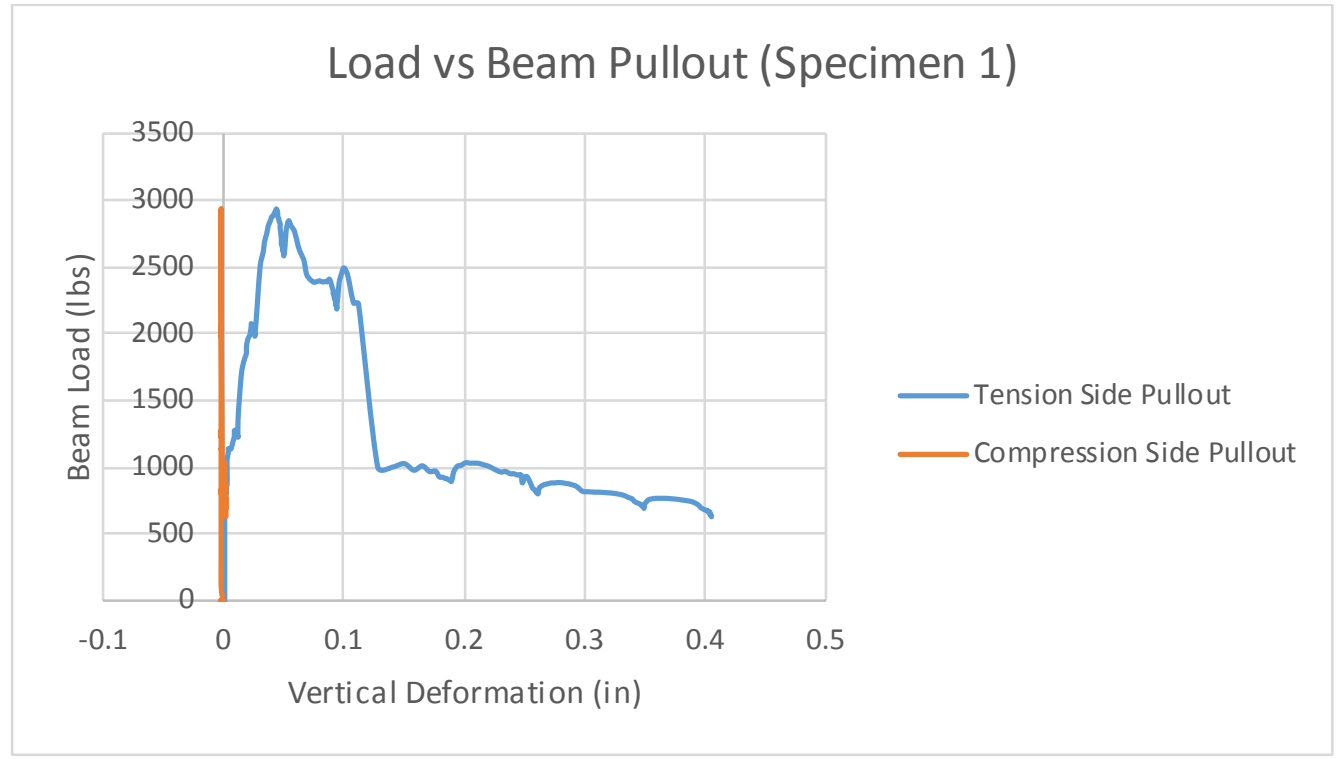

Figure A-1: Load vs Beam Pull Out (Specimen 1) 


\section{A.2 Specimen 2 Data}

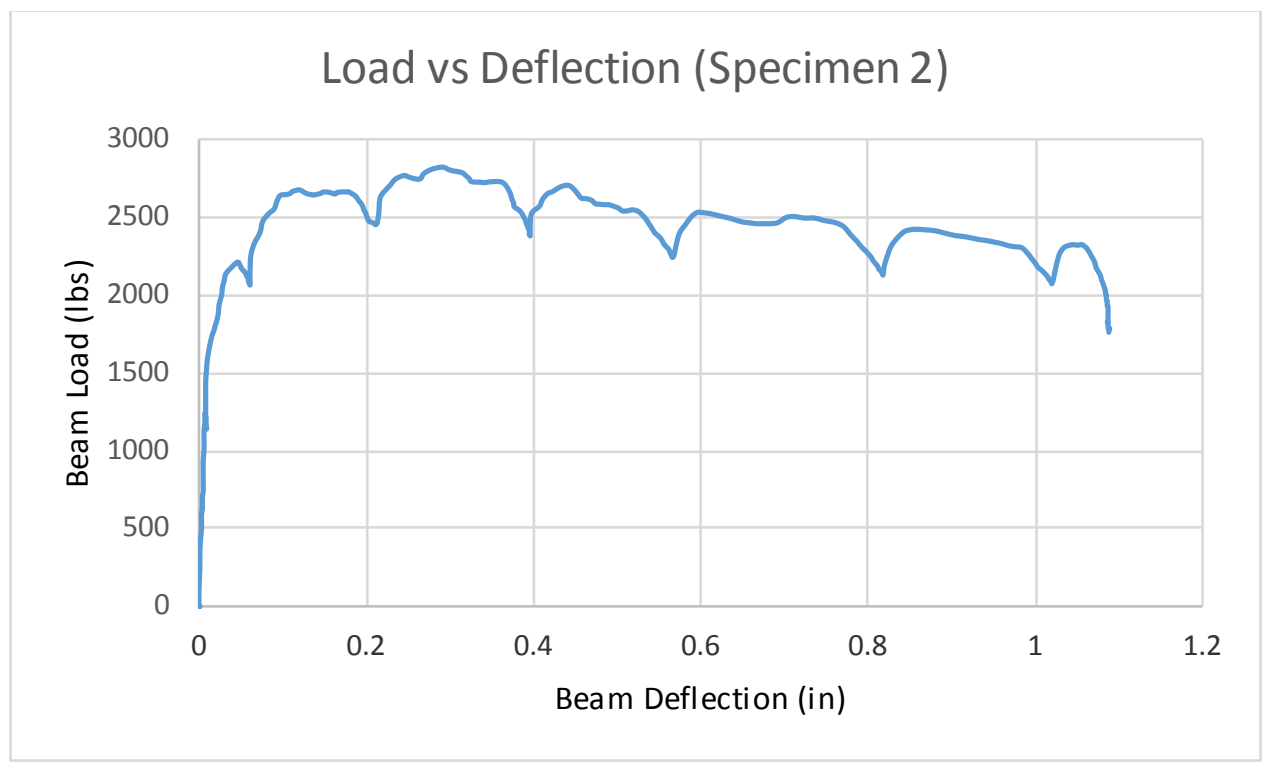

Figure A-2: Load vs Deflection (Specimen 2)

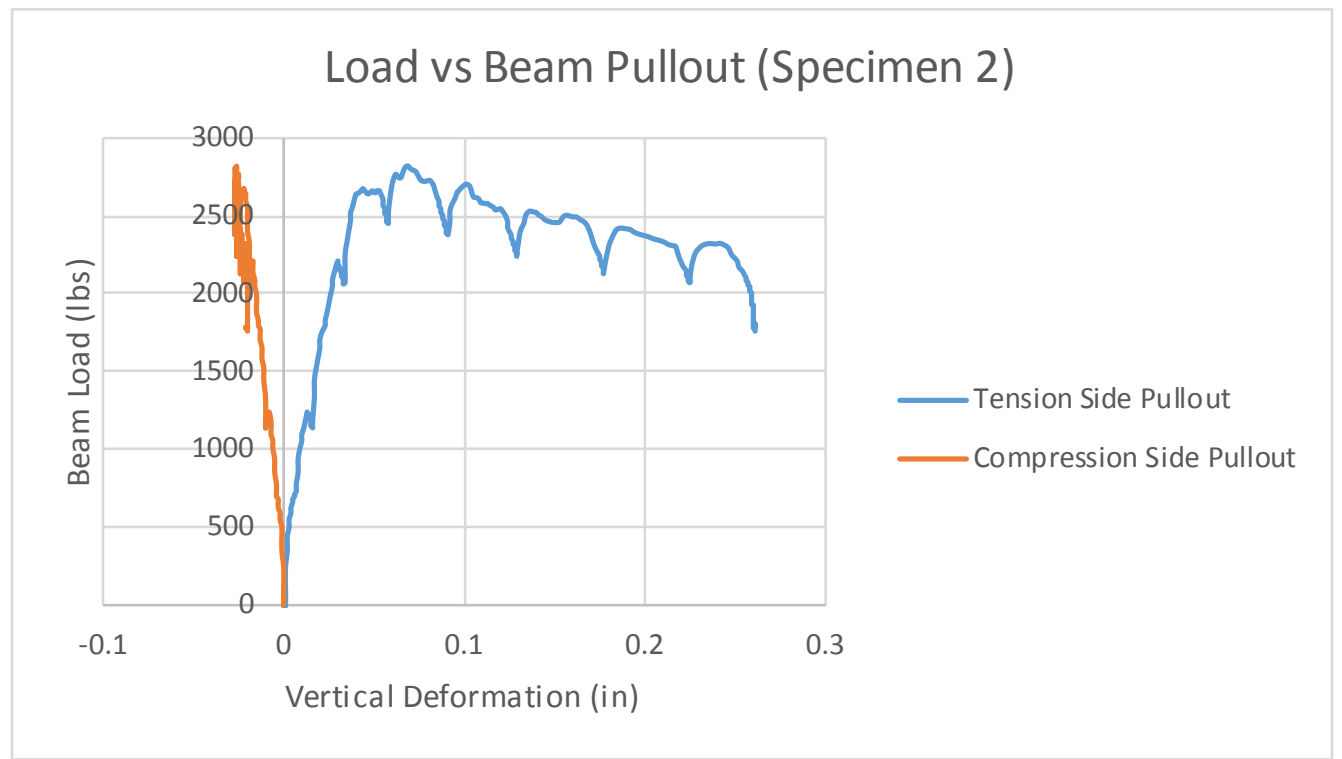

Figure A-3: Load vs Beam Pull Out (Specimen 2) 


\section{A.3 Specimen 3 Data}

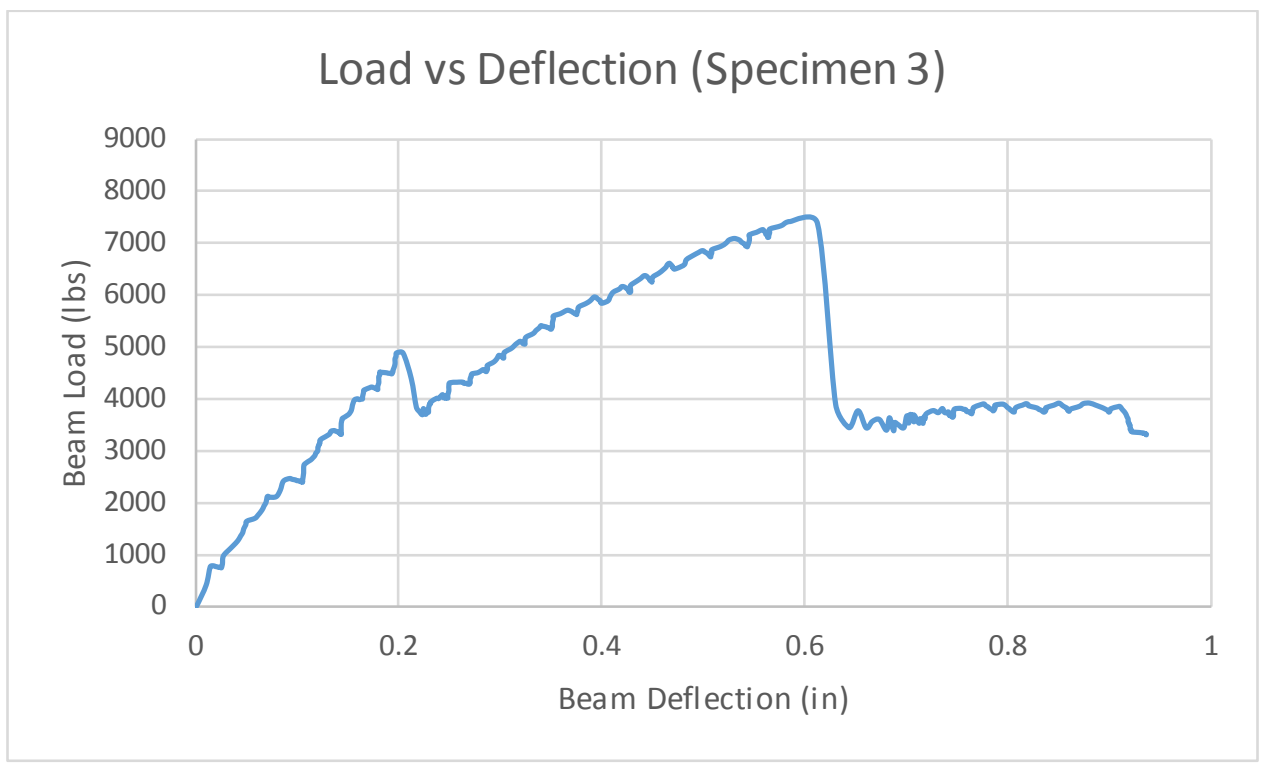

Figure A-4: Load vs Deflection (Specimen 3)

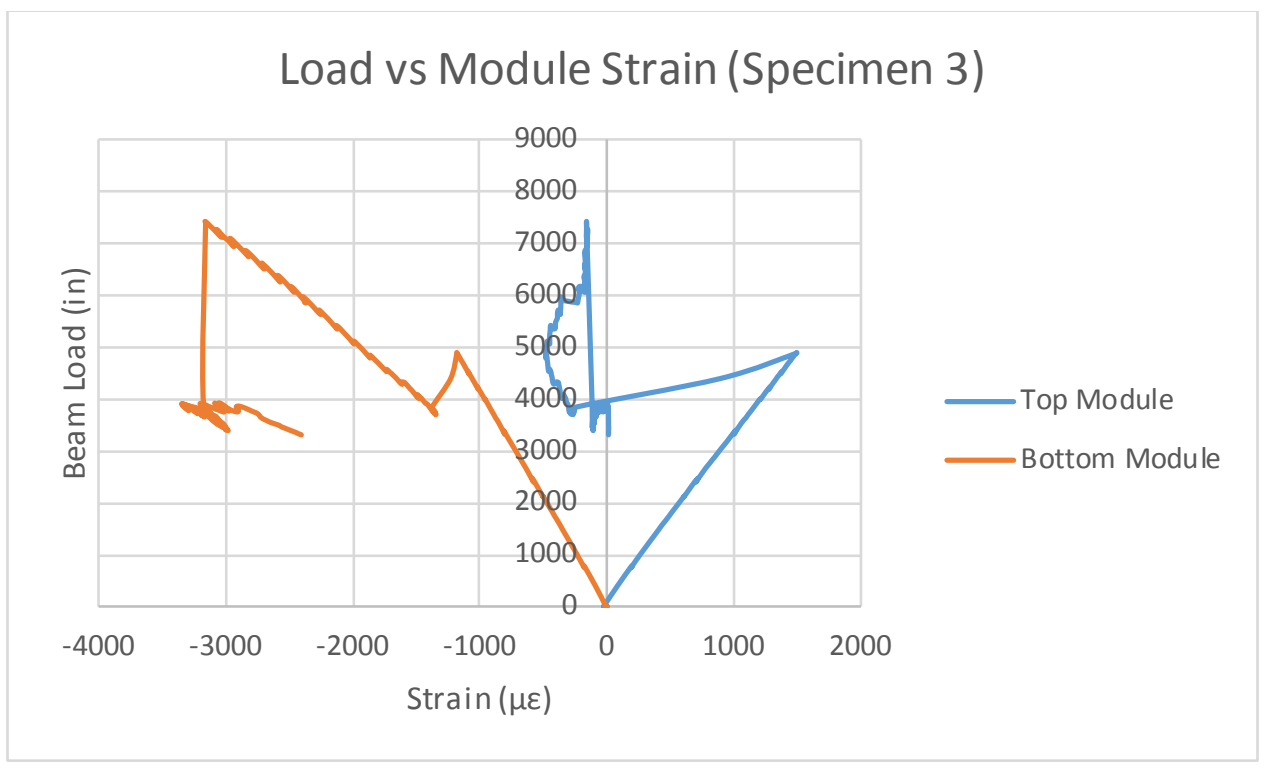

Figure A-5: Load vs Module S train (Specimen 3) 


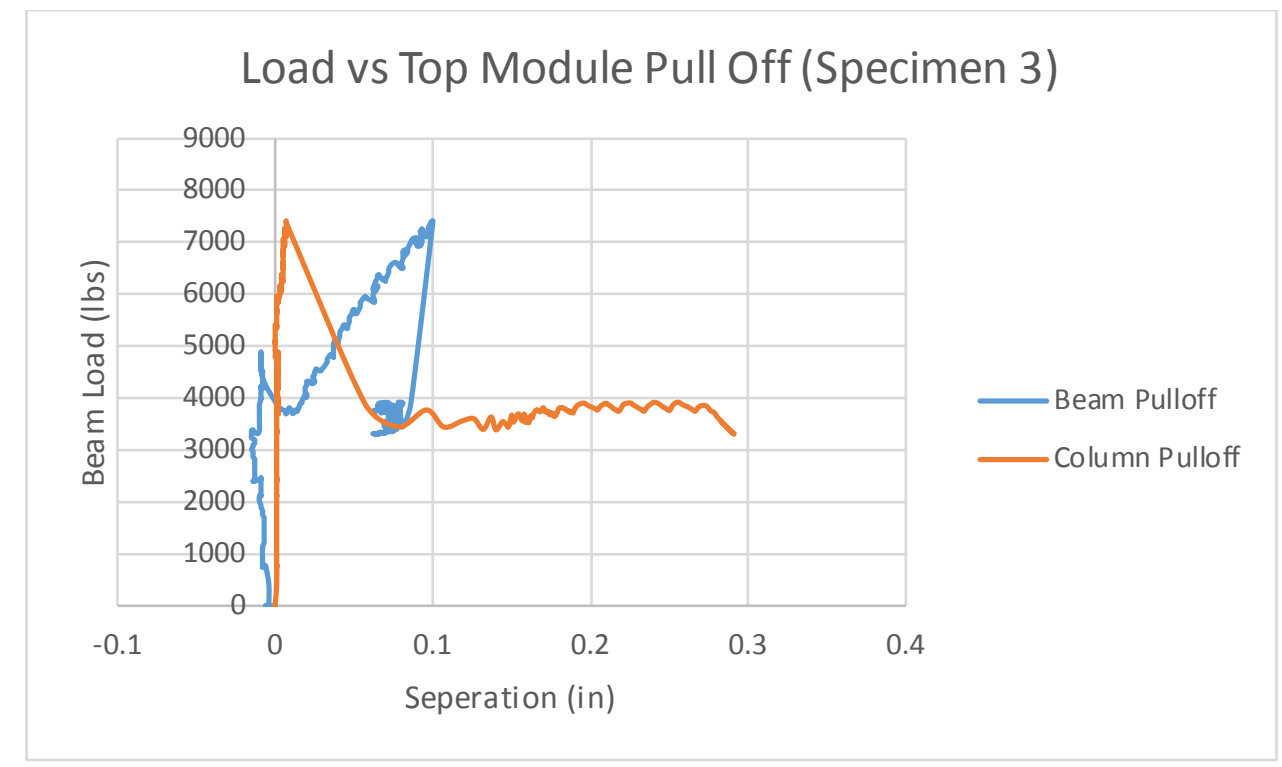

Figure A-6: Load vs Module Pull Off (Specimen 3)

\section{A.4 Specimen 4 Data}

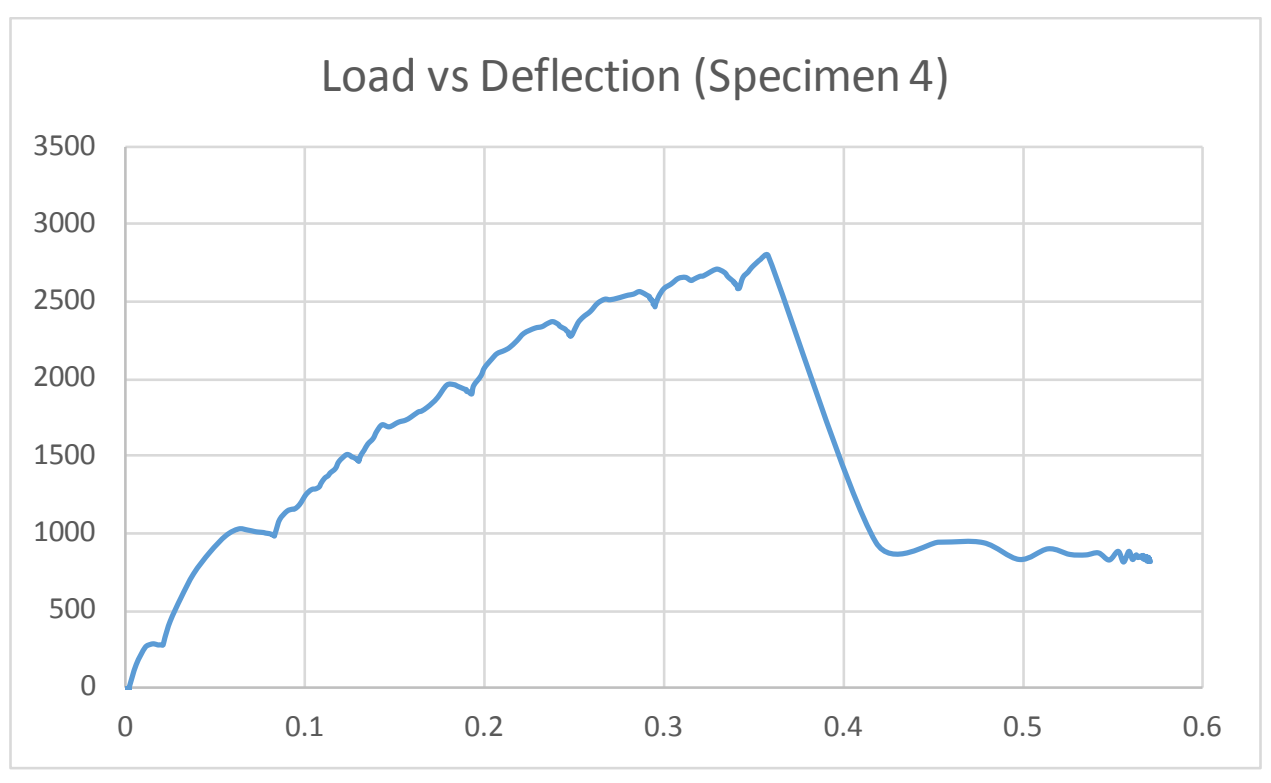

Figure A-7: Load vs Deflection (S pecimen 4) 


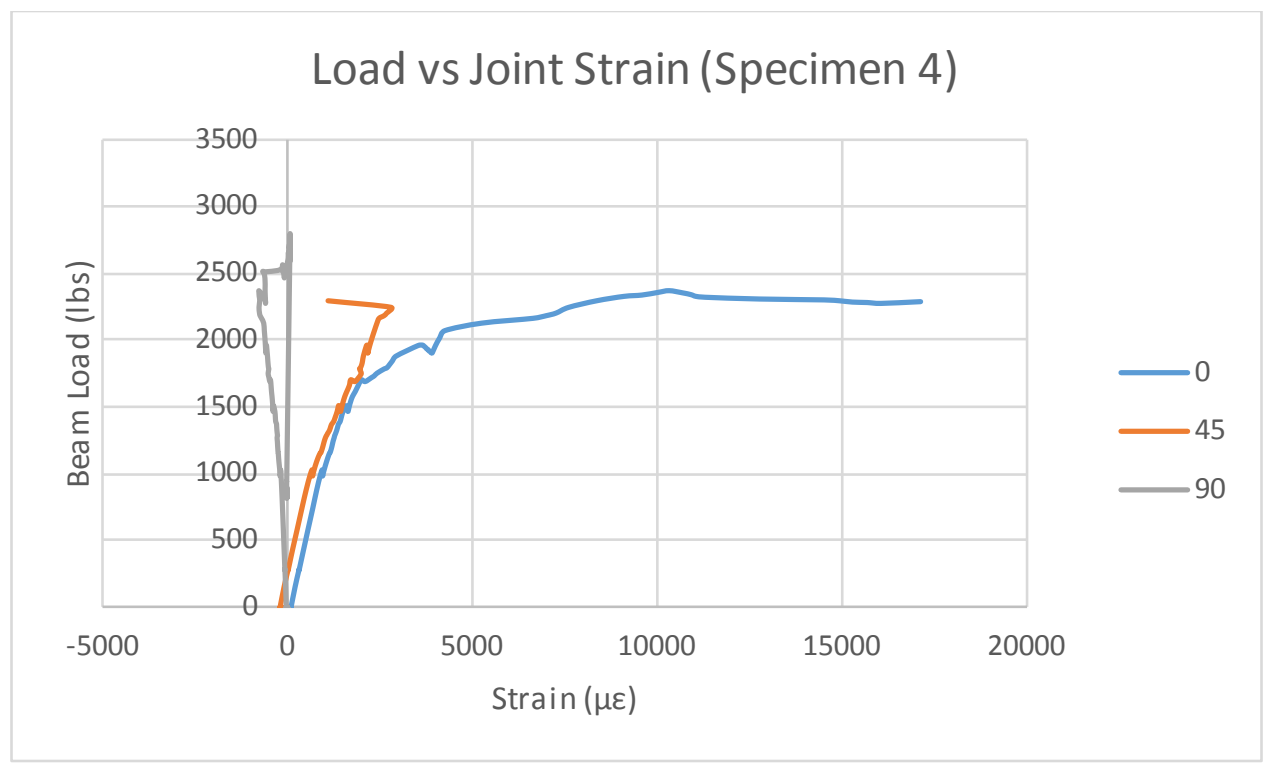

Figure A-8: Load vs Joint S train (S pecimen 4)

\section{A.5 Specimen 5 Data}

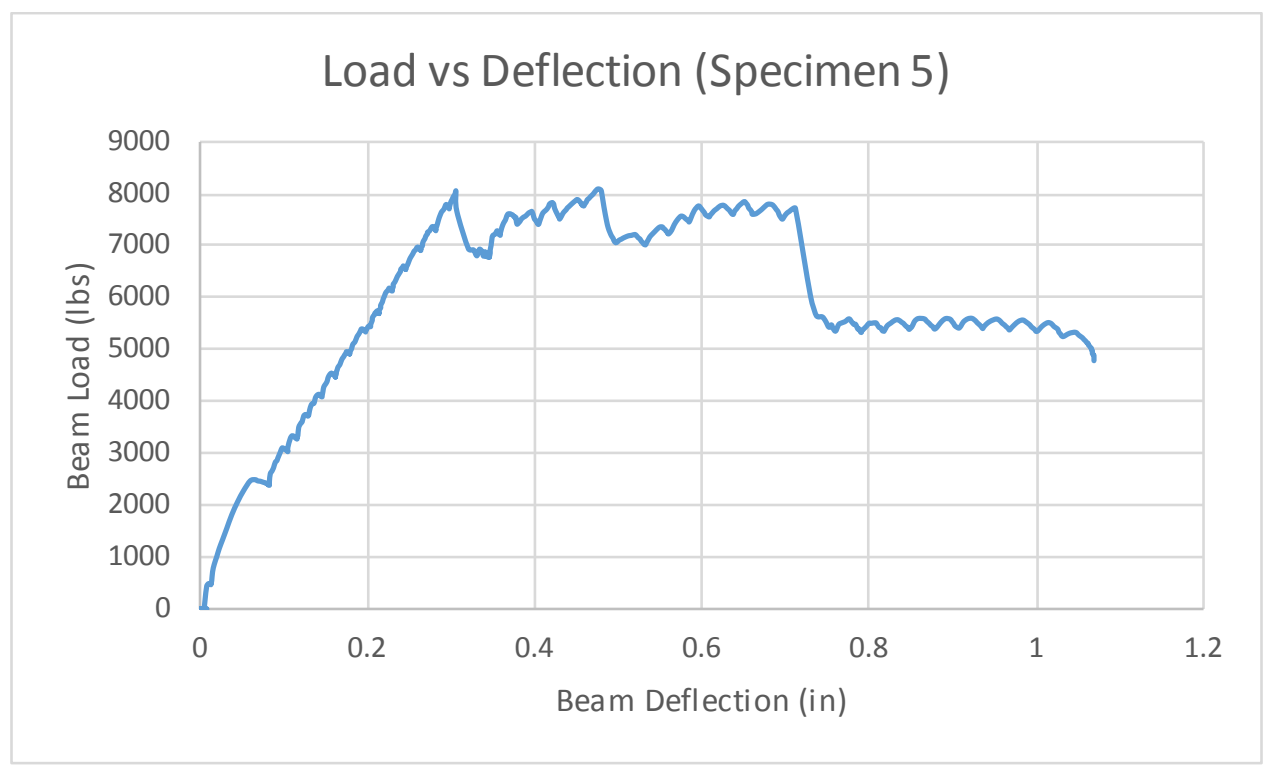

Figure A-9: Load vs Deflection (Specimen 5) 


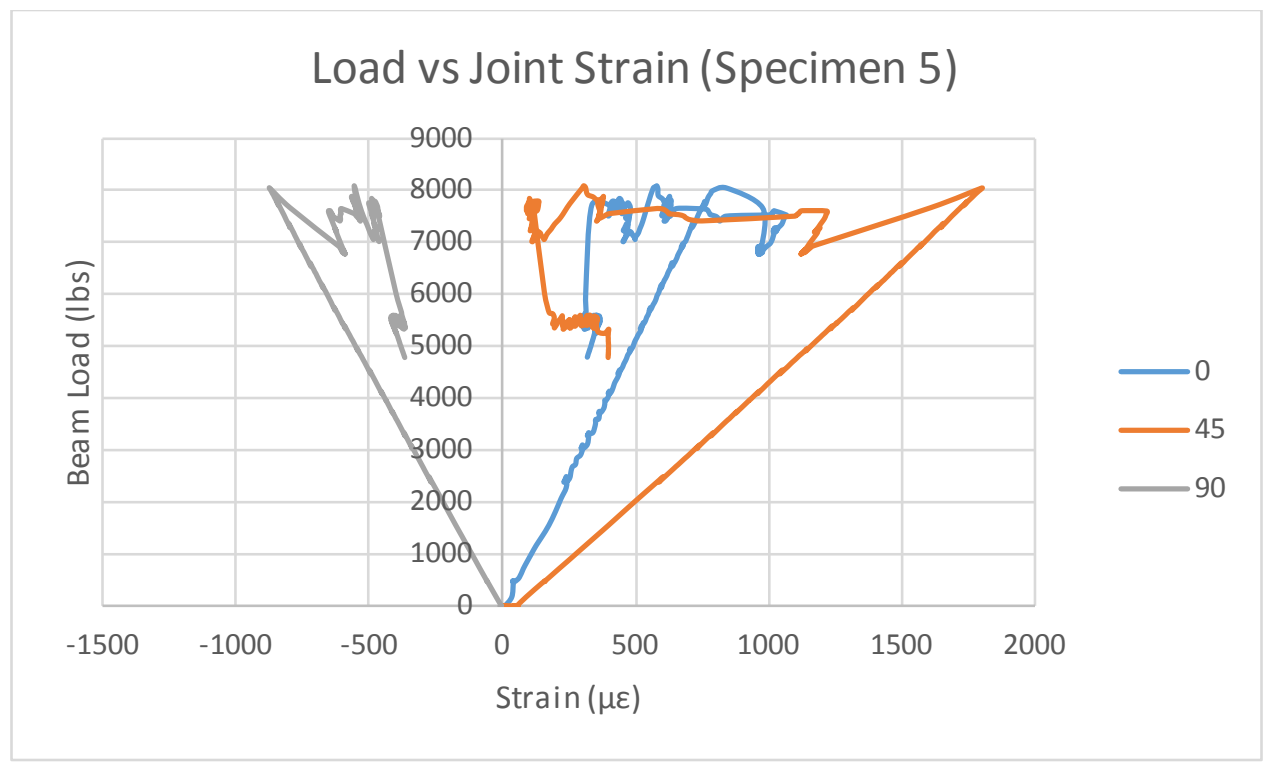

Figure A-10: Load vs Joint S train (Specimen 5)

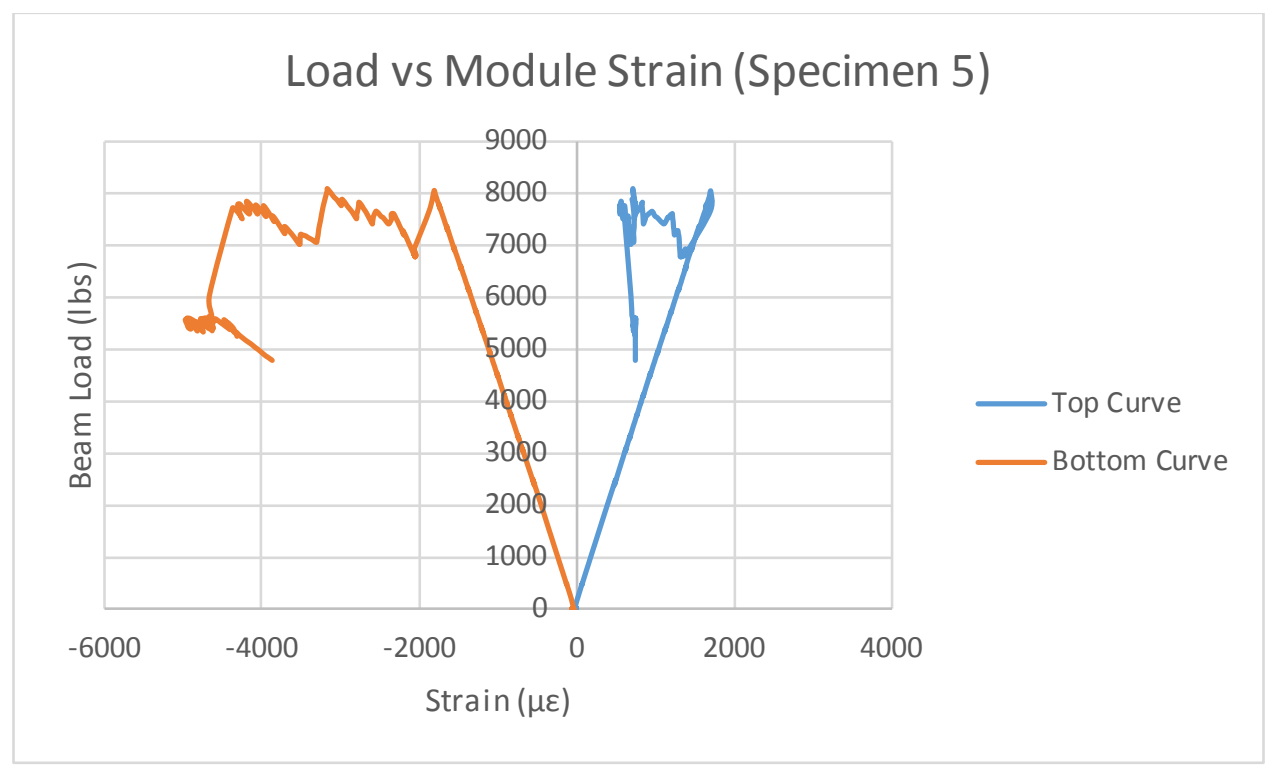

Figure A-11: Load vs Module Strain (Specimen 5) 


\section{A.6 Specimen 6 Data}

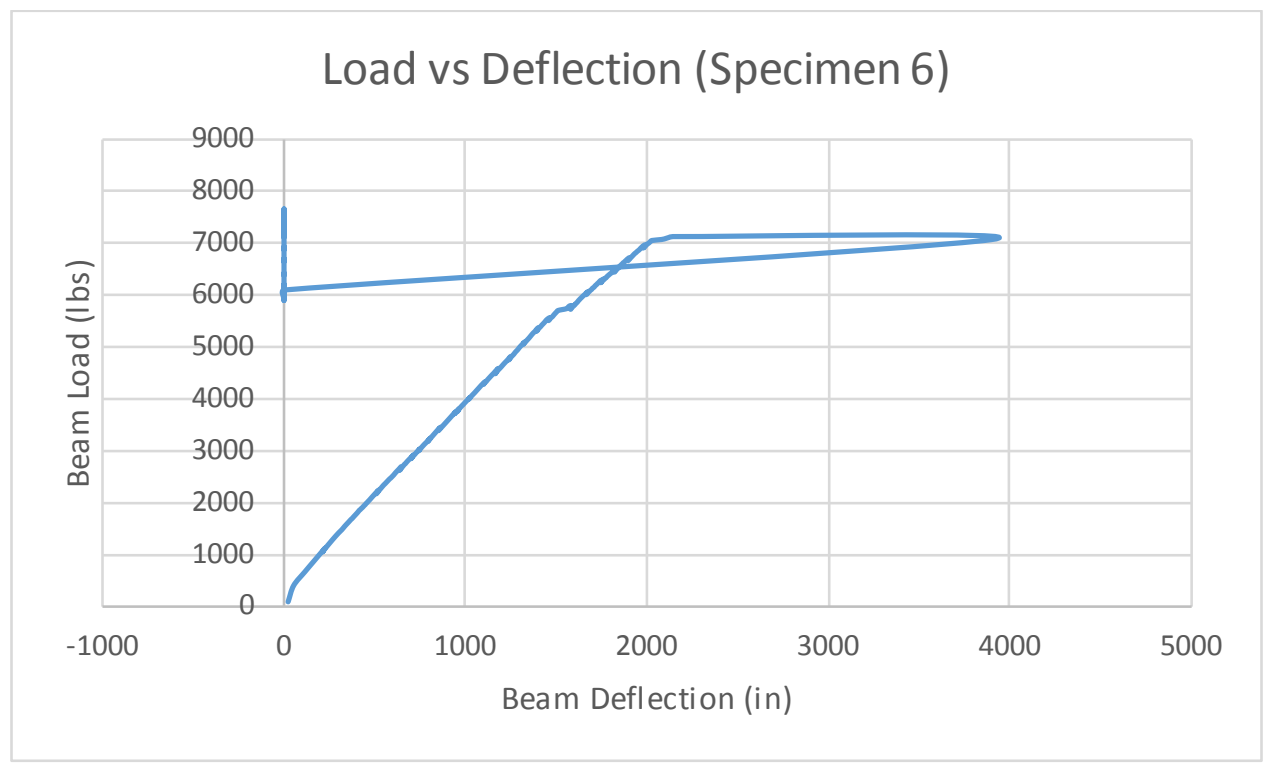

Figure A-12: Load vs Deflection (S pecimen 6)

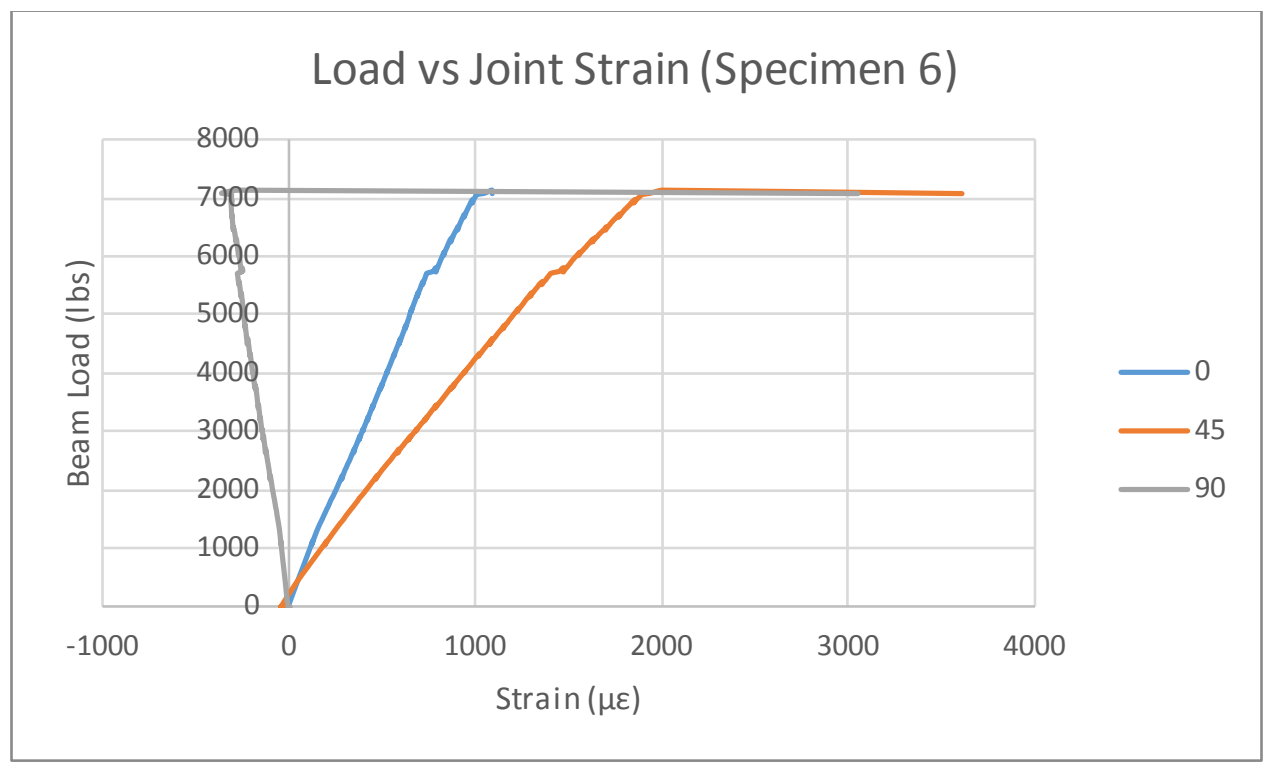

Figure A-13: Load vs Joint S train (S pecimen 6) 


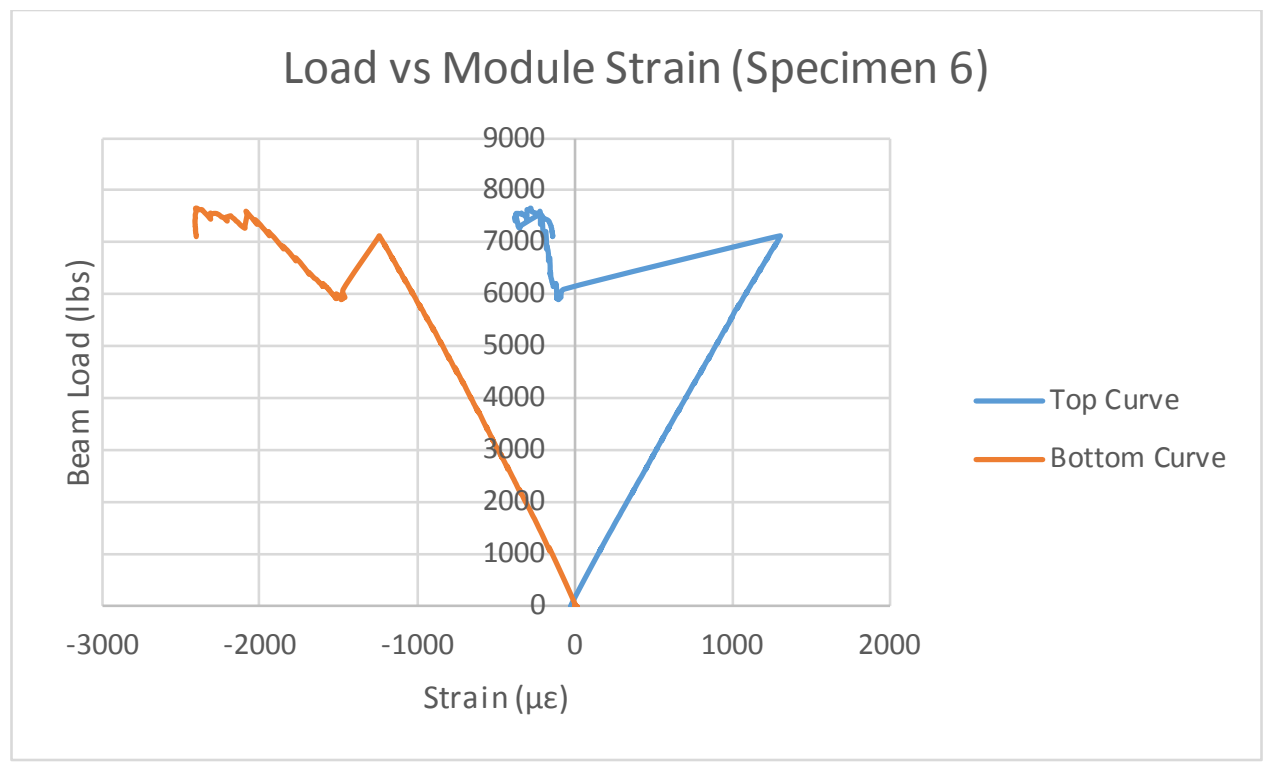

Figure A-14: Load vs Module Strain (Specimen 6)

\section{A.7 Specimen 7 Data}

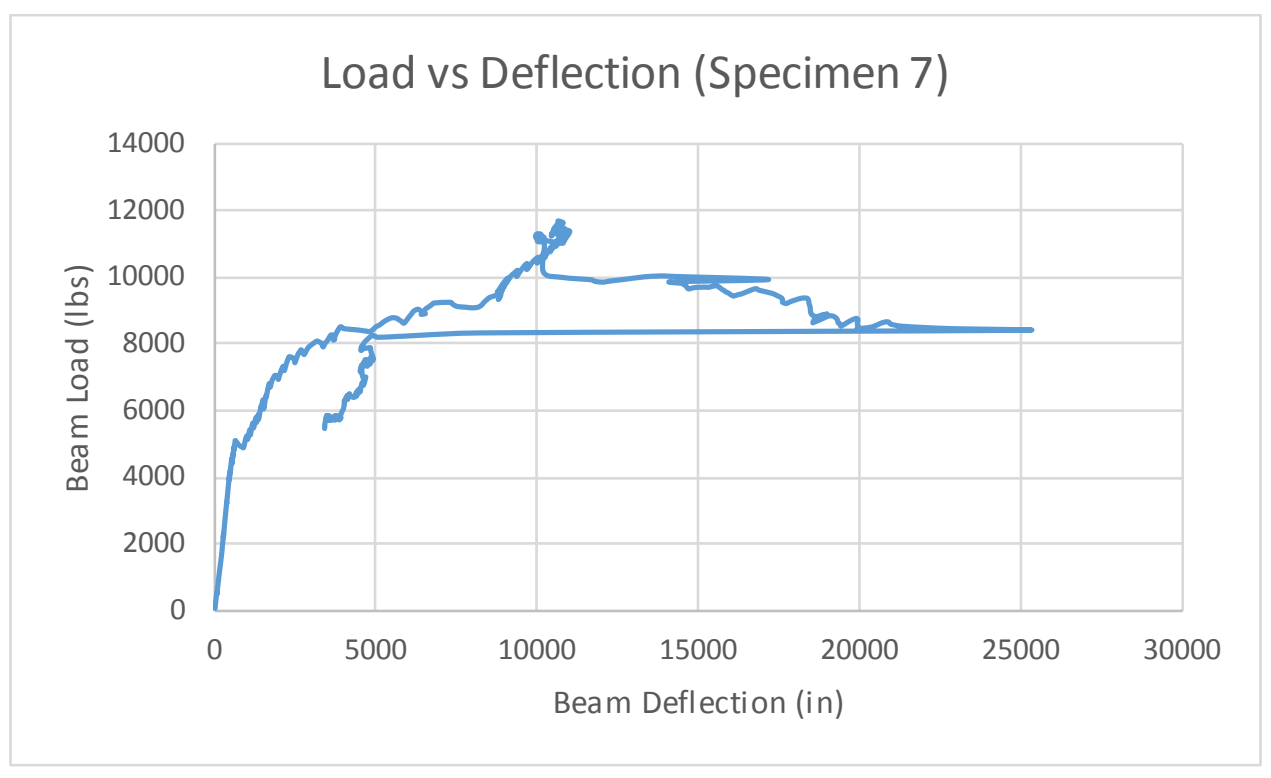

Figure A-15: Load vs Deflection (Specimen 7) 


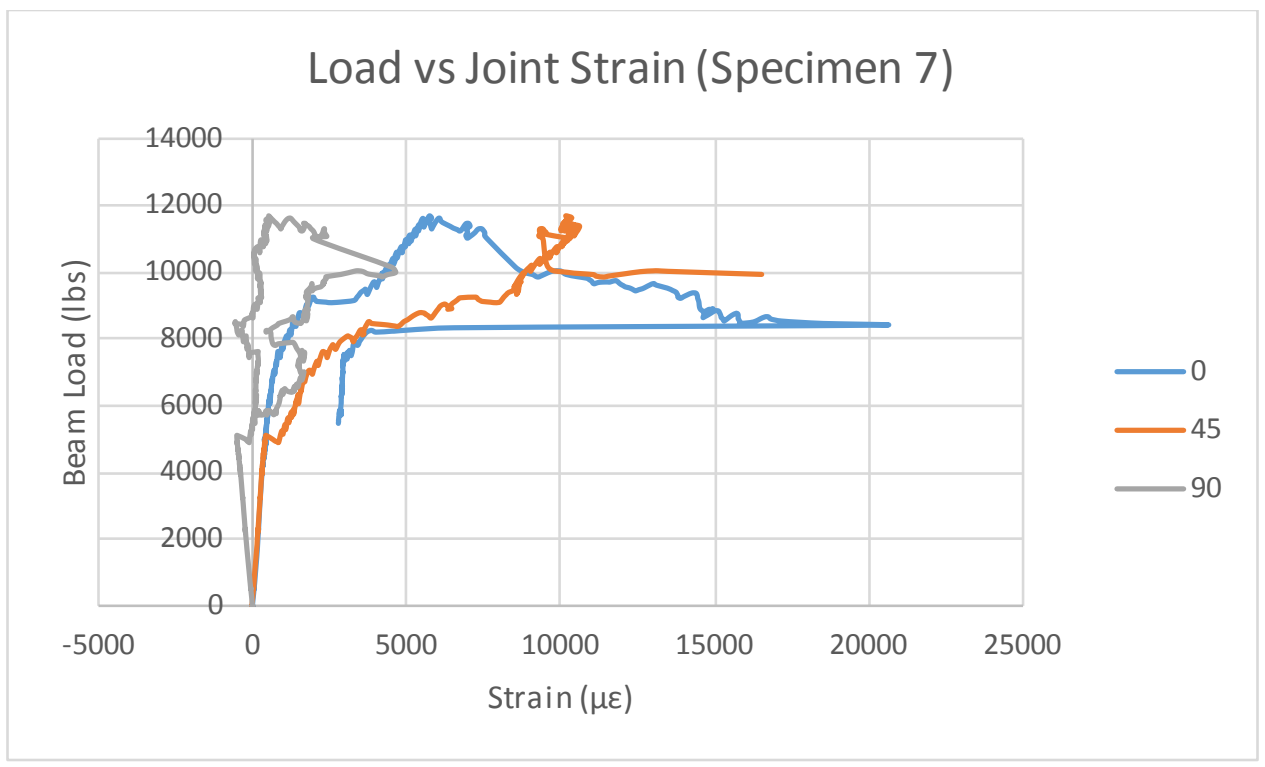

Figure A-16: Load vs Joint S train (Specimen 7)

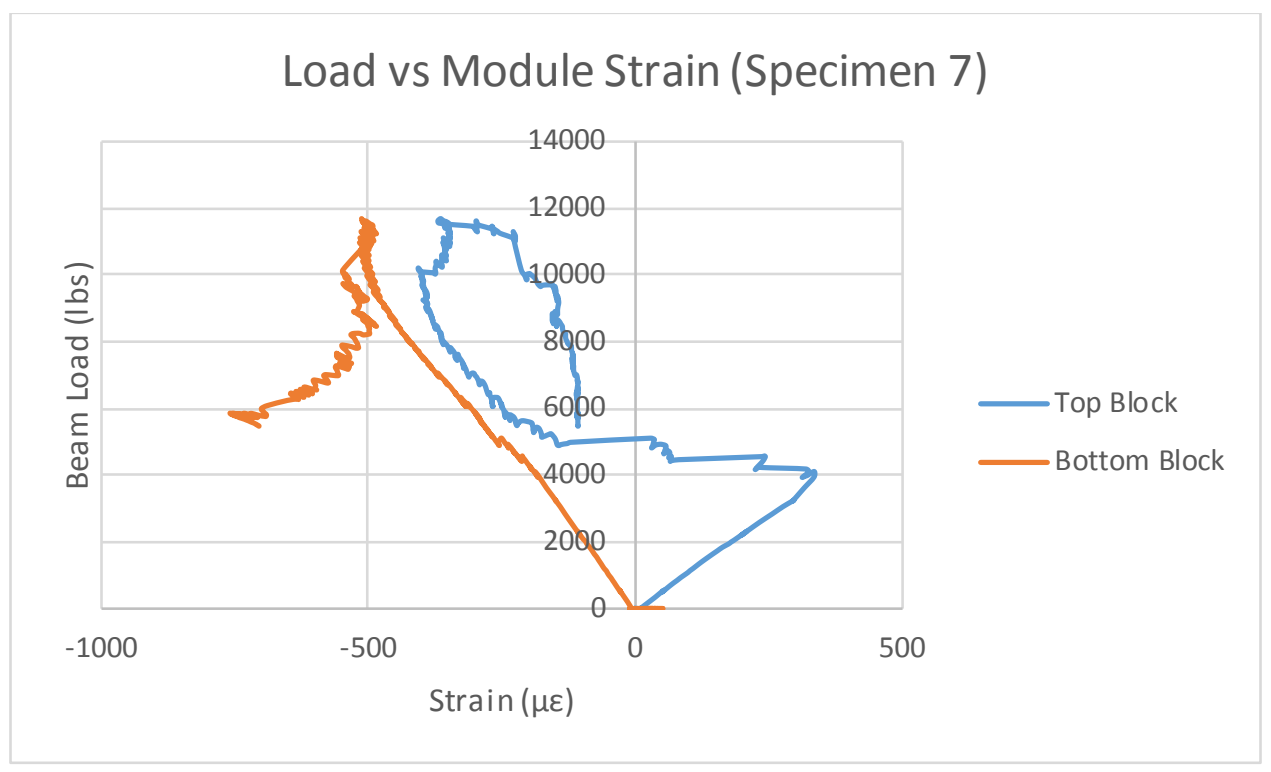

Figure A-17: Load vs Module Strain (Specimen 7) 


\section{A.8 Specimen 8 Data}

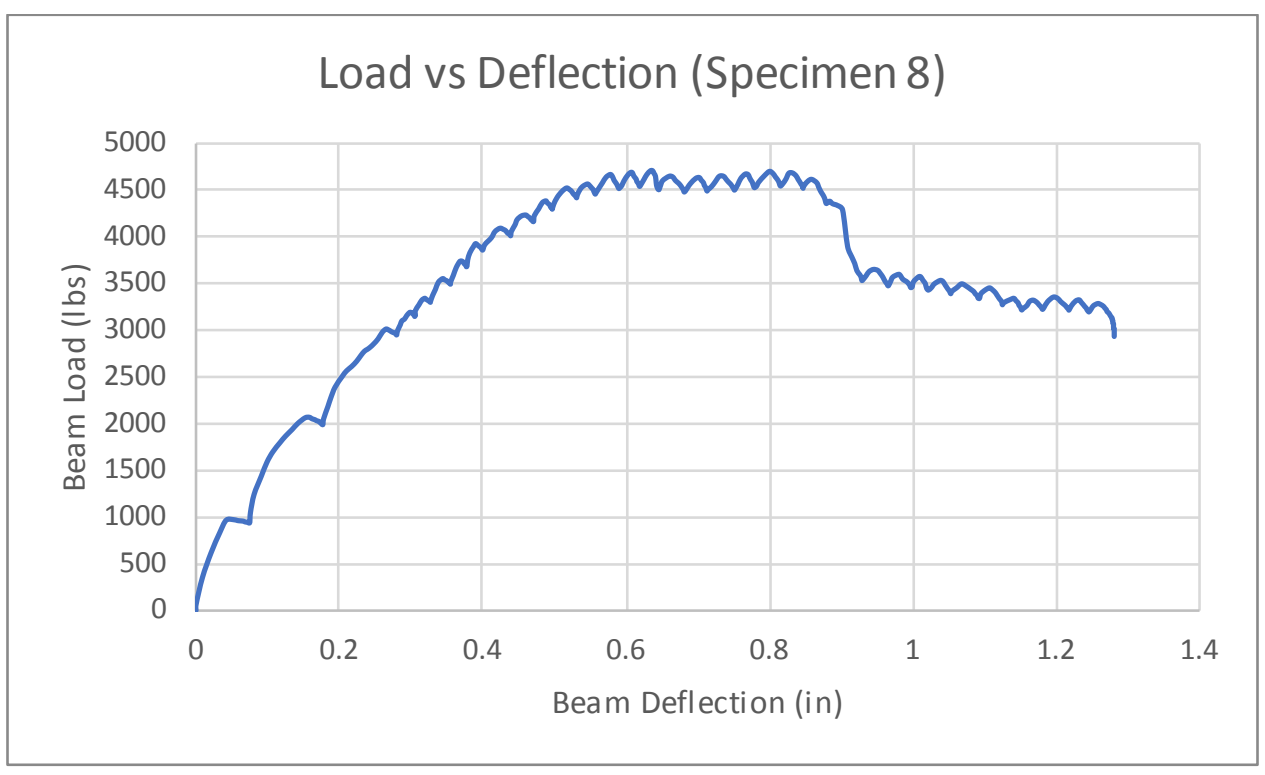

Figure A-18: Load vs Deflection (S pecimen 8)

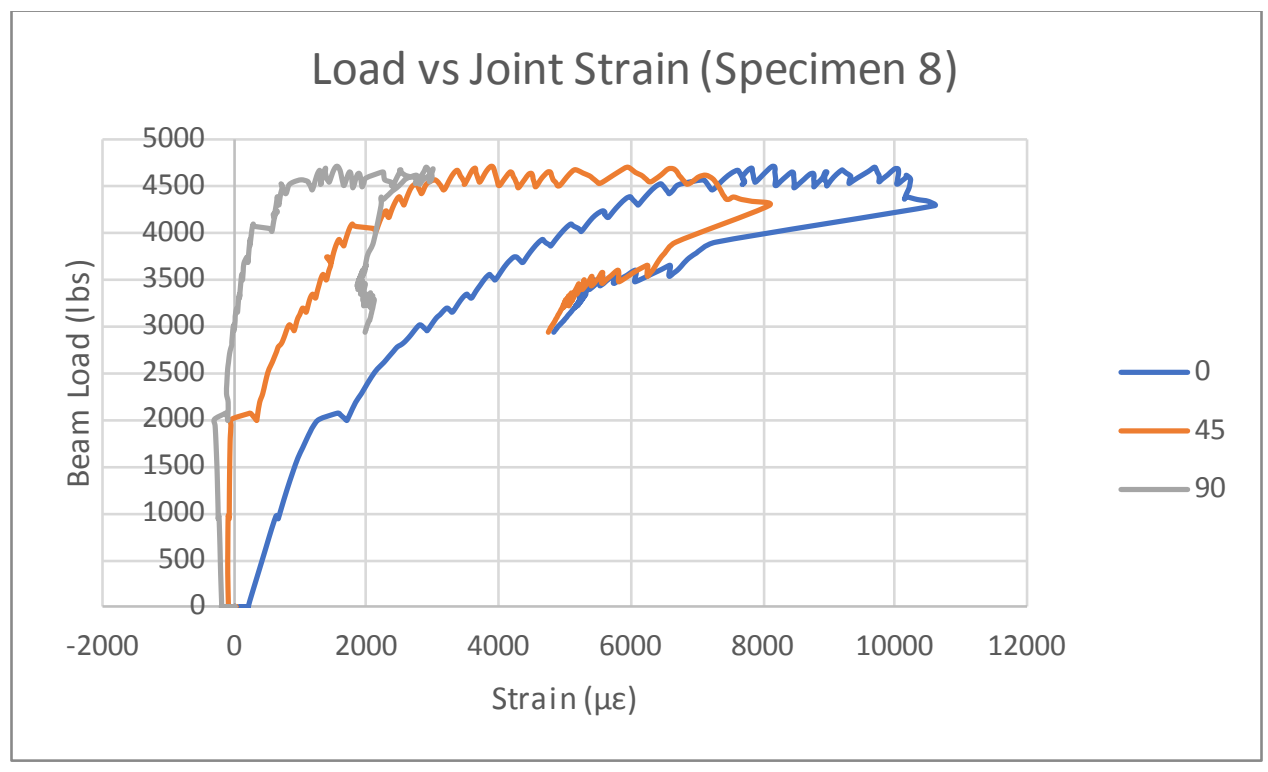

Figure A-19: Load vs Joint S train (Specimen 8) 


\section{A.9 Specimen 9 Data}

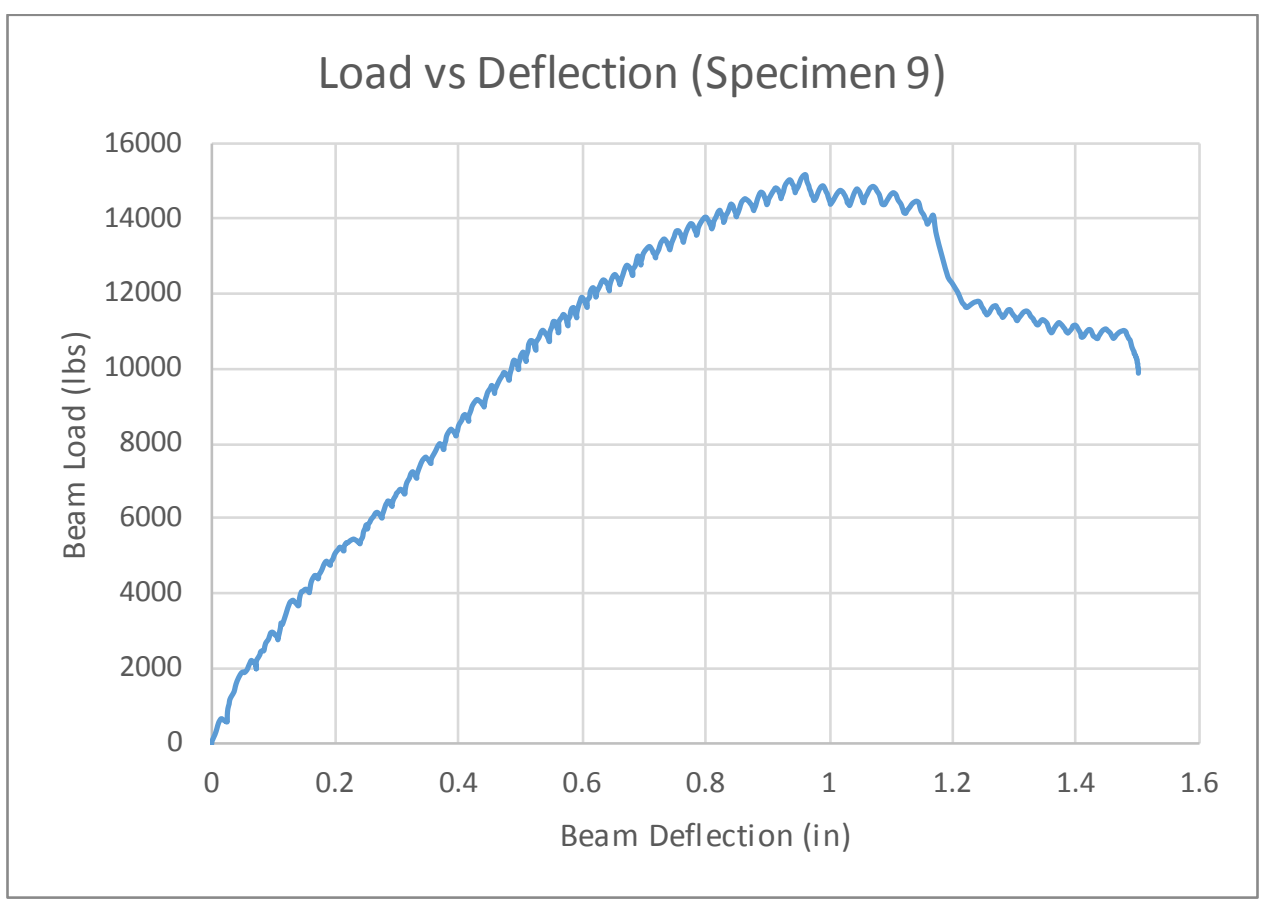

Figure A- 20: Load vs Deflection (Specimen 9)

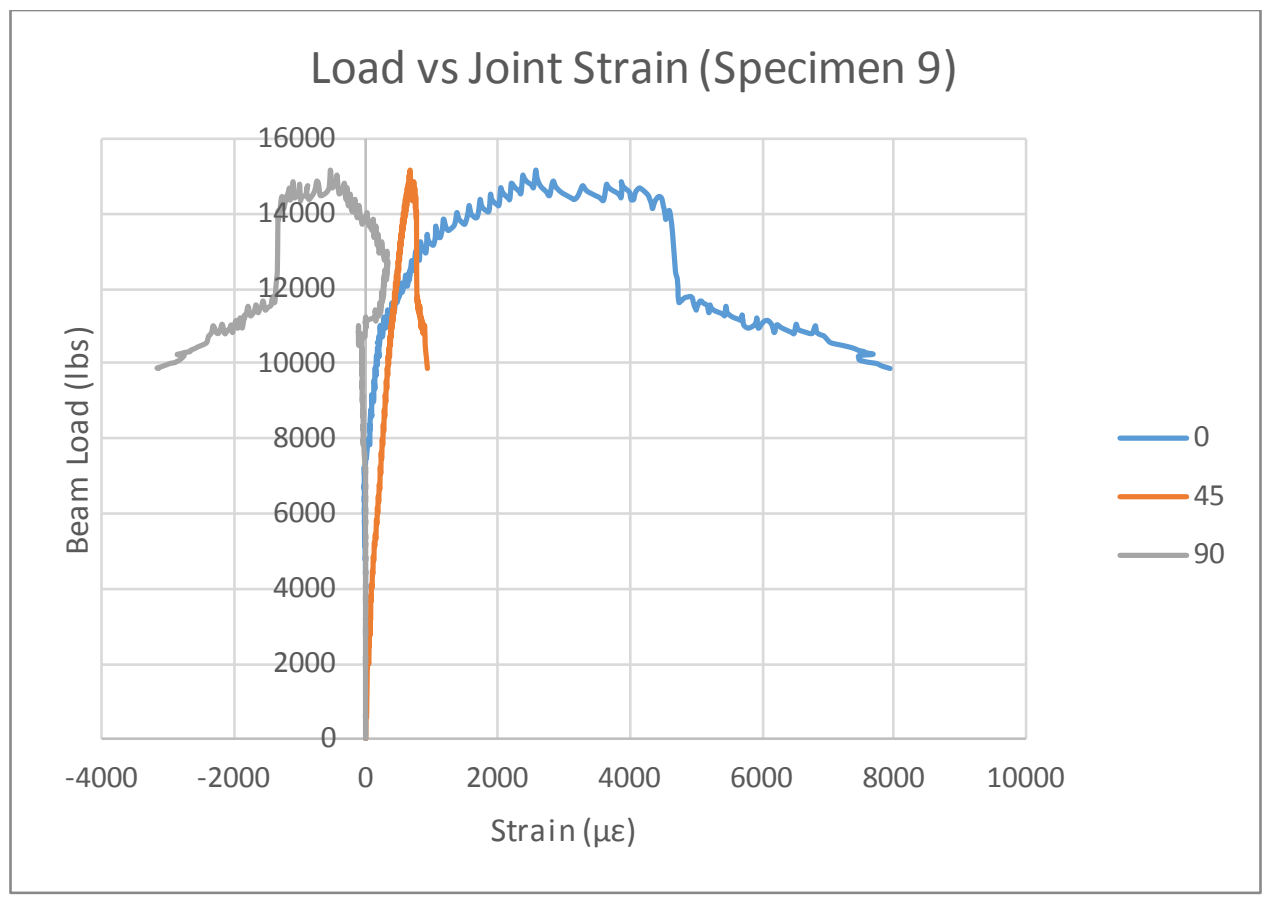

Figure A-21: Load vs Joint S train (Specimen 9) 


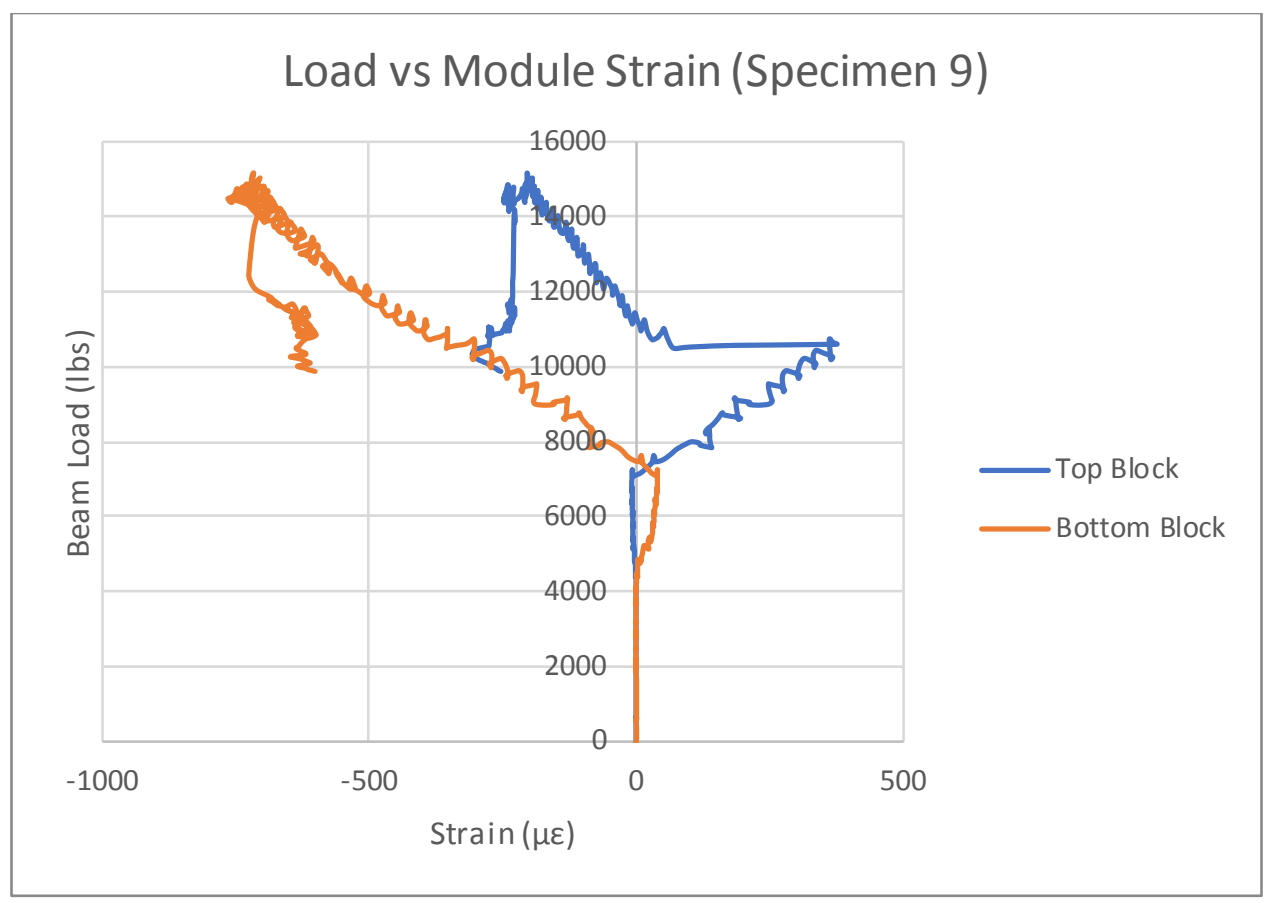

Figure A-22: Load vs Module Strain (Specimen 9)

\section{A.10 Specimen 10 Data}

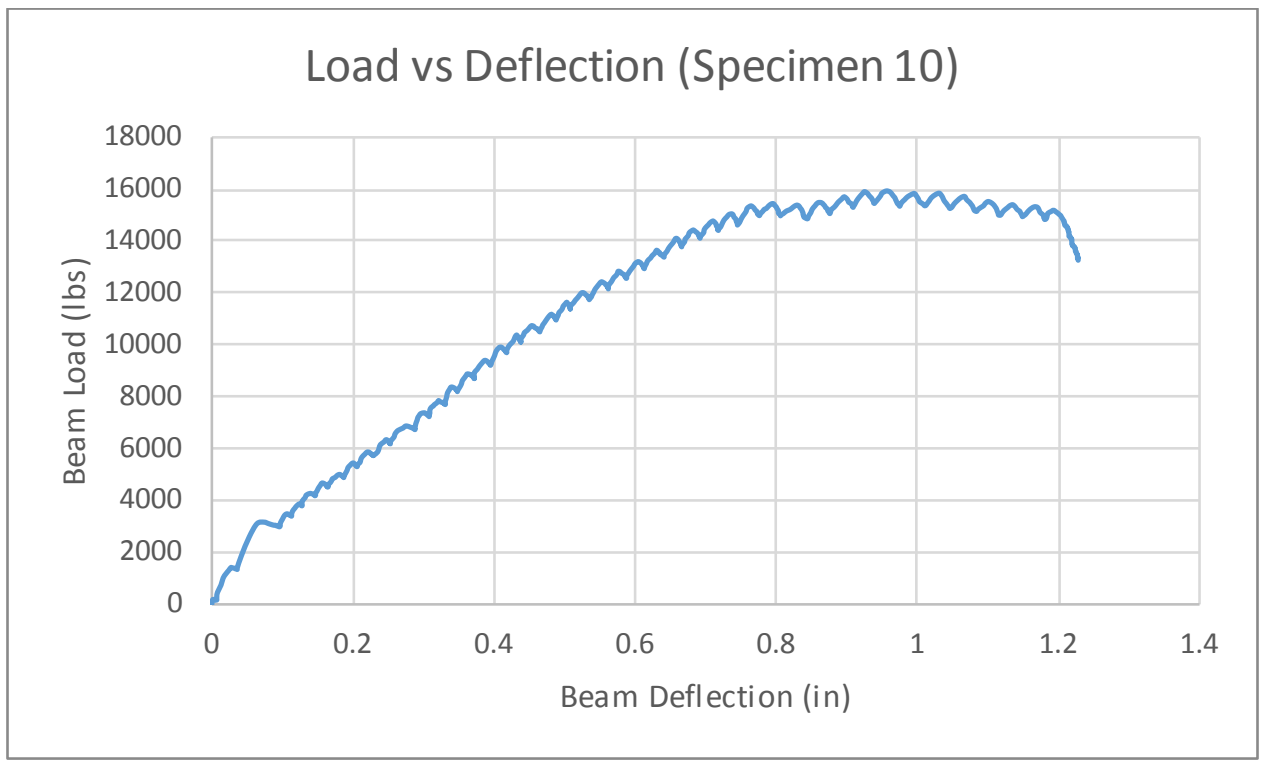

Figure A-23: Load vs Deflection (S pecimen 10) 


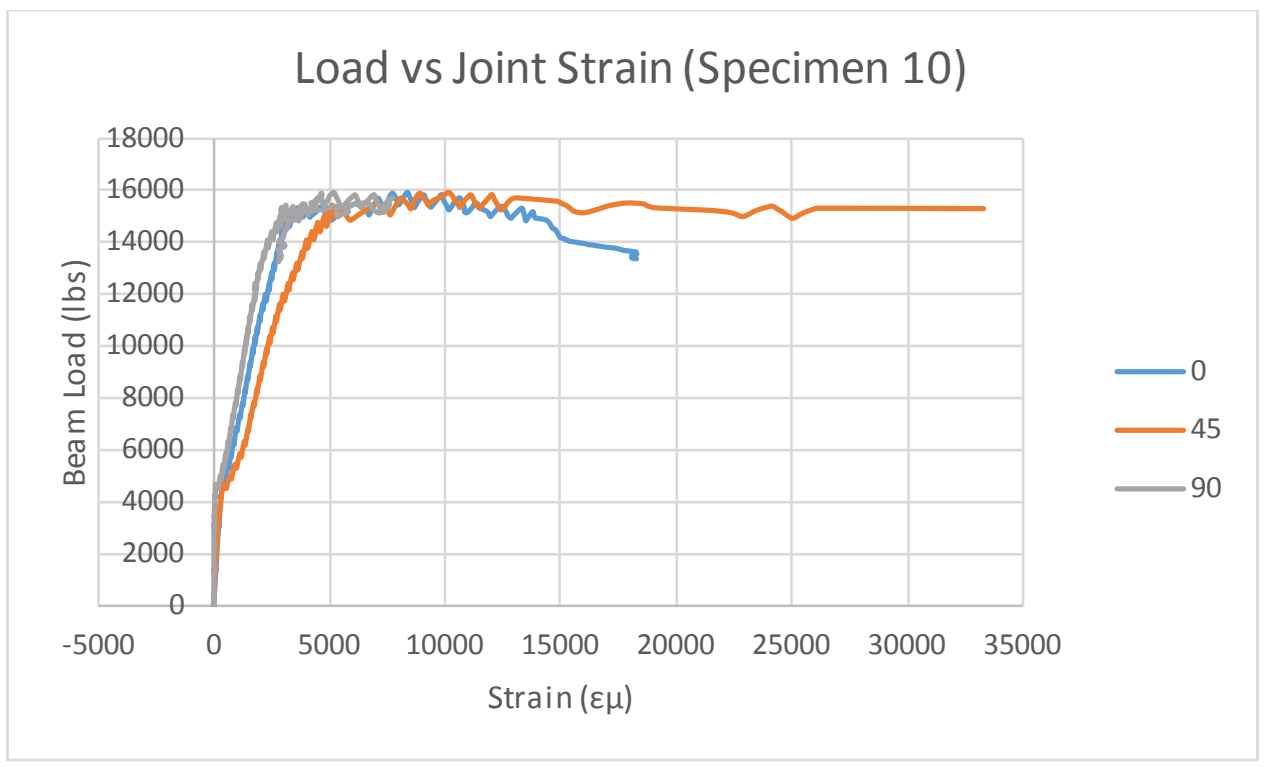

Figure A-24: Load vs Joint S train (Specimen 10)

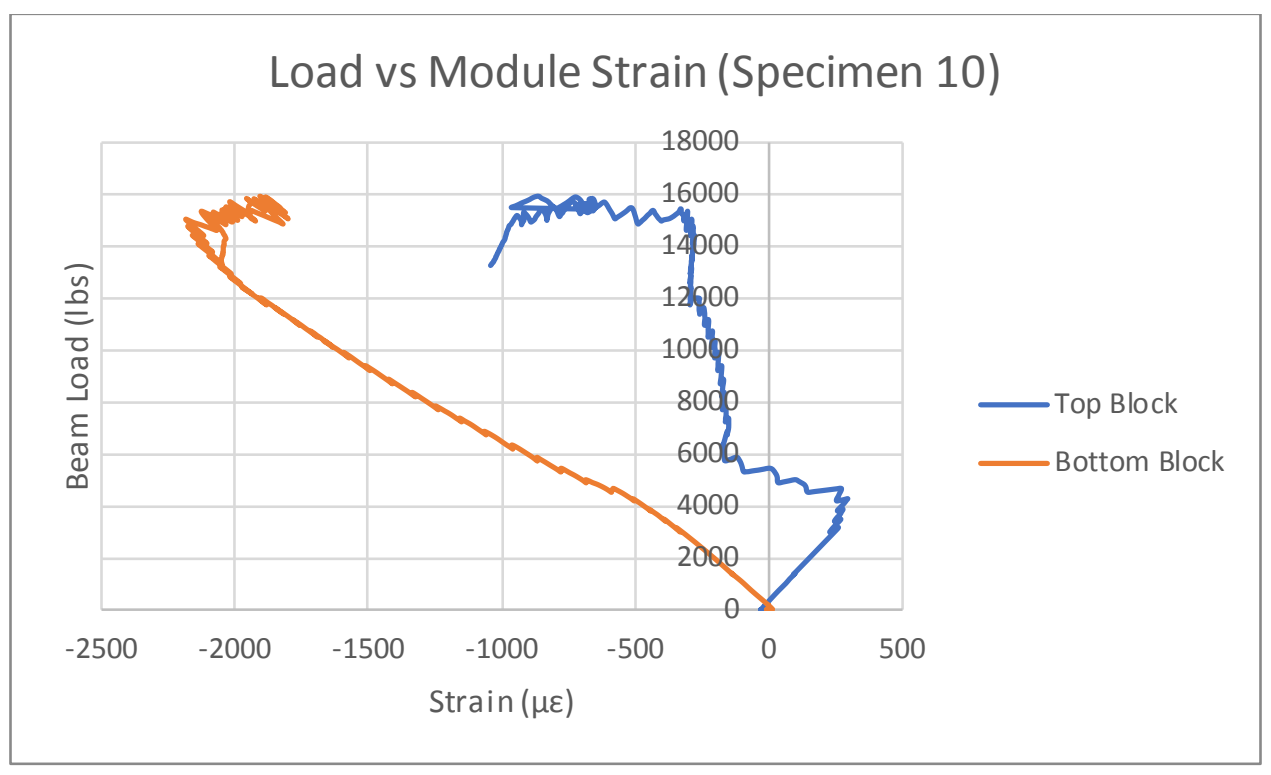

Figure A-25: Load vs Module S train (Specimen 10) 